\author{
UNIVERSIDADE DE SÃO PAULO \\ FACULDADE DE ECONOMIA, ADMINISTRAÇÃO E CONTABILIDADE \\ DEPARTAMENTO DE ECONOMIA \\ PROGRAMA DE PÓS-GRADUAÇÃO EM ECONOMIA
}

\title{
MULTIPLICADORES FISCAIS DE GASTOS E TRIBUTOS: UMA ABORDAGEM DSGE PARA A ECONOMIA BRASILEIRA
}

Vitor Kayo de Oliveira Orientadora: Prof. Dr. Fabiana Fontes Rocha Coorientadora: Prof. Dr. Roseli da Silva

SÃO PAULO 
Prof. Dr. Vahan Agopyan

Reitor da Universidade de São Paulo

Prof. Dr. Adalberto Américo Fischman

Diretor da Faculdade de Economia, Administração e Contabilidade

Prof. Dr. Eduardo Amaral Haddad

Chefe do Departamento de Economia

Prof. Dr. Ariaster Baumgratz Chimeli

Coordenador do Programa de Pós-Graduação em Economia 
VITOR KAYO DE OLIVEIRA

\section{MULTIPLICADORES FISCAIS DE GASTOS E TRIBUTOS: UMA ABORDAGEM DSGE PARA A ECONOMIA BRASILEIRA}

Dissertação apresentada ao Programa de Pós-Graduação em Economia do Departamento de Economia da Faculdade de Economia, Administração e Contabilidade da Universidade de São Paulo como requisito parcial para a obtenção do título de Mestre em Ciências.

Orientadora: Prof. Dr. Fabiana Fontes Rocha Coorientadora: Prof. Dr. Roseli da Silva

Versão Corrigida

SÃO PAULO

2018 
FICHA CATALOGRÁFICA

Elaborada por Rafael Mielli Rodrigues - CRB-8/7286

Seção de Processamento Técnico do SBD/FEA/USP

\section{Oliveira, Vitor Kayo de}

Multiplicadores fiscais de gastos e tributos: uma abordagem DSGE

para a economia brasileira / Vitor Kayo de Oliveira. - São Paulo, 2018.

$96 \mathrm{p}$.

Dissertação (Mestrado) - Universidade de São Paulo, 2018.

Orientador: Fabiana Fontes Rocha.

Co-orientador: Roseli da Silva.

1. Política fiscal 2. DSGE 3. Multiplicador fiscal 4. Política fiscal pró-cíclica I. Universidade de São Paulo. Faculdade de Economia, Administração e Contabilidade. II. Título.

CDD -336.3 


\section{Agradecimentos}

Agradeço à minha família pelo apoio durante toda a vida e em especial durante o mestrado. À Fabiana e à Roseli pelos conselhos, sugestões, críticas, dedicação e confiança. Aos amigos da pós-graduação, sobretudo Thales (TM), Leandro (LM), Alan (Dotô), Mailliw, Luiz, Danilo (Capitão), Adriano (Conselheiro), Chow, Raí e Robson, sem os quais o curso teria sido mais difícil e menos divertido. Aos professores da pósgraduação, principalmente David, Paula, Mauro, Nakane e Bruno. Ao Nakane também pelas críticas e sugestões para esta dissertação. A todos os funcionários da FEA, em particular Leka, Pinho, Luigi, Raquel e Marta. À CAPES pelo auxílio financeiro. Por fim, peço desculpas àqueles que esqueci de mencionar. 



\section{Resumo}

O presente trabalho tem o objetivo de primariamente estudar o impacto da política fiscal brasileira sobre a atividade econômica via multiplicadores fiscais desagregados e secundariamente verificar se o comportamento da política fiscal é anticíclico, acíclico ou pró-cíclico. Para tanto, estima com técnicas bayesianas um modelo DSGE com um rico arcabouço de instrumentos fiscais de gastos e tributos desagregados em consumo público, investimento público, transferências e alíquotas tributárias sobre o consumo, a renda do trabalho e a renda do capital. Em especial, usa duas bases de dados distintas de alíquotas efetivas, que são os dados tributários que representam 0 mais fidedignamente possível as alíquotas do modelo e que ainda não foram utilizadas na literatura nacional. Os resultados mostram que, em todos os horizontes de tempo, o multiplicador do investimento público é o maior, enquanto o das transferências é o menor, e que a política fiscal brasileira é, em geral, pró-cíclica, contribuindo para amplificar o ciclo econômico. Assim, os multiplicadores indicam que, sob a perspectiva da preservação da atividade econômica, um ajuste fiscal deveria evitar cortes de investimento público, bem como dão respaldo à interpretação de que a diminuição da eficácia da política fiscal em 2010-11 se deveu à perda de espaço do investimento público na composição relativa dos estímulos fiscais. Um dos exercícios de sensibilidade revela que os multiplicadores fiscais são maiores quando a política fiscal é pró-cíclica, lançando luz sobre a questão não explorada na literatura do efeito do comportamento fiscal (anticíclico, acíclico ou pró-cíclico) sobre os multiplicadores fiscais e indicando que os estudos de economias caracterizadas por políticas fiscais pró-cíclicas, como a brasileira, que não levam em conta esse comportamento fiscal tendem a subestimar os multiplicadores. Ademais, o modelo evidencia quais são os instrumentos fiscais que mais ajudam a estabilizar a dívida pública e como o comportamento pró-cíclico magnifica os efeitos da política fiscal brasileira às expensas de uma dívida pública crescente, que posteriormente para ser estabilizada exige um arrocho fiscal duradouro que afeta negativamente o produto. Também revela que os choques fiscais são responsáveis por explicar uma parcela relevante da variação do crescimento do produto, razão superávit primário-produto e razão dívida pública-produto.

Palavras-chave: Política fiscal. DSGE. Multiplicador fiscal. Política fiscal pró-cíclica. 


\section{Abstract}

The present work aims to primarily study the Brazilian fiscal policy impact on the economic activity via disaggregated fiscal multipliers and secondarily verify if the fiscal policy behavior is anticyclical, acyclical or procyclical. To do so, it estimates with Bayesian techniques a DSGE model with a rich fiscal toolkit of expenditures and taxes disaggregated into public consumption, public investment, transfers and tax rates on consumption, labor income and capital income. Specially, it uses two different databases of effective tax rates, which are the tax data that represent the model's tax rates in the most reliable way and have not yet been used in the national literature. The results show that, in all the time horizons, the public investment multiplier is the greatest, while the transfers one is the smallest, and that the Brazilian fiscal policy is, in general, procyclical, contributing to amplify the business cycle. Thus, the multipliers indicate that, from the perspective of the economic activity preservation, a fiscal adjustment should avoid cuts in public investment, as well as support the interpretation that the fiscal policy efficacy decrease in 2010-11 was due to the public investment loss of space in the relative composition of the fiscal stimuli. One of the sensibility exercises reveal that the fiscal multipliers are higher when the fiscal policy is procyclical, shedding light on the question not explored in the literature of the effect of the fiscal behavior (anticyclical, acyclical or procyclical) on the fiscal multipliers and pointing out that studies about economies characterized by procyclical fiscal policies, like the Brazilian one, that do not take into account this fiscal behavior tend to underestimate the multipliers. Furthermore, the model highlights which are the fiscal instruments that help the most to stabilize the public debt and how the procyclical behavior magnifies the effects of the Brazilian fiscal policy at the expense of a rising public debt, which later to be stabilized requires an enduring fiscal tightening which affects negatively the output. It also reveals that the fiscal shocks are responsible for explaining a relevant fraction of the variability in the output growth, primary surplus-output ratio and public debt-output ratio.

Keywords: Fiscal policy. DSGE. Fiscal multiplier. Procyclical fiscal policy. 


\section{Lista de llustrações}

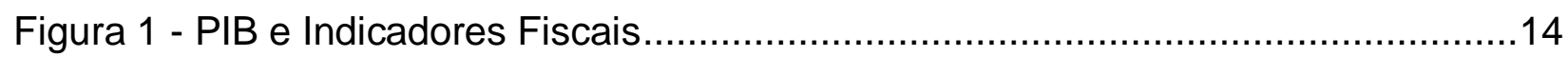

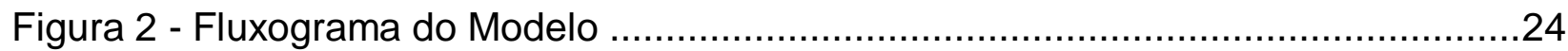

Figura 3 - Priors e Posteriors dos Parâmetros Fiscais de Resposta ao Produto.............50

Figura 4 - Choque do Consumo Público.........................................................................56

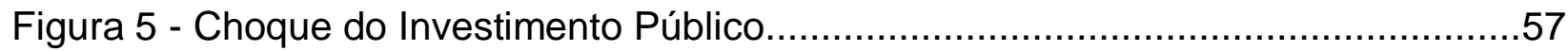

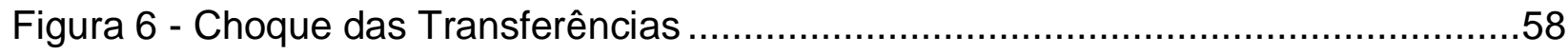

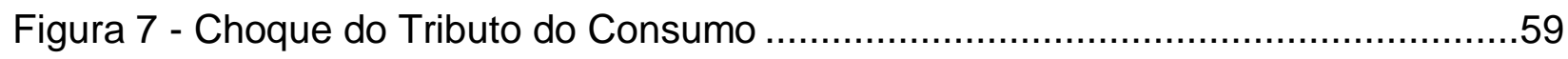

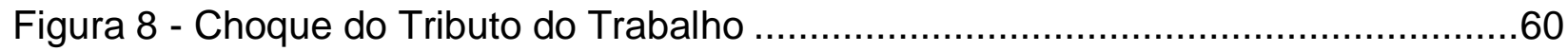

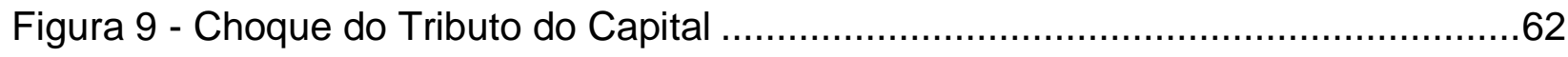

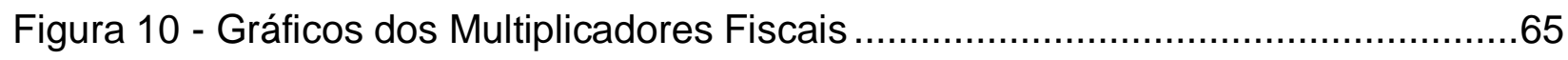

Figura 11 - Sensibilidade à Elasticidade do Produto em relação ao Capital Público.......71

Figura 12 - Sensibilidade à Fração de Famílias não Ricardianas .................................72

Figura 13 - Sensibilidade à Suavização da Taxa de Juros da Regra Monetária .............73

Figura 14 - Sensibilidade à Elasticidade do Custo de Ajustamento da Utilização do Capital

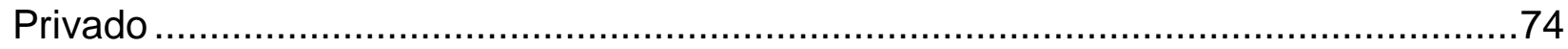

Figura 15 - Sensibilidade ao Comportamento da Política Fiscal ..................................76

Figura 16 - Alíquotas Dessazonalizadas de Azevedo e Fasolo (2015) ..........................87

Figura 17 - Alíquotas Dessazonalizadas de Almeida et al. (2017) ...............................89 


\section{Lista de Tabelas}

Tabela 1 - Tipos de Multiplicadores Fiscais ................................................................. 17

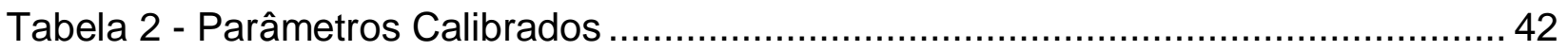

Tabela 3 - Distribuições a Priori e a Posteriori ............................................................ 44

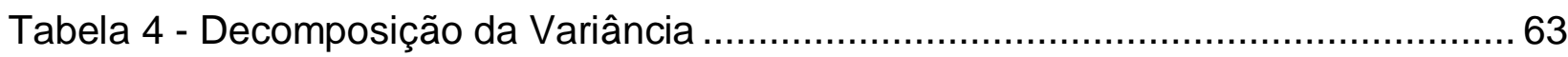

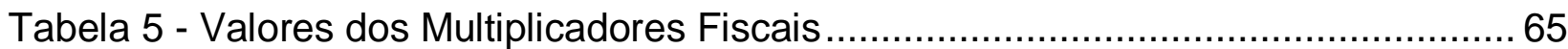

Tabela 6 - Valores dos Multiplicadores Fiscais de Estudos Nacionais ..........................68 68

Tabela 7 - Valores dos Multiplicadores Fiscais de Estudos Internacionais ..................... 69

Tabela 8 - Impostos das Receitas Tributárias de Azevedo e Fasolo (2015) ................... 86

Tabela 9 - Impostos das Receitas Tributárias de Almeida et al. (2017) .......................... 89

Tabela 10 - Filtro de Kalman Linear Gaussiano...........................................................92 


\section{Lista de Abreviaturas e Siglas}

\begin{tabular}{|ll|}
\hline BCB & Banco Central do Brasil \\
\hline Cide & Contribuição sobre Intervenção no Domínio Econômico \\
\hline CSLL & Contribuição Social sobre o Lucro Líquido \\
\hline Cofins & Contribuição para o Financiamento da Seguridade Social \\
\hline CPMF & Contribuição Provisória sobre Movimentação ou Transmissão de \\
\hline Valores e de Créditos e Direitos de Natureza Financeira \\
\hline CPSS & Contribuição para o Plano de Seguridade Social do Servidor \\
\hline FGTS & Fundo de Garantia por Tempo de Serviço \\
\hline ICMS & Imposto sobre a Circulação de Mercadorias e Serviços \\
\hline II & Imposto sobre Importação \\
\hline IOF & Imposto sobre Operações de Crédito, Câmbio e Seguros \\
\hline IPI & Imposto sobre Produtos Industrializados \\
\hline IPTU & Imposto Predial e Territorial Urbano \\
\hline IPVA & Imposto sobre a Propriedade de Veículos Automotores \\
\hline IRPF & Imposto sobre a Renda da Pessoa Física \\
\hline IRPJ & Imposto sobre a Renda da Pessoa Jurídica \\
\hline IRRF/Capital & Imposto de Renda Retido na Fonte - rendimento do capital \\
\hline IRRF/Trabalho & Imposto de Renda Retido na Fonte - rendimento do trabalho \\
\hline IRRF/Remessas & Imposto de Renda Retido na Fonte - rendimento de remessas para \\
\hline IRRF/Outros & Impostorior de Renda Retido na Fonte - outros rendimentos \\
\hline ISS & Imposto sobre Serviços de Qualquer Natureza \\
\hline ITBI & Imposto sobre a Transmissão de Bens Imóveis Inter-vivos \\
\hline ITCD & Imposto sobre a Transmissão Causa Mortis e Doação \\
\hline ITR & Imposto Territorial Rural \\
\hline LOAS & Lei Orgânica de Assistência Social \\
\hline PASEP & Programa de Formação do Patrimônio do Servidor Público \\
\hline PIS & Programa de Integração Social \\
\hline PME & Pesquisa Mensal do Emprego \\
\hline PNAD & Pesquisa Nacional por Amostra de Domicílios \\
\hline RGPS & Contribuição para o Regime Geral de Previdência Social \\
\hline RMV & Renda Mensal Vitalícia \\
\hline CNT-IBGE & Contas Nacionais Trimestrais do Instituto Brasileiro de Geografia e \\
\hline SE & Estatística \\
\hline Sistema S & Salário Educação \\
\hline SISTN & Contribuição para o Sistema S \\
\hline STN & Sistema de Coleta de Dados dos Entes da Federação \\
\hline & Secretaria do Tesouro Nacional \\
\hline
\end{tabular}





\section{Sumário}

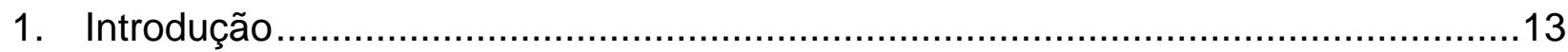

2. Multiplicadores Fiscais: Mensuração e Breve Revisão de Literatura .......................17

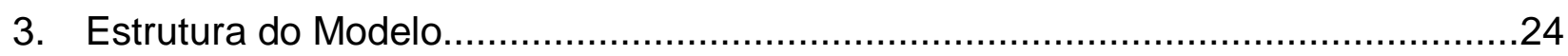

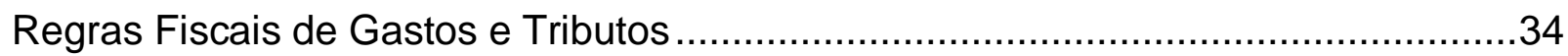

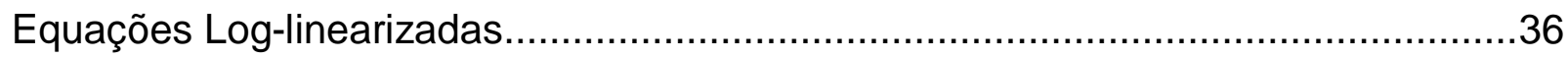

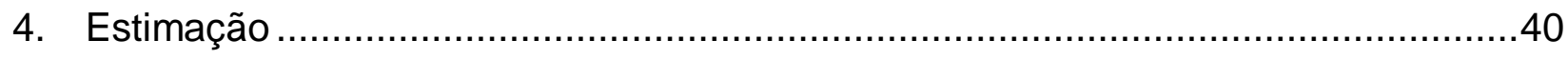

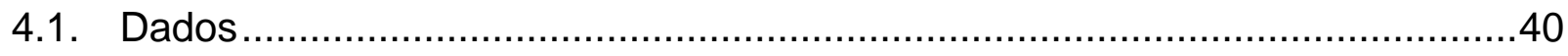

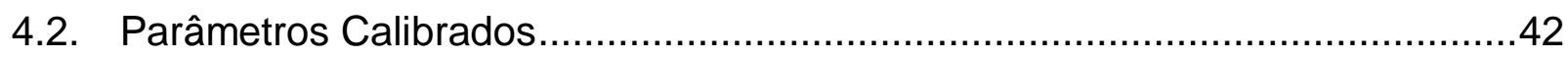

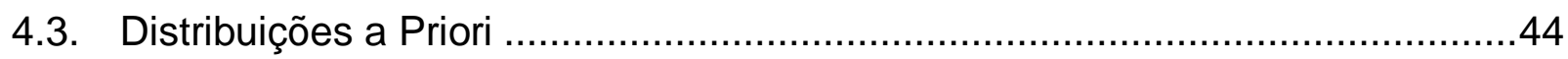

4.4. Resultados das Estimações com Foco nas Regras Fiscais ............................48

5. Resultados do Modelo: Dinâmica, Multiplicadores Fiscais e Sensibilidade .............54

5.1. Choques Fiscais de Gastos e Tributos ........................................................54

5.2. Multiplicadores Fiscais de Gastos e Tributos .............................................64

5.3. Exercícios de Sensibilidade dos Multiplicadores Fiscais ................................70

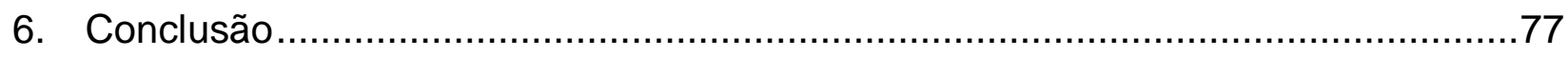

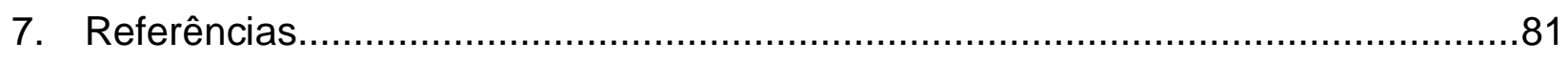

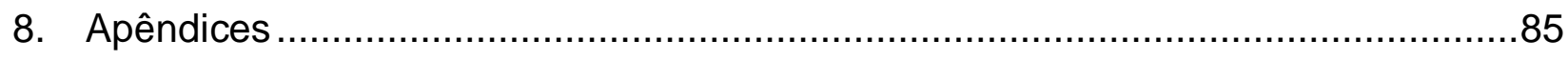

8.1. Dados de Alíquotas Efetivas de Azevedo e Fasolo (2015) ….........................85

8.2. Dados de Alíquotas Efetivas de Almeida et al. (2017) ..................................87

8.3. Estimação Bayesiana de Modelos DSGE ………....................................90

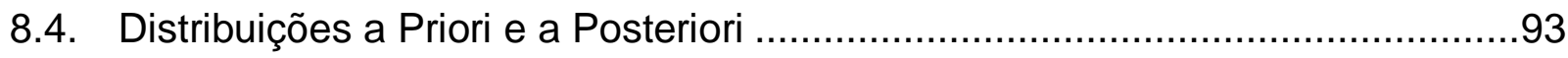





\section{Introdução}

A recente crise econômica internacional levou muitos países ao redor do mundo a adotarem políticas fiscais expansionistas a fim de complementarem os estímulos monetários, que pareciam não ser suficientes, ainda mais nas economias em que a taxa de juros nominal se encontrava perto do zero lower bound. Os EUA, por exemplo, lançaram em 2009 um pacote fiscal chamado American Recovery and Reinvestment Act, com a expectativa de reanimar a economia estadunidense. Bernstein e Romer (2009) defenderam o potencial desse pacote amparados em estudos mostrando que estímulos fiscais conseguiam impulsionar a atividade econômica. Em contraste, depois de iniciados os estímulos do pacote, Cogan et al. (2009) estimaram que o mesmo teve impacto nulo. Esse é apenas um caso do debate reacendido acerca da capacidade da política fiscal de estimular a economia, tema sobre o qual não existia nem existe ainda um consenso entre os economistas e que tem motivado diversas pesquisas buscando calcular multiplicadores fiscais, que sintetizam quantitativamente a efeito dinâmico da política fiscal sobre a atividade econômica e permitem comparar a eficácia de diferentes instrumentos fiscais.

O Brasil também recorreu tanto à política monetária quanto à política fiscal com o intuito de amenizar os efeitos negativos da crise sobre o produto e o nível de emprego. Segundo Pires (2009) e Moreira e Soares (2010), os principais estímulos monetários foram a diminuição do depósito compulsório, a redução da taxa de juros básica da economia, o aumento da oferta de crédito de bancos públicos e a realização de operações cambiais para evitar uma forte depreciação cambial. Já os principais estímulos fiscais foram desonerações tributárias (Imposto sobre a Renda da Pessoa Física, Imposto sobre Produtos Industrializados e Imposto sobre Operações de Crédito, Câmbio e Seguros), subsídios, a expansão dos programas de seguro-desemprego e do Bolsa Família e o aumento do investimento público.

Os estímulos fiscais parecem ter surtido efeito, uma vez que, após uma queda de 0,1\% em 2009, a economia brasileira se recuperou com um crescimento de $7,5 \%$ em 2010 (Figura 1), recuperação essa portentosa quando se tem em conta que a economia vinha apresentando um crescimento relativamente robusto com uma média de 4,06\% no período de 2002-08. Porém, em 2010-11, a atividade econômica mostrava sinais de 
fraqueza cada vez maiores, embora o governo mantivesse a política de estímulos fiscais, expandindo-os e prorrogando-os. Uma literatura (e.g., Afonso e Gobetti (2015), Gobetti e Orair (2015), Gobetti et al. (2016) e Orair (2016)) defende que a principal razão para essa diminuição da eficácia da política fiscal reside na mudança da composição relativa dos instrumentos fiscais, em que os investimentos públicos foram gradativamente perdendo espaço para desonerações tributárias e subsídios, em que pesem outros fatores como a tendência crescente e rígida dos gastos sociais e de pessoal e a diminuição da arrecadação tributária em virtude da desaceleração econômica.

Isso contribuiu para a forte deterioração dos principais indicadores fiscais (Figura 1). Em 2017, o déficit primário do setor público chegou a 1,69\% do PIB e a dívida pública bruta do governo geral atingiu $83 \%$ do PIB. Recentemente, o governo brasileiro tenta rever sua política fiscal a fim de restaurar as finanças públicas com reformas que passam por cortes de gastos e/ou aumento de tributos diante de uma economia enfraquecida, que amargou um encolhimento de 3,5\% em 2016.

Figura 1 - PIB e Indicadores Fiscais

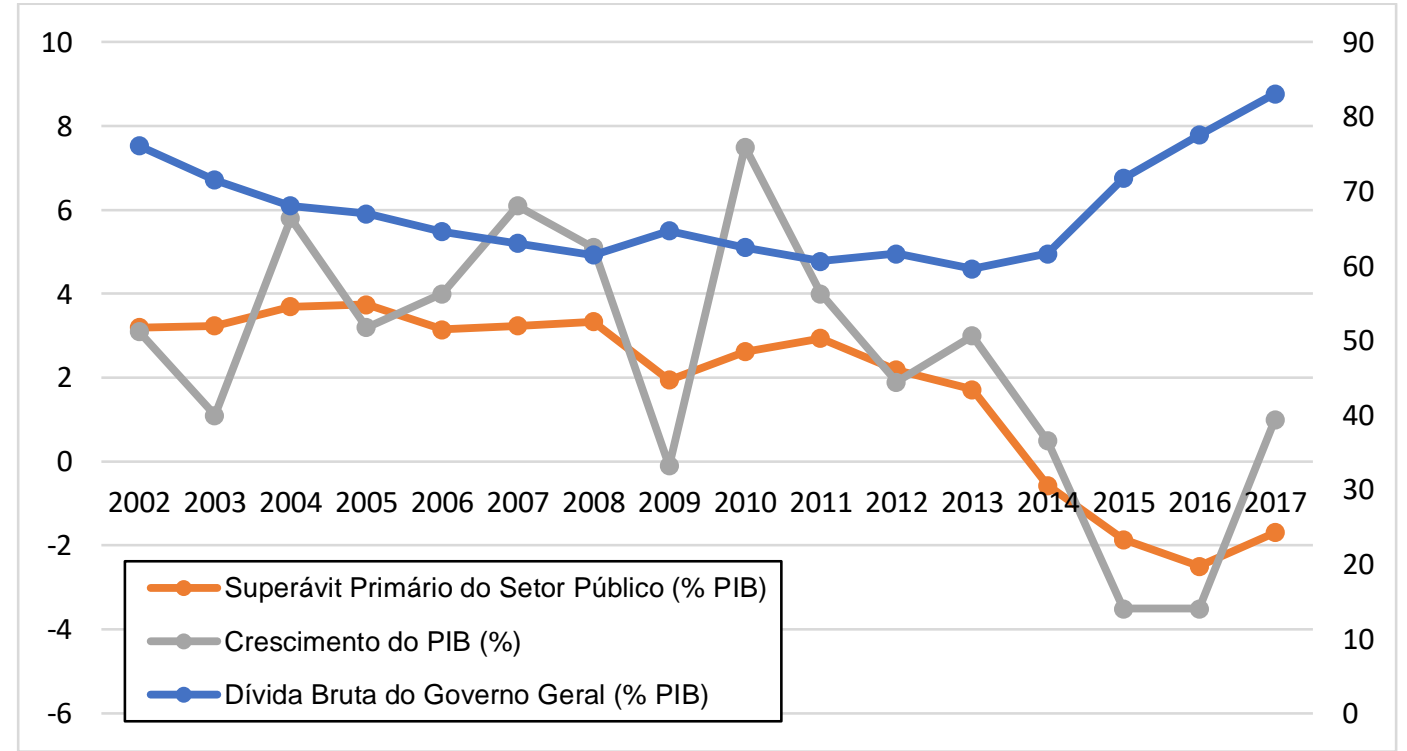

Fonte: BCB e IBGE.

Nesse contexto, este trabalho busca dar algumas contribuições para a literatura brasileira sobre política fiscal. Em primeiro plano, estima um modelo DSGE (dynamic 
stochastic general equilibrium) com um rico arcabouço de instrumentos fiscais desagregados (consumo público, investimento público, transferências e alíquotas tributárias sobre o consumo, a renda do trabalho e a renda do capital) de modo a permitir estudar o impacto sobre a atividade econômica de diferentes instrumentos de gastos e tributos via multiplicadores fiscais desagregados. Isso possibilita aos policymakers terem informações mais precisas acerca de quais instrumentos fiscais são mais eficazes e dos efeitos sobre o produto de suas escolhas de corte de gastos e/ou aumento de tributos necessários ao recente ajuste fiscal, além de ampliar a (escassa) literatura nacional sobre política fiscal e multiplicadores fiscais baseada na modelagem DSGE.

Em segundo plano, verifica se o comportamento da política fiscal brasileira é anticíclico, acíclico ou pró-cíclico também num nível desagregado, tendo em vista que a literatura, em geral, apenas analisa esse comportamento no nível mais agregado possível (gastos e receitas agregados) e que alíquotas tributárias refletem melhor a discricionariedade da política fiscal dos tributos relativamente às medidas comumente adotas na literatura envolvendo receita pública. Estudar o comportamento fiscal brasileiro se mostra relevante porque em tese uma política fiscal anticíclica ao ajudar a estabilizar o ciclo econômico é desejável, apesar de a literatura observar em países em desenvolvimento, inclusive no Brasil, um comportamento pró-cíclico, amplificando o ciclo econômico.

As estimações usam, em particular, duas bases de dados diferentes de alíquotas efetivas, permitindo uma análise de robustez. Esses dados tributários representam o mais fidedignamente possível as alíquotas do modelo e até agora nenhuma pesquisa nacional fez uso deles para analisar as questões propostas. Os resultados encontrados mostram que, em todos os horizontes de tempo, o multiplicador fiscal do investimento público é o maior, enquanto o das transferências é o menor, e que a política fiscal brasileira é, em geral, pró-cíclica, contribuindo para amplificar o ciclo econômico.

Assim, os multiplicadores indicam que, sob a perspectiva da preservação da atividade econômica, sobretudo num período de desaceleração como o atual, os policymakers deveriam evitar cortes de investimento público no recente ajuste fiscal. Também os multiplicadores dão respaldo à interpretação de que a diminuição da eficácia da política fiscal em 2010-11 se deveu à perda de espaço do investimento público na 
composição relativa dos estímulos fiscais. Os exercícios de sensibilidade mostram que os multiplicadores fiscais são maiores quando a política fiscal é pró-cíclica, lançando luz sobre uma questão ainda não explorada na literatura, qual seja, a importância do comportamento fiscal (anticíclico, acíclico ou pró-cíclico) no cálculo dos multiplicadores fiscais, e indicando que os estudos de economias caracterizadas por políticas fiscais prócíclicas, como economias em desenvolvimento, inclusive a brasileira, que não levam em conta esse comportamento fiscal tendem a obter multiplicadores subestimados.

Além disso, o modelo evidencia quais são os instrumentos fiscais que mais contribuem para a estabilização da dívida pública e, ao incorporar o comportamento prócíclico da economia brasileira, mostra que a política fiscal brasileira tem seus efeitos magnificados às expensas de uma dívida pública crescente, que posteriormente para ser estabilizada exige uma combinação de corte de gastos e oneração tributária por um período considerável, afetando negativamente o produto. Também revela que os choques fiscais são responsáveis por uma parcela relevante da explicação da variação do crescimento do produto, razão superávit primário-produto e razão dívida públicaproduto, reforçando a importância do estudo da política fiscal para a compreensão das flutuações da economia brasileira.

A estrutura do trabalho é a seguinte, além desta introdução. O capítulo 2 descreve brevemente os diferentes multiplicadores fiscais e as pesquisas que buscam calculá-los. O capítulo 3 esmiúça o modelo DSGE adotado no trabalho. O capítulo 4 descreve as bases de dados, as estimações e os resultados, enfatizando as evidências sobre 0 comportamento (anticíclico, acíclico ou pró-cíclico) da política fiscal brasileira. O capítulo 5 discute a dinâmica do modelo frente aos diversos choques fiscais, calcula os multiplicadores fiscais de gastos e tributos e realiza exercícios de sensibilidade dos multiplicadores fiscais. Por fim, o capítulo 6 apresenta a conclusão. 


\section{Multiplicadores Fiscais: Mensuração e Breve Revisão de Literatura}

Os estudos sobre política fiscal comumente reportam uma medida que sumariza o impacto de choques fiscais sobre o produto chamado de multiplicador fiscal, que é tradicionalmente definido como a razão entre a variação do produto e a variação de um instrumento fiscal que sofre um choque exógeno. A depender do modelo em questão, os instrumentos fiscais diferem, sendo, em geral, do lado dos gastos como consumo público, investimento público e transferências ou do lado dos tributos como receitas e alíquotas

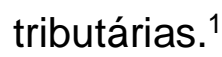

Além de seu valor depender de vários fatores, dentre os quais período e tamanho da amostra, país sob análise e hipóteses de identificação do choque, o multiplicador fiscal é calculado de diferentes maneiras (Tabela 1). Os estudos mais recentes têm convergido para o uso do multiplicador fiscal cumulativo a valor presente, sobretudo aqueles que fazem uso de modelos DSGE, pois ele resume o efeito presente de toda a dinâmica do produto causada por um choque fiscal dado num instrumento fiscal de interesse.

Tabela 1 - Tipos de Multiplicadores Fiscais

\begin{tabular}{|ccc|}
\hline Multiplicador & Fórmula & Descrição \\
\hline de Impacto & $\frac{\Delta Y_{t}}{\Delta X_{t}}$ & $\begin{array}{c}\text { Resposta do produto }(Y) \text { em } t \text { a uma variação do } \\
\text { instrumento fiscal }(X) \text { causada por um choque em } t .\end{array}$ \\
\hline de Horizonte $n$ & $\frac{\Delta Y_{t+n}}{\Delta X_{t}}$ & $\begin{array}{c}\text { Resposta do produto em } t+n \text { a uma variação do } \\
\text { instrumento fiscal causada por um choque em } t .\end{array}$ \\
\hline de Pico & $\max _{n}\left(\frac{\Delta Y_{t+n}}{\Delta X_{t}}\right)$ & $\begin{array}{c}\text { Maior resposta do produto a uma variação do } \\
\text { instrumento fiscal causada por um choque em } t .\end{array}$ \\
\hline $\begin{array}{c}\text { Cumulativo a } \\
\text { Valor Presente }\end{array}$ & $\frac{\sum_{i=0}^{n} \Delta Y_{t+i}}{\sum_{i=0}^{n} \Delta X_{t+i}}$ & $\begin{array}{c}\text { Resposta acumulada do produto até o instante } n \text { a uma } \\
\text { variação acumulada do instrumento fiscal causada por } \\
\text { und choque em } t \text {. }\end{array}$ \\
\hline$\sum_{i=0}^{n} R^{-i} \Delta X_{t+i}$ & $\begin{array}{c}\text { Resposta acumulada do produto até o instante } n \text { a uma } \\
\text { variação acumulada do instrumento fiscal causada por } \\
\text { um choque em } t \text {, trazido a valor presente com a taxa } \\
\text { de juros bruta de estado estacionário }(R) \text { Também é } \\
\text { possível usar a taxa de juros bruta do modelo }\left(R_{t}\right) .\end{array}$ \\
\hline
\end{tabular}

Fonte: Elaboração própria com base em Spilimbergo et al. (2009), Mountford e Uhlig (2009) e Leeper et al. (2010). Nota: A variação $(\Delta)$ é em relação ao estado estacionário.

\footnotetext{
${ }^{1}$ Para o cálculo dos multiplicadores fiscais de alíquotas tributárias, usa-se a variação da respectiva receita no lugar da variação da alíquota.
} 
De acordo com Batini et al. (2014), as pesquisas que visam à análise de políticas fiscais e multiplicadores fiscais podem ser agrupadas em dois ramos a depender da abordagem metodológica: um ramo diz respeito às pesquisas baseadas em modelos VAR (vector autoregression) e o outro, àquelas baseadas em modelos DSGE.

Ainda seguindo Batini et al. (2014), nos modelos VAR as variáveis de interesse (em geral, produto, consumo público, tributação, inflação e taxa de juros) são interrelacionadas e apresentam múltiplas relações causais. Seu principal objetivo é isolar choques exógenos e, para tanto, são diversas as formas de identificação dos choques, sendo que essa identificação é a maior dificuldade da estimação e as hipóteses por trás dela são o principal alvo de críticas. Além dessa desvantagem, os modelos VAR proveem estimativas médias da resposta da variável de interesse a choques fiscais a partir de informações passadas, o que faz com que o multiplicador fiscal estimado não reflita tão bem o potencial da política fiscal se as condições presentes passarem por mudanças estruturais importantes. A terceira desvantagem é que os modelos VAR são em geral lineares e não levam em conta o fato de que o multiplicador pode ser dependente do estado da economia (expansão ou contração), mas isso tem mudado com pesquisas mais recentes tentando incorporar não linearidades nos modelos VAR. ${ }^{2}$

Por outro lado, os modelos DSGE descrevem o comportamento da economia como um todo ao serem formulados a partir da interação de decisões microeconômicas, contrastando com a abordagem VAR, que leva em conta a interação de apenas algumas variáveis. Mesmo assim, os modelos DSGE também têm desvantagens. Primeiro, ainda não existe um consenso sobre a forma de modelagem da política fiscal, ao contrário, por exemplo, da política monetária, que comumente é modelada por uma regra monetária relativamente consolidada na literatura. Segundo, vários modelos DSGE se baseiam em equações linearizadas e, assim, não permitem incorporar no cálculo dos multiplicadores sua possível dependência do estado da economia. Terceiro, os resultados das simulações tendem a ser sensíveis à escolha de certos parâmetros. Quarto, os valores dos multiplicadores também dependem das hipóteses específicas do modelo em questão, sendo mais dependentes no caso de simulação que no caso de estimação.

\footnotetext{
2 Para mais detalhes sobre pesquisas que usam modelos VAR para calcular multiplicadores fiscais, ver a revisão de literatura de Gobetti et al. (2016).
} 
A seguir, faz-se uma breve exposição dos estudos internacionais voltados à análise da política fiscal e ao cálculo de multiplicadores fiscais que se baseiam em modelos DSGE.

A maioria dos estudos que adotam modelos DSGE para analisar o comportamento da política fiscal e multiplicadores fiscais analisam os Estados Unidos da América. Leeper et al. (2010) calculam multiplicadores fiscais cumulativos a valor presente para consumo público, transferências e tributo do trabalho e do capital e encontram que todos apresentam valores modestos e menores que a unidade. Christiano et al. (2011) mostram que uma economia com a taxa de juros nominal muito próxima de zero tem multiplicadores fiscais maiores, que são da ordem de 1,6 e podem chegar ao valor máximo de 2,3. Zubairy (2014) obtém estimativas que resultam em multiplicadores cumulativos a valor presente para o consumo público, tributo do trabalho e do capital, respectivamente, de 1,07, 0,13 e 0,34 no primeiro trimestre. Porém, o multiplicador de consumo público se torna permanentemente menor que a unidade após o décimo segundo trimestre, enquanto os de tributação do trabalho e capital crescem, mas não chegam a superar o valor da unidade. Drautzburg e Uhlig (2015) se baseiam no modelo de Smets e Wouters (2007) com a adição de agentes sem acesso ao mercado de crédito, impossibilidade de a taxa de juros nominal ser menor que zero, estoque de capital público e tributação distorciva. Suas estimações indicam que no curto prazo os multiplicadores cumulativos a valor presente de consumo público, investimento público e transferências atingem valores máximos de 1,1, 0,5 e 0,3, respectivamente, mas no longo prazo todos tendem a diminuir consideravelmente, chegando aos valores de -1,15, 0,25 e - -0,6, respectivamente.

Há também trabalhos que se dedicam a investigar a política fiscal de outras economias desenvolvidas a partir de modelos DSGE. Forni et al. (2009) usam dados da União Europeia para estimar um modelo DSGE com uma estrutura fiscal que leva em conta emprego do setor público. Suas estimativas indicam que os multiplicadores cumulativos de consumo público, emprego do setor público, transferências, tributo do consumo, trabalho e capital são em todos os horizontes de tempo menores que a unidade com exceção do multiplicador de consumo público no primeiro período se mostrando maior que a unidade. Stahler e Thomas (2012) constroem um modelo com uma estrutura 
de união monetária com setor público que, além de contratar trabalho, faz investimento público. Simulando a interação entre a Espanha e União Europeia como um todo, encontram evidências de que uma consolidação fiscal baseada em cortes no investimento público é menos aconselhável devido ao maior custo em termos de queda do produto com um multiplicador fiscal de $-0,46$ na média. Já uma consolidação baseada em cortes no salário do setor público é o mais indicado por gerar até mesmo um efeito positivo no produto com um multiplicador ao redor de 1,22 na média. Bhattarai e Trzeciakiewicz (2017) investigam a economia do Reino Unido, obtendo estimativas que demonstram que os multiplicadores cumulativos a valor presente de consumo público e investimento público são os maiores no $1^{\circ}$ trimestre $(0,97$ e 1,08 , respectivamente), ao passo que os multiplicadores de tributo do capital e investimento público são os maiores no $20^{\circ}$ trimestre $(0,52$ e 0,72 , respectivamente).

A literatura brasileira sobre modelos DSGE construídos para analisar políticas fiscais e multiplicadores fiscais é escassa e seus estudos são descritos a seguir.

Barros e Lima (2013) estimam os coeficientes de regras de políticas monetária e fiscal com uma metodologia que permite mudanças entre regimes ativo e passivo. Encontram evidências de que a política monetária é mais ativa (reage mais à inflação) em um regime e menos ativa (reage menos à inflação) em outro, enquanto a política fiscal é sempre passiva (é conduzida para estabilizar a dívida pública). Depois, usam os valores estimados para calibrar um modelo DSGE com mudança de regime em que a autoridade fiscal dispõe dos instrumentos de consumo público e tributação lump sum. Suas simulações indicam que um choque no consumo público provoca um aumento do hiato do produto, redução do consumo privado e queda da inflação nos casos de (i) políticas monetária mais ativa e fiscal passiva e (ii) políticas monetária menos ativa e fiscal passiva. Como a resposta à inflação é menor e a resposta ao hiato do produto é maior no caso (ii), a taxa de juros nominal acaba se elevando em reação ao aumento do hiato do produto, mesmo com a queda da inflação, e isso faz o produto crescer menos e a dívida pública a aumentar mais no caso (ii). Ao longo do tempo, o produto é menor no caso (ii), dentre outros motivos, porque o ajuste fiscal exigido pela elevação da dívida pública é maior. Assim, os multiplicadores fiscais cumulativos trazidos a valor presente, 
com a taxa de juros obtida do modelo, do consumo público no caso (i) são maiores que no caso (ii) para todos os horizontes de tempo, embora não sejam maiores que a unidade.

Cavalcanti e Vereda (2015) desenvolvem um modelo DSGE com uma rica variedade de instrumentos fiscais, compostos por tributação distorciva sobre consumo, trabalho, capital e bens intermediários importados, tributação lump sum, consumo público, investimento público, transferências e emprego no setor público, que se mostra particularmente relevante para o Brasil, onde $60 \%$ do consumo público das contas nacionais do período 2007-2009 se deve ao pagamento de salários dos servidores públicos, segundo os autores. Eles calibram o modelo para tentar reproduzir a economia brasileira e calcular multiplicadores fiscais cumulativos de choques de transferências, investimento público e emprego público sob diferentes regras fiscais. O multiplicador das transferências tem impacto positivo e menor que a unidade no curto prazo, mas assume valor negativo no longo prazo sob todas as regras. O multiplicador do investimento público no curto prazo apresenta valor negativo sob a regra de orçamento permanentemente balanceado e valor positivo sob a regra de orçamento parcialmente balanceado, enquanto no longo prazo assume valor positivo sob todas as regras. Nesse caso, o multiplicador cresce para períodos mais longos devido ao tempo necessário para o investimento público se converter em estoque de capital público e aumentar a produtividade da economia. Por último, o multiplicador do emprego público é negativo no curto e longo prazo quando está em vigor a regra de orçamento permanentemente balanceado, mas apresenta valores positivos e menores que a unidade no curto prazo e negativos próximos de zero no longo prazo sob a regra de orçamento parcialmente balanceado.

Já Moura (2015) elabora um modelo DSGE para calcular os multiplicadores fiscais cumulativos trazidos a valor presente com a taxa de juros de estado estacionário do consumo público e investimento público. Utiliza métodos bayesianos na parte de estimação do modelo, mas adota a simplificação de tributação lump sum. O multiplicador fiscal do consumo público é inicialmente positivo e maior que a unidade, mas no longo prazo se torna menor que a unidade, sendo que em alguns cenários de alta elasticidade do produto em relação ao estoque de capital público assume valores negativos. Isso acontece porque um aumento do consumo público impulsiona no curto prazo a atividade 
econômica ao mesmo tempo em que eleva a dívida pública, mas no longo prazo para estabilizar a dívida o governo corta gastos tanto com consumo quanto com investimento público, o que afeta negativamente o estoque de capital público e, por consequência, a produtividade da economia. Esse efeito negativo é tanto maior quanto mais alta for a elasticidade do produto em relação ao estoque de capital público. Por sua vez, o multiplicador fiscal do investimento público não só é positivo e maior que a unidade no curto prazo, como também é maior que a unidade no longo prazo, mesmo para pequenos valores da elasticidade do produto em relação ao estoque de capital público.

Além da importância desse parâmetro de elasticidade, Moura (2015) mostra que os parâmetros de suavização da regra monetária e de proporção de famílias sem acesso ao mercado financeiro são relevantes para o entendimento dos multiplicadores fiscais. ${ }^{3}$ Uma política monetária mais acomodatícia, ou seja, cujo parâmetro de suavização é maior, produz multiplicadores fiscais maiores no curto prazo e menores no longo prazo. Nesse caso, o aperto monetário para combater uma alta da inflação advinda da elevação da demanda agregada devido a um maior gasto do governo com consumo ou investimento público é menor no curto prazo, porém no longo prazo essa maior leniência com a inflação tem um custo maior em termos de contração da atividade econômica para trazer a inflação para o nível desejado. Se a fração de famílias que não têm acesso ao mercado financeiro é grande, então é menor o número das famílias que conseguem realocar intertemporalmente seus recursos a fim de suavizar seu consumo. Mais especificamente, quando o governo aumenta seus gastos com consumo ou investimento público, aquelas famílias com acesso ao mercado financeiro tendem a diminuir seu consumo e aumentar sua poupança, pois anteveem que o governo elevará a tributação, enquanto as outras famílias aumentam seu consumo ao verem sua renda aumentar em virtude do aumento da atividade econômica. Assim, quanto maior é a proporção de famílias sem acesso ao mercado financeiro, tanto maiores são os multiplicadores fiscais no curto e longo prazo.

Por fim, Costa Jr. et al. (2017) desenvolvem um modelo DSGE para a economia brasileira e ressaltam que, em contraste com os pontos fracos de calibração de

\footnotetext{
${ }^{3} \mathrm{O}$ presente trabalho também analisa a sensibilidade dos multiplicadores fiscais a esses três parâmetros, além da elasticidade do custo de ajustamento da utilização do capital privado e do comportamento da política fiscal, na subseção Exercícios de Sensibilidade dos Multiplicadores Fiscais.
} 
Cavalcanti e Vereda (2015) e de tributação lump sum de Moura (2015), estimam o modelo com técnicas bayesianas e incorporam tributação distorciva. Além do tributo do consumo, trabalho e capital, o governo dispõe de gastos com consumo, investimento público e transferências como instrumentos fiscais. A análise da decomposição da variância do erro de previsão revela que o consumo público e o investimento público são as variáveis fiscais mais relevantes para explicar a flutuação do produto no período de 2002-14. Isso se deve, segundo os autores, aos Programas de Aceleração do Crescimento 1 e 2 , lançados pelo governo. Ademais, os cálculos dos multiplicadores fiscais cumulativos revelam que todos são menores que a unidade no curto e longo prazo. Em particular, os multiplicadores fiscais de tributo do consumo e consumo público são os maiores, com seus valores variando de 0,09 a 0,12 e de 0,04 a 0,06 , respectivamente. Os demais apresentam valores muito próximos de zero.

O presente trabalho vai na mesma direção de Costa Jr. et al. (2017) ao utilizar estimação bayesiana e um modelo DSGE com um arcabouço fiscal que incorpora tributação distorciva, mas diferencia-se sobretudo na parte de modelagem e dados. Embora muitas fricções nominais e reais sejam iguais, cada um adota uma forma específica de incorporá-las - e.g., tipos de função e referências na literatura. Os dados de alíquotas efetivas de Azevedo e Fasolo (2015) e de Almeida et al. (2017) usados no presente trabalho representam diretamente as alíquotas tributárias do modelo, enquanto Costa Jr. et al. (2017) utilizam dados de receitas das alíquotas, o que torna as estimações dos parâmetros ligados à tributação menos precisas e, logo, os resultados dos multiplicadores mais sujeitos a críticas. Ademais, Costa Jr. et al. (2017) não usam dados para a variável de investimento público, também reforçando a falta de precisão das estimativas dos parâmetros e do multiplicador associados a essa variável, ao passo que o presente trabalho adota a série de investimento público construída por Orair (2016). 


\section{Estrutura do Modelo}

O modelo é baseado em Smets e Wouters (2003) e Bhattarai e Trzeciakiewicz (2017). Em suma, seus principais elementos são rigidez de preços e salários, formação de hábito, custo de ajustamento do investimento privado, utilização variável do estoque de capital privado, famílias com e sem acesso aos mercados de ativos e um rico arcabouço de instrumentos fiscais desagregados em consumo público, investimento público, transferências e alíquotas tributárias sobre o consumo, a renda do trabalho e a renda do capital. ${ }^{4}$ A Figura 2 esquematiza a estrutura do modelo e suas interrelações.

Figura 2 - Fluxograma do Modelo

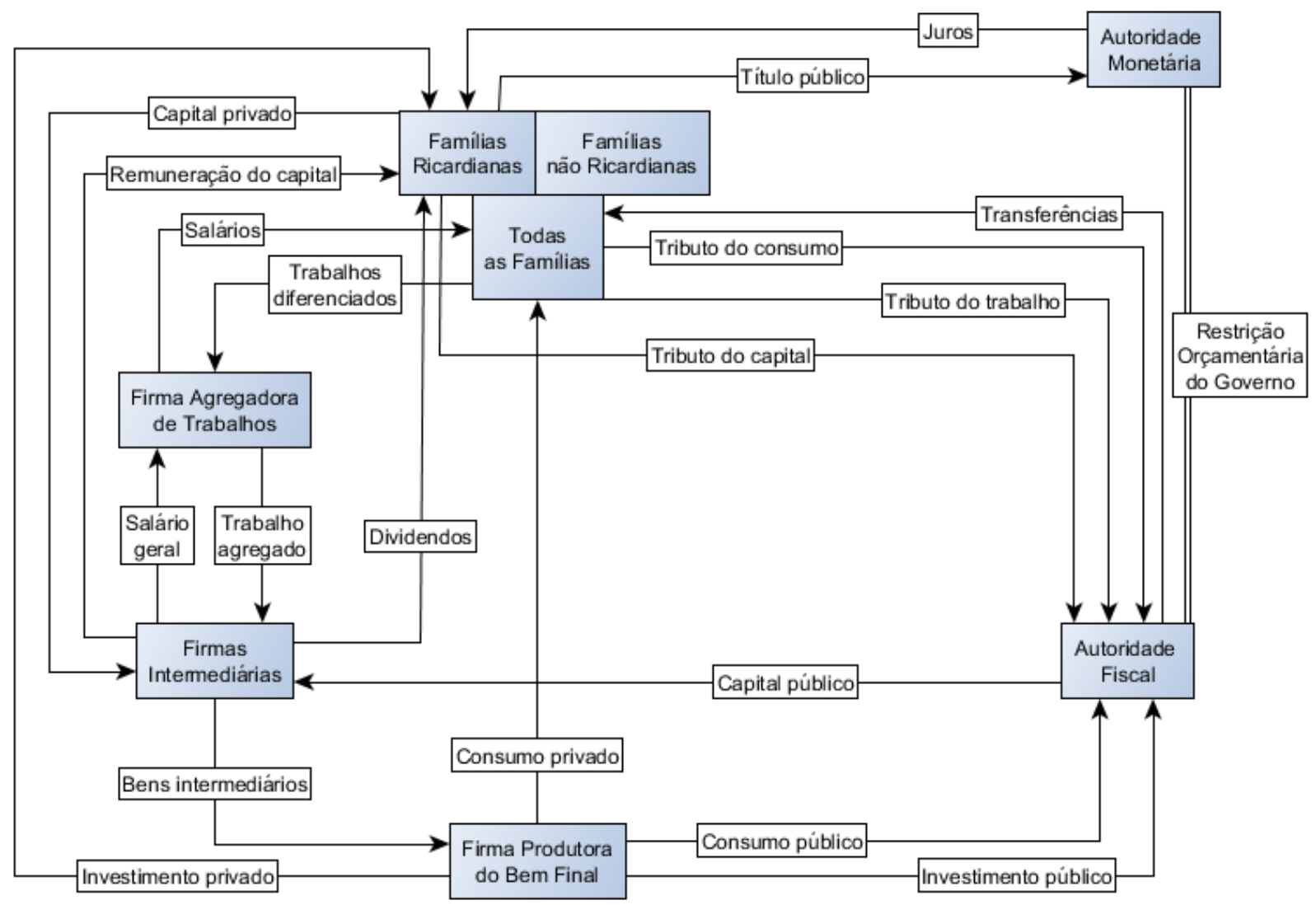

Fonte: Elaboração própria.

\footnotetext{
4 Tal como em Smets e Wouters (2003) e Bhattarai e Trzeciakiewicz (2017), o modelo não tem um setor externo, o que se justifica pelo pouco ganho de aproximação com a economia brasileira, caracterizada por ser relativamente fechada, vis-à-vis o custo de aumentar a complexidade de um modelo já com vários elementos.
} 
A economia é caracterizada por um contínuo de famílias, indexadas por $l \in[0,1]$. Seguindo Campbell e Mankiw (1989), Mankiw (2000) e Galí et al. (2007), uma fração $v$ delas é composta por famílias não ricardianas (também chamadas de famílias rule-ofthumb ou de famílias não otimizadoras), indexadas por $m$, que não têm acesso aos mercados de ativos (títulos públicos, estoque de capital privado e propriedade das firmas) e simplesmente consomem sua renda corrente líquida de tributos advinda da venda de trabalho e recebimento de transferências. A fração restante $(1-v)$ é composta por famílias ricardianas (também chamadas de famílias otimizadoras), indexadas por $n$, que internalizam os gastos e os tributos do governo em suas decisões e têm acesso aos mercados de ativos, maximizando sua utilidade ao longo do tempo sujeito a uma restrição orçamentária e à evolução do estoque de capital privado. Os dois tipos de famílias vendem trabalho diferenciado, o que as faz ter poder de mercado para escolher seus salários de acordo com um mecanismo de Calvo (1983) com indexação parcial à inflação passada.

Existe um contínuo de firmas produtoras de bens intermediários diferenciados, indexadas por $j \in[0,1]$, que operam sob concorrência monopolística, podem reajustar preços de acordo com um mecanismo de Calvo (1983) com indexação parcial à inflação passada e contratam trabalho e capital privado. A firma produtora do bem final compra bens intermediários como insumos para sua produção sob concorrência perfeita.

O governo é constituído por uma autoridade monetária e uma autoridade fiscal. A autoridade monetária obedece a uma regra monetária. A autoridade fiscal dispõe de seis instrumentos fiscais: do lado dos gastos, consumo público, investimento público e transferências, e, do lado dos tributos, alíquotas sobre o consumo, a renda do trabalho e a renda do capital. Para cada um dos instrumentos, existe uma correspondente regra fiscal.

\section{Famílias Ricardianas}

A função utilidade de cada família ricardiana tem a seguinte forma:

$$
E_{0} \sum_{t=0}^{\infty} \varepsilon_{t}^{b} \beta^{t}\left[\frac{\left(C_{r, t}^{n}-h C_{r, t-1}\right)^{1-\sigma_{C}}}{1-\sigma_{C}}-\frac{\left(L_{r, t}^{n}\right)^{1+\sigma_{L}}}{1+\sigma_{L}}\right]
$$


onde $0<\beta<1$ representa o fator de desconto, $\sigma_{L}>0$ é o inverso da elasticidade da oferta de trabalho $\left(L_{r, t}^{n}\right), \sigma_{C}>0$ é o inverso da elasticidade de substituição intertemporal do consumo $\left(C_{r, t}^{n}\right), h C_{r, t-1}$ representa a formação de hábito externo, com $0<h<1$ sendo o grau de persistência de hábito e $C_{r, t-1}$ sendo o consumo agregado passado das famílias ricardianas, e $\varepsilon_{t}^{b}$ é um choque de preferência. ${ }^{5}$

A restrição orçamentária garante que o gasto com consumo $\left(C_{r, t}^{n}\right)$, investimento em capital privado $\left(I_{r, t}^{n}\right)$ e acumulação de títulos públicos de um período de maturação $\left(b_{r, t}^{n}\right)$ é igual à renda real total disponível $\left(i n c_{r, t}^{n}\right)$ :

$$
b_{r, t}^{n}-\frac{b_{r, t-1}^{n}}{\Pi_{t}}+I_{r, t}^{n}+\left(1+\tau_{t}^{c}\right) C_{r, t}^{n}=i n c_{r, t}^{n}
$$

onde $\Pi_{t}$ denota a taxa de inflação bruta e $\tau_{t}^{c}$ denota a alíquota tributária sobre 0 consumo $^{6}$. A renda real total disponível de cada família ricardiana é dada por:

$$
\begin{gathered}
\text { inc }_{r, t}^{n}=\left(1-\tau_{t}^{l}\right) w_{r, t}^{n} L_{r, t}^{n}+\left(1-\tau_{t}^{k}\right) r_{k, t} u_{r, t}^{n} K_{r, t-1}^{n}-a\left(u_{r, t}^{n}\right) K_{r, t-1}^{n}+\operatorname{prof}_{r, t}^{n}+ \\
T_{r, t}^{n}+\frac{\left(R_{t-1}-1\right) b_{r, t-1}^{n}}{\Pi_{t}}+A_{r, t}^{n}
\end{gathered}
$$

onde (i) $\left(1-\tau_{t}^{l}\right) w_{r, t}^{n} L_{r, t}^{n}$ é a renda do trabalho líquida de tributação, sendo $w_{r, t}^{n}$ o salário real e $\tau_{t}^{l}$ a alíquota tributária sobre a renda do trabalho; (ii) $\left(1-\tau_{t}^{k}\right) r_{k, t} u_{r, t}^{n} K_{r, t-1}^{n}$ é a renda do capital efetivamente utilizado líquida de tributação, sendo $r_{k, t}$ a taxa de retorno real do capital privado, $K_{r, t-1}^{n}$ o estoque de capital privado no fim do período $t-1, u_{r, t}^{n}$ a taxa de utilização do capital e $\tau_{t}^{k}$ a alíquota tributária sobre a renda do capital; (iii) $a\left(u_{r, t}^{n}\right) K_{r, t-1}^{n}$ é o custo associado a variações do grau de utilização do estoque de capital privado7; (iv) $\operatorname{prof}_{r, t}^{n}$ é a renda de dividendos pela posse das firmas intermediárias ${ }^{8} ;(\mathrm{v}) T_{r, t}^{n}$ é a

\footnotetext{
${ }^{5}$ Adianta-se que todos os choques do modelo log-linearizado são processos autorregressivos de primeira ordem com termos de erro sendo ruídos brancos gaussianos, à exceção do choque monetário, que é diretamente um ruído branco gaussiano. As equações dos choques são apresentadas na subseção Equações Log-linearizadas.

${ }^{6}$ Sem perda de generalidade, os tributos são inseridos apenas no lado das famílias, o que faz os preços pagos pelas famílias serem os preços recebidos pelas firmas acrescidos da alíquota sobre o consumo. Assim, mais precisamente, $\Pi_{t}$ é a taxa de inflação bruta dos produtores (exclusive a alíquota sobre o consumo) e $\Pi_{t}^{C}$ é a taxa de inflação bruta dos consumidores (inclusive alíquota sobre o consumo).

${ }^{7}$ A função $a($. $)$ é tal que $a^{\prime}>0, a^{\prime \prime}>0$ e $a(1)=0$. A última propriedade significa que a função assume valor zero quando a utilização do capital é total, o que acontece no estado estacionário.

8 Por simplicidade, os lucros das firmas intermediárias são distribuídos igualmente entre as famílias ricardianas.
} 
transferência do governo na forma lump sum; (vi) $\frac{\left(R_{t-1}-1\right) b_{r, t-1}^{n}}{\Pi_{t}}$ é a renda de juros dos títulos públicos, sendo $R_{t-1}$ a taxa de juros nominal bruta dos títulos públicos; e (vii) $A_{r, t}^{n}$ é o fluxo de renda advindo da participação num seguro contra variações na renda do trabalho específicas a cada família ricardiana, fazendo as escolhas de consumo e ativos serem iguais para todas as famílias ricardianas. ${ }^{9}$

A acumulação do estoque de capital privado é dada por:

$$
K_{r, t}^{n}=(1-\delta) K_{r, t-1}^{n}+I_{r, t}^{n}\left[1-S\left(\varepsilon_{t}^{I} \frac{I_{r, t}^{n}}{I_{r, t-1}^{n}}\right)\right]
$$

onde $0<\delta<1$ é a taxa de depreciação do estoque de capital privado, $S($ ) ) é a função custo de ajustamento do investimento privado ${ }^{10}$ e $\varepsilon_{t}^{I}$ é um choque de custo do investimento privado.

A combinação das condições de primeira ordem para o consumo e a demanda por títulos públicos resulta na equação de Euler:

$$
U_{r, c, t}=\beta E_{t}\left[\frac{R_{t}}{\Pi_{t+1}} \frac{1+\tau_{t}^{c}}{1+\tau_{t+1}^{c}} U_{r, c, t+1}\right]
$$

onde $U_{r, c, t} \equiv \varepsilon_{t}^{b}\left(C_{r, t}-h C_{r, t}\right)^{-\sigma_{C}}$ é a utilidade marginal do consumo.

A condição de primeira ordem para a taxa de utilização do capital privado mostra que uma taxa de retorno do capital maior ou uma alíquota tributária do capital menor leva a uma utilização do capital maior até o ponto em que os benefícios extras se igualam aos custos extras:

$$
\left(1-\tau_{t}^{k}\right) r_{k, t}=a^{\prime}\left(u_{r, t}\right)
$$

Considerando o preço-sombra do estoque de capital (também chamado de $Q$ de Tobin) como $Q_{t} \equiv \mu_{r, t} / \lambda_{r, t}$, em que $\mu_{r, t}$ e $\lambda_{r, t}$ são, respectivamente, os multiplicadores lagrangeanos da restrição orçamentária e da restrição da evolução do estoque de capital privado, a condição de primeira ordem para o estoque de capital mostra que o valor do estoque de capital instalado depende da expectativa do seu valor futuro levando em conta a taxa de depreciação do capital e da expectativa do retorno do capital líquido de

\footnotetext{
${ }^{9}$ Esse seguro em conjunto com algumas combinações das condições de primeira ordem para o problema das famílias ricardianas permite mostrar que todas elas fazem as mesmas escolhas ótimas. Daí a razão para suprimir o sobrescrito $n$ nas equações resultantes das condições de primeira ordem.

${ }^{10}$ A função $S($.) é tal que depende positivamente da taxa de variação do investimento privado e no estado estacionário é caracterizada por $\left.S\right|_{s s}=0,\left.S^{\prime}\right|_{s s}=0$ e $\left.S^{\prime \prime}\right|_{s s}>0$.
} 
tributação menos a expectativa do custo associado a variações do grau de utilização do estoque de capital:

$$
Q_{t}=\beta E_{t}\left\{\frac{\lambda_{r, t}}{\lambda_{r, t+1}}\left[\left(1-\tau_{t+1}^{k}\right) r_{k, t+1} u_{r, t+1}-a\left(u_{r, t+1}\right)+Q_{t+1}(1-\delta)\right]\right\}
$$

Por fim, a condição de primeira ordem para o investimento privado estabelece que o investimento presente depende do investimento passado e esperado, do valor corrente e esperado do estoque de capital instalado e do choque de custo do investimento presente e esperado:

$$
\begin{array}{r}
1=Q_{t}\left[1-S\left(\varepsilon_{t}^{I} \frac{I_{r, t}}{I_{r, t-1}}\right)-S^{\prime}\left(\varepsilon_{t}^{I} \frac{I_{r, t}}{I_{r, t-1}}\right) \varepsilon_{t}^{I} \frac{I_{r, t}}{I_{r, t-1}}\right]+ \\
\beta E_{t}\left[Q_{t+1} \frac{\lambda_{r, t+1}}{\lambda_{r, t}} S^{\prime}\left(\varepsilon_{t+1}^{I} \frac{I_{r, t+1}}{I_{r, t}}\right) \varepsilon_{t+1}^{I}\left(\frac{I_{r, t+1}}{I_{r, t}}\right)^{2}\right]
\end{array}
$$

\section{Famílias não Ricardianas}

Como as famílias não ricardianas não têm acesso aos mercados de ativos, elas simplesmente consomem sua renda do trabalho e das transferências, líquida da tributação do trabalho e do consumo:

$$
\left(1+\tau_{t}^{c}\right) C_{n r, t}^{m}=\left(1-\tau_{t}^{l}\right) w_{n r, t}^{m} L_{n r, t}^{m}+T_{n r, t}^{m}
$$

\section{Firma Agregadora de Trabalhos Diferenciados}

Seguindo Erceg et al. (2000) e Benigno e Woodford (2003), assume-se a existência de uma firma agregadora de trabalhos diferenciados sob concorrência perfeita que tem como único papel transformar os diferentes tipos de trabalho das famílias num trabalho agregado, que é vendido para as firmas produtoras de bens intermediários. Tomando como dado o salário de cada família $W_{t}^{l}$, a firma agregadora maximiza seu lucro:

$$
W_{t} N_{t}-\int_{0}^{1} W_{t}^{l} L_{t}^{l} d l
$$

sujeita à tecnologia de agregação de trabalhos diferenciados:

$$
N_{t}=\left[\int_{0}^{1}\left(L_{t}^{l}\right)^{\frac{1}{1+\varepsilon_{t}^{w}}} d l\right]^{1+\varepsilon_{t}^{w}}
$$


onde $L_{t}^{l}$ denota o montante de trabalho ofertado pela família $l, W_{t}$ denota 0 índice agregador de salários, $N_{t}$ denota o trabalho agregado e $\varepsilon_{t}^{w}$ é um choque de markup de salários, resultando na demanda por trabalho da família $l$ dada por:

$$
L_{t}^{l}=\left(\frac{W_{t}^{l}}{W_{t}}\right)^{-\frac{1+\varepsilon_{t}^{w}}{\varepsilon_{t}^{w}}} N_{t}
$$

A elasticidade de substituição entre os trabalhos diferenciados é $\left(1+\varepsilon_{t}^{w}\right) / \varepsilon_{t}^{w} \mathrm{e}$ varia no tempo devido ao choque $\varepsilon_{t}^{w}$. Como o lucro é zero, o índice agregador de salários tem a seguinte forma:

$$
W_{t}=\left[\int_{0}^{1}\left(W_{t}^{l}\right)^{-\frac{1}{\varepsilon_{t}^{w}}} d l\right]^{-\varepsilon_{t}^{w}}
$$

\section{Escolha do Salário Nominal Ótimo das Famílias Ricardianas}

Cada família ricardiana detém um tipo diferenciado de trabalho, o que dá a elas poder de mercado. Nesse ambiente de concorrência monopolística, elas escolhem o salário nominal ótimo por meio de um mecanismo de Calvo (1983). Em particular, a probabilidade de uma família ser sorteada para poder reajustar seu salário nominal no período $t$ é constante e igual a $\left(1-\varpi_{w}\right)$, onde $0 \leq \varpi_{w} \leq 1$. Se não for sorteada, então seu salário nominal segue uma regra de indexação parcial segundo a qual o salário é reajustado parcialmente pela inflação do período anterior, ou seja, $W_{r, t}^{n}=\Pi_{t-1}^{\gamma_{w}} W_{r, t-1}^{n}$, com $0 \leq \gamma_{w} \leq 1$ sendo o grau de indexação dos salários. Assim, uma família ricardiana sorteada para reajustar seu salário nominal no período $t$ escolhe um novo salário de modo a maximizar sua utilidade esperada sujeita à restrição orçamentária e à demanda por seu trabalho, levando em consideração a possibilidade de não poder reajustar seu salário nos períodos seguintes. Esse problema pode ser escrito como a maximização em $W_{r, t+s}^{n}$ de:

$$
E_{t} \sum_{s=0}^{\infty}\left(\beta \varpi_{w}\right)^{s}\left[-\varepsilon_{t+s}^{b} \frac{\left(L_{r, t+s}^{n}\right)^{1+\sigma_{L}}}{1+\sigma_{L}}+\lambda_{r, t+s}^{n}\left(1-\tau_{t+s}^{l}\right) \frac{W_{r, t+s}^{n}}{P_{t+s}} L_{r, t+s}^{n}\right]
$$

sujeito a: 


$$
\begin{gathered}
L_{r, t+s}^{n}=\left(\frac{W_{r, t+s}^{n}}{W_{t+s}}\right)^{-\frac{1+\varepsilon_{t+s}^{w}}{\varepsilon_{t+s}^{w}}} N_{t+s} \\
W_{r, t+s}^{n}=W_{r, t}^{n}\left(\frac{P_{t+s-1}}{P_{t-1}}\right)^{\gamma_{w}}
\end{gathered}
$$

Como em Erceg et al. (2000) e Christiano et al. (2005), todas as famílias que podem reajustar seus salários nominais escolhem o mesmo salário $\widetilde{W}_{r, t}$. Se os salários são perfeitamente flexíveis $\left(\varpi_{w}=0\right)$, então 0 salário real se torna $\widetilde{W}_{r, t} / P_{t}=$ $-\left(1+\varepsilon_{t}^{w}\right) \frac{U_{r, L, t}}{U_{r, c, t}} \frac{1+\tau_{t}^{c}}{1-\tau_{t}^{l}}$, onde $U_{r, L, t} \equiv-\varepsilon_{t}^{b}\left(L_{r, t}\right)^{\sigma_{L}}$ é a desutilidade marginal do trabalho e $1+$ $\varepsilon_{t}^{w}$ é a taxa de markup de salários bruta.

\section{Escolha do Salário Ótimo das Famílias não Ricardianas}

Por simplicidade, seguindo Erceg et al. (2005), assume-se que as famílias não ricardianas que são sorteadas para reajustar seus salários nominais estabelecem o novo salário como sendo igual à média dos salários das famílias ricardianas, o que implica $W_{t}=W_{r, t}=W_{n r, t}$. Como todas as famílias se deparam com a mesma demanda por trabalho, a oferta de trabalho das famílias ricardianas é igual à das famílias não ricardianas, ou seja, $L_{t}=L_{r, t}=L_{n r, t}$. Assim, o índice agregador de salários pode ser reescrito como:

$$
W_{t}=\left[\left(1-\varpi_{w}\right) \widetilde{W}_{t}^{-\frac{1}{\varepsilon_{t}^{w}}}+\varpi_{w}\left(\Pi_{t-1}^{\gamma_{w}} W_{t-1}\right)^{-\frac{1}{\varepsilon_{t}^{w}}}\right]^{-\varepsilon_{t}^{w}}
$$

\section{Firma Produtora do Bem Final}

Analogamente à agregação dos trabalhos diferenciados, existe uma firma responsável por comprar bens intermediários diferenciados $\left(Y_{j, t}\right)$ e agregá-los num bem final $\left(Y_{t}\right)$, que pode ser consumido ou investido. Operando sob competição perfeita e tomando como dado o preço de cada bem intermediário $\left(P_{j, t}\right)$, ela maximiza seu lucro:

$$
P_{t} Y_{t}-\int_{0}^{1} P_{j, t} Y_{j, t} d j
$$

sujeita à tecnologia de agregação de bens intermediários: 


$$
Y_{t}=\left[\int_{0}^{1}\left(Y_{j, t}\right)^{\frac{1}{1+\varepsilon_{t}^{p}}} d j\right]^{1+\varepsilon_{t}^{p}}
$$

onde $P_{t}$ é o índice agregador de preços e $\varepsilon_{t}^{p}$ é um choque de markup de preços, resultando na demanda pelo bem intermediário $j$ dada por:

$$
Y_{j, t}=\left(\frac{P_{j, t}}{P_{t}}\right)^{-\frac{1+\varepsilon_{t}^{p}}{\varepsilon_{t}^{p}}} Y_{t}
$$

A elasticidade de substituição entre bens intermediários é $\left(1+\varepsilon_{t}^{p}\right) / \varepsilon_{t}^{p}$ e sofre mudanças ao longo do tempo causadas pelo choque $\varepsilon_{t}^{p}$. Devido ao resultado de lucro nulo, o índice agregador de preços é dado por:

$$
P_{t}=\left[\int_{0}^{1}\left(P_{j, t}\right)^{-\frac{1}{\varepsilon_{t}^{p}}} d j\right]^{-\varepsilon_{t}^{p}}
$$

\section{Firmas Produtoras de Bens Intermediários}

Em um ambiente de concorrência monopolística, cada firma intermediária $j$ produz um bem intermediário diferenciado e tem acesso à tecnologia de produção:

$$
Y_{j, t}=\varepsilon_{t}^{A}\left(\bar{K}_{j, t-1}\right)^{\alpha}\left(N_{j, t}\right)^{1-\alpha}\left(K_{G, t-1}\right)^{\alpha_{G}}-\Phi
$$

onde $\bar{K}_{j, t-1} \equiv u_{t} K_{j, t-1}$ é a utilização efetiva de capital privado alugado das famílias ricardianas, $N_{j, t}$ é o índice agregador de trabalhos usado pela firma, $K_{G, t-1}$ é o estoque de capital público, $\Phi$ é o custo fixo ${ }^{11}, 0<\alpha<1$ representa a elasticidade do nível de produção em relação ao estoque de capital privado, $\alpha_{G}>0$ é a elasticidade do nível de produção em relação ao estoque de capital público, e $\varepsilon_{t}^{A}$ é um choque de tecnologia comum a todas as firmas produtoras de bens intermediários.

O estoque de capital público tem o papel de representar diversos tipos de insumos providos pelo governo, como infraestrutura em geral e segurança, que podem produzir economias de escala no setor privado. Isso se reflete na função de produção das firmas intermediárias, que é caracterizada por retornos constantes de escala nos insumos privados (trabalho e capital privado), porém por retornos crescentes de escala em todos os insumos (trabalho, capital privado e capital público).

\footnotetext{
11 O custo fixo garante que no estado estacionário o lucro das firmas intermediárias seja zero.
} 
Sujeita a essa tecnologia para um dado nível de produção e tomando como dados o índice agregador de salários $\left(W_{t}\right)$ e a taxa de retorno nominal do capital $\left(R_{k, t}\right)$, cada firma intermediária minimiza seu custo nominal total dado por:

$$
R_{k, t} \bar{K}_{j, t}+W_{t} N_{j, t}
$$

Das condições de primeira ordem, mostra-se que a razão $\bar{K}_{j, t} / N_{j, t}$ é a mesma para todas as firmas intermediárias, já que se deparam com a mesma razão dos preços dos insumos:

$$
\frac{\bar{K}_{t}}{N_{t}}=\frac{\bar{K}_{j, t}}{N_{j, t}}=\frac{\alpha}{1-\alpha} \frac{W_{t}}{R_{k, t}}
$$

E o custo marginal nominal $\left(P_{t} m c_{t}\right)$ é igual para todas elas:

$$
P_{t} m c_{t}=\left(\frac{1}{1-\alpha}\right)^{1-\alpha}\left(\frac{1}{\alpha}\right)^{\alpha}\left(\varepsilon_{t}^{A}\right)^{-1}\left(K_{G, t-1}\right)^{-\alpha_{G}}\left(W_{t}\right)^{1-\alpha}\left(R_{k, t}\right)^{\alpha}
$$

O custo marginal depende positivamente do índice de salários e da taxa de retorno do capital privado e negativamente do estoque de capital público. Um choque de tecnologia positivo impacta negativamente o custo marginal.

\section{Escolha do Preço Ótimo das Firmas Produtoras de Bens Intermediários}

O lucro da firma intermediária $j$ pode ser escrito como uma função do custo marginal ${ }^{12}$ :

$$
P_{j, t} Y_{j, t}-m c_{t} P_{t}\left(Y_{j, t}+\Phi\right)
$$

As firmas intermediárias detêm poder de mercado por produzirem bens diferenciados. Supõe-se que elas escolhem o preço do seu respectivo bem intermediário por meio de um mecanismo de Calvo (1983). Em particular, cada firma intermediária tem uma probabilidade constante $\left(1-\varpi_{p}\right)$ de no período $t$ ser sorteada para poder reajustar seu preço, com $0 \leq \varpi_{p} \leq 1$. Caso não seja sorteada, o seu preço é reajustado parcialmente pela inflação do período anterior, ou seja, $P_{j, t}=\Pi_{t-1}^{\gamma_{p}} P_{j, t-1}$, com $0 \leq \gamma_{p} \leq 1$ sendo o grau de indexação dos preços. Assim, uma firma intermediária sorteada para reajustar seu preço no período $t$ maximiza seu lucro esperado ao longo do tempo sujeita à demanda por seu produto, levando em consideração um fator de desconto que reflete

\footnotetext{
12 Para o lucro das firmas intermediárias ser zero no estado estacionário, é necessário que $\Phi=\frac{(1-m c)}{m c} Y$.
} 
sua posse por parte das famílias ricardianas e a possibilidade de não poder reajustar seu preço nos períodos seguintes. Esse problema pode ser escrito como a maximização em $P_{j, t+s}$ de:

$$
E_{t} \sum_{s=0}^{\infty}\left(\beta \varpi_{p}\right)^{s}\left(\frac{\lambda_{r, t+s}}{\lambda_{r, t}}\right)\left[\frac{P_{j, t+s} Y_{j, t+s}}{P_{t+s}}-m c_{t+s}\left(Y_{j, t+s}+\Phi\right)\right]
$$

sujeito a:

$$
\begin{gathered}
Y_{j, t+s}=\left(\frac{P_{j, t+s}}{P_{t+s}}\right)^{-\frac{1+\varepsilon_{t}^{p}}{\varepsilon_{t}^{p}}} Y_{t+s} \\
P_{j, t+s}=P_{j, t}\left(\frac{P_{t+s-1}}{P_{t-1}}\right)^{\gamma_{p}}
\end{gathered}
$$

Como em Erceg et al. (2000) e Christiano et al. (2005), todas as firmas intermediárias que podem reajustar seus preços escolhem o mesmo preço $\tilde{P}_{t}$. Se os preços são perfeitamente flexíveis $\left(\varpi_{p}=0\right)$, então o preço se torna $\tilde{P}_{t}=\left(1+\varepsilon_{t}^{p}\right) P_{t} m c_{t}$, onde $1+\varepsilon_{t}^{p}$ é taxa de markup de preços bruta. Assim, o índice de preços pode ser reescrito como:

$$
P_{t}=\left[\left(1-\varpi_{p}\right) \tilde{P}_{t}^{-\frac{1}{\varepsilon_{t}^{p}}}+\varpi_{p}\left(\Pi_{t-1}^{\gamma_{p}} P_{t-1}\right)^{-\frac{1}{\varepsilon_{t}^{p}}}\right]^{-\varepsilon_{t}^{p}}
$$

\section{Regra Monetária}

A autoridade monetária segue a regra monetária dada por ${ }^{13}$ :

$$
\hat{R}_{t}=\rho \hat{R}_{t-1}+(1-\rho)\left(\rho_{\Pi} \widehat{\Pi}_{t}+\rho_{Y} \hat{Y}_{t}\right)+\eta_{t}^{m}
$$

onde a taxa de juros nominal $\left(\hat{R}_{t}\right)$ responde à taxa de juros nominal passada $\left(\hat{R}_{t-1}\right)$, à taxa de inflação corrente $\left(\widehat{\Pi}_{t}\right)$, ao produto corrente $\left(\widehat{Y}_{t}\right)$ e a um choque monetário $\left(\eta_{t}^{m}\right)$. Além disso, $0 \leq \rho \leq 1$ mede o grau de suavização da taxa de juros nominal e $\rho_{\Pi}$ e $\rho_{Y}$ medem o quão forte é a reação da autoridade monetária frente a mudanças da taxa de inflação e do produto, respectivamente.

13 Variáveis com um acento circunflexo estão sob a forma log-linearizada em relação ao estado estacionário. 


\section{Regras Fiscais de Gastos e Tributos}

A autoridade fiscal dispõe de seis instrumentos fiscais: do lado das gastos, consumo público $\left(G_{t}\right)$, investimento público $\left(I_{G, t}\right)$ e transferências totais $\left(T_{t}\right)$, e, do lado dos tributos, alíquotas sobre o consumo $\left(\tau_{t}^{c}\right)$, a renda do trabalho $\left(\tau_{t}^{l}\right)$ e a renda do capital $\left(\tau_{t}^{k}\right)$. Analogamente a Leeper et al. (2010), os instrumentos de gastos e tributos respondem ao produto $\left(\hat{Y}_{t}\right)$ e à dívida pública passada $\left(\hat{b}_{t-1}\right)$, originando regras fiscais:

$$
\begin{gathered}
\hat{X}_{t}=-\phi_{b, X} \hat{b}_{t-1}-\phi_{Y, X} \hat{Y}_{t}+\hat{\varepsilon}_{t}^{X} \\
\hat{Z}_{t}=\phi_{b, Z} \hat{b}_{t-1}+\phi_{Y, Z} \hat{Y}_{t}+\hat{\varepsilon}_{t}^{Z}
\end{gathered}
$$

onde $X \in\left\{G, I_{G}, T\right\}, Z \in\left\{\tau^{c}, \tau^{l}, \tau^{k}\right\}$ e $\hat{\varepsilon}_{t}^{X}$ e $\hat{\varepsilon}_{t}^{Z}$ são choques fiscais. Essas regras fiscais são consistentes com o fato de que a condução da política fiscal visa a influenciar a atividade econômica e a manter uma trajetória sustentável da dívida pública. Os parâmetros $\phi_{Y, X}$ e $\phi_{Y, Z}$ medem o quão forte é a reação dos gastos e tributos ao produto, respectivamente. Leeper et al. (2010) postulam que esses parâmetros são positivos de forma a obrigar os instrumentos a ajudarem na estabilização do produto, porém neste trabalho postula-se que eles podem assumir quaisquer valores (positivos, nulo e negativos), porque, como é explicado com mais detalhes na seção de estimação, isso permite ao modelo incorporar a possibilidade de a política fiscal de gastos e tributos ser anticíclica $\left(\phi_{Y, X}>0\right.$ e $\phi_{Y, Z}>$ $0)$, acíclica $\left(\phi_{Y, X}=0\right.$ e $\left.\phi_{Y, Z}=0\right)$ ou pró-cíclica $\left(\phi_{Y, X}<0\right.$ e $\left.\phi_{Y, Z}<0\right)$. Já os parâmetros $\phi_{b, X}$ e $\phi_{b, Z}$ são positivos e medem quanto os gastos e tributos ajudam na estabilização da dívida pública. ${ }^{14}$

A acumulação do estoque de capital público, que é disponibilizado a todas as firmas intermediárias como um insumo cujo uso aumenta a produtividade e não gera custos para elas, é dada por:

$$
K_{G, t}=\left(1-\delta_{G}\right) K_{G, t-1}+I_{G, t}
$$

onde $0<\delta_{G}<1$ é a taxa de depreciação do estoque de capital público.

\section{Agregação e Equilíbrio}

\footnotetext{
${ }^{14}$ O Brasil adota um sistema de metas de superávit primário com o objetivo de balizar a evolução da dívida pública, ancorando as expectativas dos agentes. Embora não incorpore uma regra fiscal de superávit primário, o modelo tem regras fiscais que fazem cada instrumento reagir à dívida pública de forma a auxiliar na sua estabilização, aproximando-o do sistema de metas no que se refere a seu objetivo.
} 
A restrição orçamentária do governo requer que o total de receitas advindas da tributação do consumo, da renda do trabalho e da renda do capital privado mais a dívida pública emitida seja igual ao total de despesas com pagamento de juros, consumo público, investimento público e transferências ${ }^{15}$ :

$$
\tau_{t}^{c} C_{t}+\tau_{t}^{l} w_{t} L_{t}+\tau_{t}^{k} r_{k, t} u_{t} K_{t-1}+b_{t}=\frac{R_{t-1} b_{t-1}}{\Pi_{t}}+G_{t}+I_{G, t}+T_{t}
$$

onde $C_{t} \equiv(1-v) C_{r, t}+v C_{n r, t}$ é o consumo agregado, $K_{t-1} \equiv(1-v) K_{r, t-1}$ é a oferta agregada de capital privado e $b_{t}$ é a oferta agregada de títulos públicos.

O mercado de capital privado está em equilíbrio quando a demanda total por capital das firmas intermediárias é igual à oferta total de capital das famílias ricardianas:

$$
\int_{0}^{1} K_{j, t} d j=(1-v) K_{r, t}
$$

O mercado de trabalho está em equilíbrio se a demanda total por trabalho das firmas intermediárias é igual à oferta total de trabalho das famílias ricardianas e não ricardianas:

$$
\int_{0}^{1} N_{j, t} d j=(1-v) L_{r, t}+v L_{n r, t}
$$

Já o mercado de dívida pública está em equilíbrio se a oferta total de dívida pública do governo é igual à demanda total por dívida pública das famílias ricardianas:

$$
b_{t}=(1-v) b_{r, t}
$$

Por fim, o mercado do bem final está em equilíbrio quando a oferta total do bem final menos o custo associado a variações do grau de utilização do estoque de capital privado agregado é igual à soma do consumo agregado, consumo público, investimento privado agregado $\left(I_{t} \equiv(1-v) I_{r, t}\right)$ e investimento público:

$$
Y_{t}-a\left(u_{t}\right) K_{t-1}=C_{t}+G_{t}+I_{t}+I_{G, t}
$$

\footnotetext{
${ }^{15}$ Por simplicidade, as transferências totais do governo são distribuídas igualmente entre todos os tipos de famílias. Essa hipótese é adequada no contexto do presente trabalho, que busca analisar o impacto de diferentes instrumentos fiscais, dentre os quais as transferências, que afetam fortemente as decisões das famílias não ricardianas e fracamente as escolhas das famílias ricardianas. Porém, é implausível em outros contextos, como num trabalho sobre o sistema previdenciário baseado num modelo de gerações sobrepostas.
} 


\section{Equações Log-linearizadas}

A seguir, apresentam-se as equações log-linearizadas em torno do estado estacionário em que a taxa de inflação bruta é igual a um $(\Pi=1)$, a utilização do estoque de capital privado é plena $(u=1)$ e o consumo das famílias ricardianas e não ricardianas é o mesmo $\left(C=C_{r}=C_{n r}\right) \cdot{ }^{16,17}$

A equação do consumo das famílias não ricardianas é dada por:

$$
\left(1+\tau^{c}\right) \frac{C}{Y}\left(\hat{C}_{n r, t}+\frac{\tau^{c}}{1+\tau^{c}} \hat{\tau}_{t}^{c}\right)=\frac{w L}{Y}\left[\left(1-\tau^{l}\right)\left(\widehat{w}_{t}+\hat{L}_{t}\right)-\tau^{l} \hat{\tau}_{t}^{l}\right]+\frac{T}{Y} \widehat{T}_{t}
$$

O consumo das famílias não ricardianas é uma função da renda do salário e das transferências, deduzidos os tributos do trabalho e do consumo. Como esse tipo de família consome toda a renda corrente em cada período, um aumento da renda do salário ou um aumento das transferências têm impacto positivo direto sobre o consumo, enquanto uma elevação do tributo do consumo ou do tributo do trabalho levam a uma diminuição do consumo. Isso ocorre porque elas não conseguem suavizar seu consumo ao longo do tempo e não levam em conta a expectativa de tributação futura.

A equação do consumo das famílias ricardianas é dada por:

$$
\hat{C}_{r, t}=\frac{E_{t} \hat{C}_{r, t+1}}{1+h}+\frac{h \hat{C}_{r, t-1}}{1+h}-\frac{1}{\sigma_{C}} \frac{1-h}{1+h}\left[\hat{R}_{t}-E_{t} \widehat{\Pi}_{t+1}+\frac{\tau^{c}}{1+\tau^{c}}\left(\hat{\tau}_{t}^{c}-E_{t} \hat{\tau}_{t+1}^{c}\right)\right]+\hat{\varepsilon}_{t}^{b}
$$

Com a hipótese de formação de hábito externo, o consumo presente das famílias ricardianas depende de uma média ponderada do consumo futuro e passado, sendo que quanto maior o grau de persistência de hábito $(h)$, tanto maior é o peso do consumo passado. A elasticidade do consumo em relação à taxa de juros real é maior quando o inverso da elasticidade de substituição do consumo $\left(\sigma_{C}\right)$ é maior ou o grau de persistência de hábito é maior. Um tributo do consumo mais elevado no presente leva a uma diminuição do consumo presente, porém o efeito é o contrário quando da elevação do tributo do consumo futuro.

\footnotetext{
${ }^{16}$ Como o modelo do trabalho é em essência o de Smets e Wouters (2003) com a inclusão de famílias não ricardianas e uma autoridade fiscal que segue regras fiscais ad hoc para diferentes instrumentos de gastos e tributos, a derivação e as equações log-linearizadas resultantes são bastante parecidas com as de Smets e Wouters (2003).

17 Seguindo Smets e Wouters (2003), Chen (2007), Smets e Wouters (2007) e Justiniano et al. (2008), os choques de preferência, custo de investimento privado, markup de salários e markup de preços são normalizados. Justiniano et al. (2008) em seu apêndice ressaltam que esse procedimento serve para facilitar a escolha das distribuições a priori para os desvios-padrão dos choques e para melhorar as propriedades de convergência na estimação bayesiana.
} 
A equação do investimento privado é dada por:

$$
\hat{I}_{t}=\frac{\hat{Q}_{t}}{\varphi(1+\beta)}+\frac{\hat{I}_{t-1}}{1+\beta}+\frac{\beta E_{t} \hat{I}_{t+1}}{1+\beta}+\hat{\varepsilon}_{t}^{I}
$$

onde $\varphi$ é definido como o valor que $S^{\prime \prime}($.) assume no estado estacionário, ou seja, $\varphi \equiv$ $\left.S^{\prime \prime}\right|_{s s}$. O investimento privado presente depende do valor presente do estoque de capital privado instalado e de uma média ponderada do investimento passado e do investimento esperado. Quanto maior o desconto intertemporal $(\beta)$, tanto maior é o efeito do investimento esperado. Enfatiza-se a normalização do choque de custo de investimento privado de modo a poder interpretá-lo quando positivo como um choque que aumenta a produtividade do investimento privado ao diminuir seu custo.

A equação do preço-sombra do investimento ( $Q$ de Tobin) é dada por:

$$
\hat{Q}_{t}=-\left(\hat{R}_{t}+E_{t} \widehat{\Pi}_{t+1}\right)+\frac{(1-\delta) E_{t} \hat{Q}_{t+1}}{1-\delta+\left(1-\tau^{k}\right) r_{k}}+\frac{\left(1-\tau^{k}\right) r_{k}}{1-\delta+\left(1-\tau^{k}\right) r_{k}}\left(E_{t} \hat{r}_{k, t+1}-\frac{\tau^{k}}{1-\tau^{k}} E_{t} \hat{\tau}_{t+1}^{k}\right)
$$

O valor presente do estoque de capital privado depende negativamente da taxa de juros real e da expectativa da tributação do capital, enquanto depende positivamente do seu valor futuro e da expectativa da taxa de retorno do capital.

A equação da utilização do capital privado é dada por:

$$
\hat{u}_{t}=\frac{1}{\kappa}\left(\hat{r}_{k, t}-\frac{\tau^{k}}{1-\tau^{k}} \hat{\tau}_{t}^{k}\right)
$$

onde $\kappa \equiv a^{\prime \prime}(1) / a^{\prime}(1)$ é a elasticidade do custo de ajustamento da utilização do capital privado. A taxa de utilização do capital privado é uma função positiva da taxa de retorno do capital e negativa da tributação do capital.

A equação da acumulação de capital privado é dada por:

$$
\widehat{K}_{t}=(1-\delta) \widehat{K}_{t-1}+\delta \hat{I}_{t}
$$

A equação da curva de Phillips para salários é dada por:

$$
\begin{gathered}
\widehat{w}_{t}=\frac{\beta E_{t} \widehat{w}_{t+1}}{1+\beta}+\frac{\widehat{w}_{t-1}}{1+\beta}+\frac{\beta E_{t} \widehat{\Pi}_{t+1}}{1+\beta}-\frac{\left(1+\beta \gamma_{w}\right) \widehat{\Pi}_{t}}{1+\beta}+\frac{\gamma_{w} \widehat{\Pi}_{t-1}}{1+\beta}-\frac{1}{1+\beta} \frac{\left(1-\beta \varpi_{w}\right)\left(1-\varpi_{w}\right)}{\left(1+\left(\frac{1+\varepsilon^{w}}{\varepsilon^{w}}\right) \sigma_{L}\right) \varpi_{w}}\left[\widehat{w}_{t}-\right. \\
\left.\sigma_{L} \hat{L}_{t}-\frac{\sigma_{C}}{1-h}\left(\hat{C}_{r, t}-\hat{C}_{r, t-1}\right)-\frac{\tau^{c}}{1+\tau^{c}} \hat{\tau}_{t}^{c}-\frac{\tau^{l}}{1-\tau^{l}} \hat{\tau}_{t}^{l}\right]+\hat{\varepsilon}_{t}^{w}
\end{gathered}
$$

O salário real é uma função do salário esperado e do salário passado ponderados pelo fator de desconto, bem como da inflação esperada, da inflação presente e da inflação passada ponderadas pelo grau de indexação dos salários $\left(\gamma_{w}\right)$. Quando não existe 
indexação, a inflação passada deixa de ser relevante. Se o grau de rigidez dos salários $\left(\varpi_{w}\right)$ é menor ou a elasticidade de substituição de trabalhos diferenciados no estado estacionário $\left(\left(1+\varepsilon^{w}\right) / \varepsilon^{w}\right)$ é menor ou o inverso da elasticidade da oferta de trabalho $\left(\sigma_{L}\right)$ é menor, então é maior o efeito negativo do desvio do salário real em relação ao salário real que prevaleceria numa situação sem rigidez no mercado de trabalho.

A equação de produção é dada por:

$$
\hat{Y}_{t}=\varphi_{Y}\left[\hat{\varepsilon}_{t}^{A}+\alpha \widehat{K}_{t-1}+\alpha \hat{u}_{t}+(1-\alpha) \hat{L}_{t}+\alpha_{G} \widehat{K}_{G, t-1}\right]
$$

onde $\varphi_{Y} \equiv 1+\Phi / Y$, ou seja, é um mais a fração do custo fixo em relação ao produto no estado estacionário.

A equação da demanda por trabalho é dada por:

$$
\widehat{L}_{t}=\hat{u}_{t}+\hat{r}_{k, t}+\widehat{K}_{t-1}-\widehat{w}_{t}
$$

A equação da curva de Phillips para preços é dada por:

$$
\widehat{\Pi}_{t}=\frac{\beta E_{t} \widehat{\Pi}_{t+1}}{1+\beta \gamma_{p}}+\frac{\gamma_{p} \widehat{\Pi}_{t-1}}{1+\beta \gamma_{p}}+\frac{\left(1-\beta \varpi_{p}\right)\left(1-\varpi_{p}\right)}{\left(1+\beta \gamma_{p}\right) \varpi_{p}} \widehat{m c}_{t}+\hat{\varepsilon}_{t}^{p}
$$

A inflação presente depende da inflação esperada e da inflação passada, ponderadas pelo grau de indexação dos preços $\left(\gamma_{p}\right)$, e também do custo marginal. Quanto mais indexada é a economia, tanto maior é a influência do componente backward-looking. Se não há nenhuma indexação, a curva de Phillips se torna puramente forward-looking. A elasticidade da inflação presente com relação a mudanças no custo marginal depende sobretudo do grau de rigidez dos preços $\left(\varpi_{p}\right)$ e é tanto maior quanto menor a rigidez.

A equação do custo marginal é dada por:

$$
\widehat{m c}_{t}=\alpha \hat{r}_{k, t}+(1-\alpha) \widehat{w}_{t}-\hat{\varepsilon}_{t}^{A}-\alpha_{G} \widehat{K}_{G, t-1}
$$

O custo marginal eleva-se quando a taxa de retorno do capital ou o salário real aumentam, porém cai quando ocorre um choque de tecnologia positivo ou aumenta 0 estoque de capital público. A introdução de capital público como um insumo disponível sem custos para as firmas intermediárias abre a possibilidade de o governo gerar 0 mesmo efeito qualitativo que o choque de tecnologia.

A equação da inflação dos consumidores é dada por:

$$
\widehat{\Pi}_{t}^{c}=\widehat{\Pi}_{t}+\frac{\tau^{c}}{1+\tau^{c}}\left(\hat{\tau}_{t}^{c}-\hat{\tau}_{t-1}^{c}\right)
$$


onde $\widehat{\Pi}_{t}^{c}$ é a inflação dos preços com que os consumidores se deparam, que consiste da inflação dos preços com que os produtores se defrontam $\left(\widehat{\Pi}_{t}\right)$ mais a diferença da tributação do consumo presente e passado.

As equações da regra monetária e das regras fiscais de gastos e tributos são dadas respectivamente por (31), (32) e (33), escritas novamente abaixo:

$$
\begin{gathered}
\hat{R}_{t}=\rho \hat{R}_{t-1}+(1-\rho)\left(\rho_{\Pi} \widehat{\Pi}_{t}+\rho_{Y} \hat{Y}_{t}\right)+\eta_{t}^{m} \\
\hat{X}_{t}=-\phi_{b, X} \hat{b}_{t-1}-\phi_{Y, X} \hat{Y}_{t}+\hat{\varepsilon}_{t}^{X} \\
\hat{Z}_{t}=\phi_{b, Z} \hat{b}_{t-1}+\phi_{Y, Z} \hat{Y}_{t}+\hat{\varepsilon}_{t}^{Z}
\end{gathered}
$$

para $X \in\left\{G, I_{G}, T\right\}$ e $Z \in\left\{\tau^{c}, \tau^{l}, \tau^{k}\right\}$.

A equação da acumulação de capital público é dada por:

$$
\widehat{K}_{G, t}=\left(1-\delta_{G}\right) \widehat{K}_{G, t-1}+\delta_{G} \hat{I}_{G, t}
$$

A equação da restrição orçamentária do governo é dada por:

$$
\begin{gathered}
\frac{\tau^{c} C}{Y}\left(\hat{\tau}_{t}^{c}+\hat{C}_{t}\right)+\frac{\tau^{l} w L}{Y}\left(\hat{\tau}_{t}^{l}+\widehat{w}_{t}+\hat{L}_{t}\right)+\frac{\tau^{k} r_{k} K}{Y}\left(\hat{\tau}_{t}^{k}+\hat{r}_{k, t}+\hat{u}_{t}+\widehat{K}_{t-1}\right)= \\
\frac{1}{\beta} \frac{b}{Y}\left(\hat{R}_{t-1}-\widehat{\Pi}_{t}+\hat{b}_{t-1}\right)-\frac{b}{Y} \hat{b}_{t}+\frac{G}{Y} \widehat{G}_{t}+\frac{I_{G}}{Y} \hat{I}_{G, t}+\frac{T}{Y} \widehat{T}_{t}
\end{gathered}
$$

A equação do consumo total é dada por:

$$
\hat{C}_{t}=(1-v) \hat{C}_{r, t}+v \hat{C}_{n r, t}
$$

A equação do equilíbrio no mercado do bem final é dada por:

$$
\hat{Y}_{t}=\frac{C}{Y} \hat{C}_{t}+\frac{I}{Y} \hat{I}_{t}+\frac{G}{Y} \hat{G}_{t}+\frac{I_{G}}{Y} \hat{I}_{G}+\left(1-\tau^{k}\right) \frac{r_{k} K}{Y} \hat{u}_{t}
$$

Por fim, os choques de preferência $\left(\hat{\varepsilon}_{t}^{b}\right)$, investimento privado $\left(\hat{\varepsilon}_{t}^{I}\right)$, markup de salários $\left(\hat{\varepsilon}_{t}^{w}\right)$, tecnologia $\left(\hat{\varepsilon}_{t}^{A}\right)$, markup de preços $\left(\hat{\varepsilon}_{t}^{p}\right)$ e instrumentos fiscais $\left(\hat{\varepsilon}_{t}^{G}, \hat{\varepsilon}_{t}^{I G}, \hat{\varepsilon}_{t}^{T}, \hat{\varepsilon}_{t}^{\tau^{c}}, \hat{\varepsilon}_{t}^{\tau^{l}}, \hat{\varepsilon}_{t}^{\tau^{k}}\right)$ seguem um processo autorregressivo de primeira ordem:

$$
\hat{\varepsilon}_{t}^{o}=\rho_{o} \hat{\varepsilon}_{t-1}^{o}+\eta_{t}^{o}
$$

onde $0<\rho_{o}<1$ mede a persistência do choque e $\eta_{t}^{o} \sim N\left(0, \sigma_{o}^{2}\right)$ é um termo de erro independente e identicamente distribuído para $o \in\left\{b, I, w, A, p, G, I_{G}, T, \tau^{c}, \tau^{l}, \tau^{k}\right\}$. E o choque monetário $\eta_{t}^{m} \sim N\left(0, \sigma_{m}^{2}\right)$ é diretamente um termo de erro independente e identicamente distribuído. 


\section{Estimação}

A estimação do modelo é feita com métodos bayesianos, que permitem ao pesquisador atribuir distribuições a priori para os parâmetros com base em informações que, em geral, advêm de pesquisas anteriores e restrições teóricas e utilizar os dados em conjunto com o modelo para atualizar sua crença, obtendo as distribuições a posteriori dos parâmetros.

De acordo com Griffoli (2013), existem vantagens na escolha pela estimação bayesiana de modelos DSGE, algumas das quais são descritas brevemente. Primeiro, a estimação bayesiana faz uso de toda a estrutura do modelo DSGE representado por suas equações, o que se contrasta, por exemplo, com o método dos momentos generalizados, que utiliza apenas algumas equações. Segundo, ao levar em consideração as distribuições a priori como pesos para distintas regiões do espaço paramétrico, ela evita estimações com valores absurdos. Terceiro, a inclusão das distribuições a priori ajuda na identificação dos parâmetros ao dar mais curvatura à distribuição a posteriori usada no processo de maximização numérico, ou seja, tende a contornar o problema de valores distintos para um mesmo parâmetro levarem à mesma distribuição para as variáveis observáveis. Quarto, permite lidar explicitamente com problemas de especificação do modelo ao incorporar choques nas equações estruturais, que podem ser entendidos como erros de observação.

\subsection{Dados}

$\mathrm{Na}$ estimação são usadas séries sobre consumo privado, investimento privado, consumo público, investimento público, transferências, taxa de juros nominal, taxa de inflação e alíquotas tributárias sobre o consumo, sobre a renda do trabalho e sobre a renda do capital. ${ }^{18} \mathrm{~A}$ frequência é trimestral e o período abrange 1999T3-2013T4..$^{19}$

As séries de consumo privado e consumo público são obtidas diretamente das Contas Nacionais Trimestrais do Instituto Brasileiro de Geografia e Estatística (CNT-

\footnotetext{
${ }^{18}$ A estimação bayesiana exige que o número de choques estruturais seja igual ou maior que o número de variáveis observáveis para evitar o problema de stochastic singularity. Como existem 12 choques estruturais e 10 variáveis observáveis, essa condição é satisfeita.

19 Seguem-se Castro et al. (2011) na escolha do início do período amostral em 1999T3. Restringem-se as séries até 2013T4 porque, como ficará mais claro a seguir, o trabalho usa duas bases de dados diferentes para as alíquotas tributárias como exercício de robustez, sendo uma delas mais restrita e indo até 2013 T4.
} 
IBGE). A série de investimento público é produzida por Orair $(2016)^{20}$, que, quando subtraída da série de formação bruta de capital fixo das CNT-IBGE, dá origem à série de investimento privado. A série de transferências é composta pelos dados de benefícios previdenciários, abono, seguro-desemprego e benefícios assistências da Lei Orgânica de Assistência Social (LOAS) e Renda Mensal Vitalícia (RMV), fornecidos pela Secretaria do Tesouro Nacional (STN). ${ }^{21}$ A série de taxa de juros nominal é a taxa Selic (média geométrica), calculada pelo Banco Central do Brasil (BCB). A taxa de inflação (dos consumidores) é a taxa de inflação calculada com o Índice Nacional de Preços ao Consumidor Amplo (IPCA), obtida do IBGE.

Como exercício de robustez, o trabalho faz uso de duas bases de alíquotas tributárias efetivas distintas: uma de Azevedo e Fasolo (2015) e outra de Almeida et al. (2017). ${ }^{22}$ Designam-se a base de dados formada pelas séries citadas no parágrafo anterior mais as alíquotas de Azevedo e Fasolo (2015) por "base de dados A", enquanto a outra base formada pelas mesmas séries mencionadas no parágrafo anterior mais as alíquotas de Almeida et al. (2017) por "base de dados B".

Todas as séries com exceção da taxa de juros, taxa de inflação e alíquotas são deflacionadas pelo IPCA e todas as séries com exceção da taxa de juros nominal são dessazonalizadas. Para estacionarizar as séries de produto, consumo privado, investimento privado, consumo público, investimento público e transferências, aplica-se a primeira diferença do logaritmo natural e, em seguida, subtrai-se a respectiva média. As séries de taxa de juros nominal, taxa de inflação e alíquotas têm suas respectivas médias subtraídas, com exceção da série de alíquota tributária sobre a renda do trabalho de Azevedo e Fazolo (2015), que tem sua tendência linear subtraída para ser estacionarizada.

\footnotetext{
${ }^{20}$ Através de técnicas de desagregação temporal e previsão contemporânea, Orair (2016) constrói a série de investimento público correspondente à formação bruta de capital fixo do governo geral e empresas públicas federais, que é harmonizada ao conceito usado no sistema de contas nacionais.

${ }^{21}$ Não se incluem os dados do programa Bolsa Família na série de transferências porque a hipótese de que no modelo as transferências totais são distribuídas igualmente entre todas as famílias não condiz com a característica de o programa ser voltado para um segmento específico, qual seja, famílias em situação de pobreza e extrema pobreza.

22 Para mais detalhes sobre as alíquotas efetivas estimadas por Azevedo e Fasolo (2015) e por Almeida et al. (2017), ver Apêndices 1 e 2, respectivamente. As principais diferenças são a classificação de alguns impostos no cômputo das bases tributárias e o método de desagregação temporal para transformar séries de baixa em alta frequência.
} 


\subsection{Parâmetros Calibrados}

Os parâmetros calibrados estão na Tabela 2 e referem-se às alíquotas e razões no estado estacionário, além de parâmetros difíceis de estimar ou não identificados. Destaca-se que nenhum dos parâmetros das regras fiscais é calibrado, uma vez que são o foco da estimação do presente trabalho. A escolha dos valores se ampara na média amostral ou em alguma pesquisa específica.

Tabela 2 - Parâmetros Calibrados

\begin{tabular}{|c|c|c|c|c|}
\hline \multicolumn{2}{|r|}{ Descrição } & \multicolumn{2}{|c|}{ Valor } & Referência \\
\hline & & Dados A & Dados B & \\
\hline \multicolumn{5}{|c|}{ Fração em relação ao Produto no Estado Estacionário } \\
\hline$C / Y$ & Cons. Priv. & 0,61 & 0,61 & Resíduo \\
\hline$I / Y$ & Inv. Priv. & 0,17 & 0,17 & Resíduo \\
\hline$G / Y$ & Cons. Púb. & 0,19 & 0,19 & Média amostral \\
\hline$I_{G} / Y$ & Inv. Púb. & 0,03 & 0,03 & Média amostral \\
\hline$T / Y$ & Transf. & 0,12 & 0,15 & Resíduo \\
\hline$b / Y$ & Dív. Púb. & 2,48 & 2,48 & Média amostral \\
\hline \multicolumn{5}{|c|}{ Alíquotas no Estado Estacionário } \\
\hline$\tau^{c}$ & Trib. Cons. & 0,26 & 0,23 & Média amostral \\
\hline$\tau^{l}$ & Trib. Trab. & 0,23 & 0,28 & Média amostral \\
\hline$\tau^{k}$ & Trib. Cap. & 0,16 & 0,20 & Média amostral \\
\hline \multicolumn{5}{|c|}{ Parâmetros Estruturais Calibrados } \\
\hline$\beta$ & Fator Desconto & & & Castro et al. (2011) \\
\hline$\alpha$ & Elast. Prod.-Cap. Priv. & & & Cavalcanti e Vereda (2011) \\
\hline$\delta$ & Tx. Deprec. Cap. Priv. & & & Cavalcanti e Vereda (2011) \\
\hline$\delta_{G}$ & Tx. Deprec. Cap. Púb. & & & Moura (2015) \\
\hline$\alpha_{G}$ & Elast. Prod.-Cap. Púb. & & & Moura (2015) \\
\hline$\varepsilon^{w}$ & Tx. Markup Salários & & & Castro et al. (2011) \\
\hline$\sigma_{L}$ & Inverso Elast. Oferta. Trab. & & & Castro et al. (2011) \\
\hline$\sigma_{c}$ & Inverso Elast. Subst. Cons. & & & Castro et al. (2011) \\
\hline$\kappa$ & Elast. Custo Ajust. Utiliz. Cap. & & & Smets e Wouters (2007) \\
\hline$\varphi_{Y}$ & Razão Custo Fixo-Prod. & & & Smets e Wouters (2007) \\
\hline
\end{tabular}

Fonte: Elaboração própria. Nota: Seguindo Moura (2015), supõe-se que a taxa de depreciação do estoque de capital público é igual à do capital privado. A média amostral da razão dívida pública-produto é obtida com a série de dívida bruta do governo geral do BCB.

Os valores no estado estacionário das razões consumo público-produto $(G / Y)$ e investimento público-produto $\left(I_{G} / Y\right)$ são fixados, respectivamente, nas médias amostrais 
de 0,19 e 0,03 . Para as alíquotas sobre o consumo $\left(\tau^{c}\right)$, a renda do trabalho $\left(\tau^{l}\right)$ e a renda do capital $\left(\tau^{k}\right)$ no estado estacionário, com base na média amostral, são atribuídos, respectivamente, os valores de $0,26,0,23$ e 0,16 no caso da base de dados $A$ e os valores $0,23,0,28$ e 0,20 no caso da base de dados $B$. Usa-se a série de dívida bruta do governo geral do BCB para obter o valor da média amostral de 2,48, que serve para calibrar a razão no estado estacionário dívida pública-produto $(b / Y)$. Os demais valores calibrados são calculados como resíduo e se assemelham às médias amostrais. ${ }^{23}$

Baseado em Castro et al. (2011), o fator de desconto $(\beta)$ é calibrado em 0,989, a taxa de markup de salários líquida $\left(\varepsilon^{w}\right)$ em 0,5 , o inverso da elasticidade da oferta de trabalho $\left(\sigma_{L}\right)$ em 1 e o inverso da elasticidade de substituição intertemporal do consumo $\left(\sigma_{c}\right)$ em 1,3. Segue-se a literatura relatada em Cavalcanti e Vereda (2011) para calibrar a elasticidade do produto em relação ao estoque de capital privado $(\alpha)$, correspondente à fração da renda do capital na renda total no estado estacionário, em 0,3 e a taxa de depreciação do estoque de capital privado $(\delta)$ em 0,025 , porque assim algumas razões de estado estacionário ficam mais próximas das médias amostrais. Já a taxa de depreciação do estoque de capital público $\left(\delta_{G}\right)$ é calibrada no mesmo valor da taxa de depreciação do estoque de capital privado, ou seja, em 0,025, que é o procedimento de calibração usado por Moura (2015) para esse mesmo parâmetro devido à falta de referência na literatura. ${ }^{24} \mathrm{~A}$ elasticidade do produto em relação ao estoque de capital público $\left(\alpha_{G}\right)$ é calibrada no valor de 0,02 baseado em Moura (2015). ${ }^{25}$

Não se encontra na literatura nacional referência para a elasticidade do custo de ajustamento da utilização do capital $(\kappa)$ nem para a razão custo fixo-produto mais um $\left(\varphi_{Y}\right)$. Por isso, esses parâmetros são calibrados, respectivamente, em 0,54 e 1,6 conforme estimativas de Smets e Wouters (2007).

23 Dadas as relações $R=\frac{1}{\beta}, r_{k}=\frac{1}{1-\tau^{k}}(R-(1-\delta)), \frac{r_{k} K}{Y}=\alpha$ e $\frac{w L}{Y}=1-\alpha$, calculam-se por resíduo $\frac{I}{Y}=$ $\delta \frac{r_{k} K}{Y} \frac{1}{r_{k}}, \frac{C}{Y}=1-\frac{I}{Y}-\frac{G}{Y}-\frac{I_{G}}{Y} \mathrm{e} \frac{T}{Y}=\tau^{c} \frac{C}{Y}+\tau^{l} \frac{w L}{Y}+\tau^{k} \frac{r_{k} K}{Y}-\frac{G}{Y}-\frac{I_{G}}{Y}+(1-R) \frac{b}{Y}$.

24 Usar as calibrações de Castro et al. (2011) para os últimos parâmetros, ou seja, $\alpha=0,448$ e $\delta=\delta_{G}=$ 0,015 , não muda praticamente os resultados das estimações.

${ }^{25}$ Moura (2015) enfatiza que não existe consenso na literatura para o valor da $\alpha_{G}$ e usa em seu modelo DSGE o valor "conservador" de 0,02 para mostrar a importância do investimento público mesmo num cenário com $\alpha_{G}$ pequeno. Tal como ele, faz-se uma análise de sensibilidade para esse parâmetro. 


\subsection{Distribuições a Priori}

A Tabela 3 mostra os parâmetros a serem estimados e as respectivas distribuições a priori com a média e o desvio-padrão. As escolhas são feitas respeitando os valores teóricos que tais parâmetros podem assumir e amparando-se em outras pesquisas, de preferência Castro et al. (2011).

Tabela 3 - Distribuições a Priori e a Posteriori

\begin{tabular}{|c|c|c|c|c|c|c|c|c|c|c|}
\hline \multirow{2}{*}{\multicolumn{2}{|c|}{ Parâmetro }} & \multicolumn{3}{|c|}{ Prior } & \multicolumn{3}{|c|}{ Posterior (Estimação A) } & \multicolumn{3}{|c|}{ Posterior (Estimação B) } \\
\hline & & Dist. & Méd. & Dp. & Méd. & Inter & Cred. & Méd. & Inter & Sred. \\
\hline \multicolumn{11}{|c|}{ Rigidez Nominal e Real } \\
\hline$\varphi$ & $\begin{array}{l}\text { Custo Ajust. Inv. } \\
\text { Priv. }\end{array}$ & $\mathrm{N}$ & 4 & 1,5 & 6,48 & 3,84 & 9,04 & 6,73 & 4,04 & 9,33 \\
\hline$\gamma_{p}$ & Index. Preços & B & 0,65 & 0,2 & 0,37 & 0,08 & 0,64 & 0,39 & 0,10 & 0,68 \\
\hline$\gamma_{w}$ & Index. Salários & B & 0,65 & 0,15 & 0,61 & 0,36 & 0,86 & 0,62 & 0,38 & 0,88 \\
\hline$\varpi_{p}$ & Calvo Preços & B & 0,65 & 0,1 & 0,66 & 0,50 & 0,81 & 0,68 & 0,52 & 0,84 \\
\hline$\varpi_{w}$ & Calvo Salários & B & 0,75 & 0,1 & 0,78 & 0,67 & 0,90 & 0,80 & 0,69 & 0,91 \\
\hline$v$ & $\begin{array}{l}\text { Fração não } \\
\text { Ricard. }\end{array}$ & B & 0,4 & 0,15 & 0,27 & 0,09 & 0,45 & 0,22 & 0,07 & 0,38 \\
\hline$h$ & Persist. Hábito & B & 0,85 & 0,05 & 0,86 & 0,81 & 0,92 & 0,86 & 0,81 & 0,92 \\
\hline \multicolumn{11}{|c|}{ Regra Monetária } \\
\hline$\rho$ & $\begin{array}{l}\text { Suaviz. Tx. } \\
\text { Juros Nom. }\end{array}$ & B & 0,6 & 0,15 & 0,89 & 0,86 & 0,92 & 0,90 & 0,86 & 0,92 \\
\hline$\rho_{\Pi}$ & Resp. Inflação & $\mathrm{N}$ & 2 & 0,35 & 2,23 & 1,75 & 2,75 & 2,27 & 1,79 & 2,75 \\
\hline$\rho_{Y}$ & Resp. Prod. & $\mathrm{G}$ & 0,25 & 0,1 & 0,11 & 0,04 & 0,16 & 0,10 & 0,04 & 0,15 \\
\hline \multicolumn{11}{|c|}{ Resposta ao Produto dos Instrumentos Fiscais } \\
\hline$\phi_{Y, G}$ & Cons. Púb. & $\mathrm{N}$ & 0 & 1 & $-0,26$ & $-0,68$ & 0,15 & $-0,25$ & $-0,67$ & 0,17 \\
\hline$\phi_{Y, I_{G}}$ & Inv. Púb. & $\mathrm{N}$ & 0 & 1 & $-0,54$ & $-1,44$ & 0,36 & $-0,59$ & $-1,53$ & 0,32 \\
\hline$\phi_{Y, T}$ & Transf. & $\mathrm{N}$ & 0 & 1 & 0,15 & $-0,19$ & 0,49 & 0,15 & $-0,21$ & 0,51 \\
\hline$\phi_{Y, \tau^{c}}$ & Trib. Cons. & $\mathrm{N}$ & 0 & 1 & $-0,13$ & $-0,25$ & $-0,01$ & $-0,12$ & $-0,21$ & $-0,03$ \\
\hline$\phi_{Y, \tau^{l}}$ & Trib. Trab. & $\mathrm{N}$ & 0 & 1 & $-0,06$ & $-0,11$ & $-0,03$ & 0,03 & $-0,04$ & 0,11 \\
\hline$\phi_{Y, \tau^{k}}$ & Trib. Cap. & $\mathrm{N}$ & 0 & 1 & $-0,17$ & $-0,25$ & $-0,10$ & $-0,20$ & $-0,28$ & $-0,11$ \\
\hline \multicolumn{11}{|c|}{ Resposta à Dívida Pública dos Instrumentos Fiscais } \\
\hline$\phi_{b, G}$ & Cons. Púb. & $\mathrm{G}$ & 0,4 & 0,2 & 0,25 & 0,06 & 0,44 & 0,21 & 0,04 & 0,37 \\
\hline$\phi_{b, I_{G}}$ & Inv. Púb. & G & 0,4 & 0,2 & 0,32 & 0,08 & 0,55 & 0,29 & 0,07 & 0,50 \\
\hline$\phi_{b, T}$ & Transf. & G & 0,4 & 0,2 & 0,20 & 0,05 & 0,34 & 0,19 & 0,04 & 0,33 \\
\hline$\phi_{b, \tau^{c}}$ & Trib. Cons. & G & 0,4 & 0,2 & 0,20 & 0,09 & 0,30 & 0,13 & 0,06 & 0,20 \\
\hline$\phi_{b, \tau^{l}}$ & Trib. Trab. & G & 0,4 & 0,2 & 0,07 & 0,04 & 0,11 & 0,10 & 0,05 & 0,15 \\
\hline$\phi_{b, \tau^{k}}$ & Trib. Cap. & $\mathrm{G}$ & 0,4 & 0,2 & 0,09 & 0,03 & 0,15 & 0,16 & 0,11 & 0,22 \\
\hline \multicolumn{11}{|c|}{ Persistência dos Choques } \\
\hline$\rho_{A}$ & Tecn. & $B$ & 0,5 & 0,25 & 0,48 & 0,07 & 0,88 & 0,50 & 0,09 & 0,91 \\
\hline$\rho_{b}$ & Pref. & B & 0,5 & 0,25 & 0,14 & 0 & 0,28 & 0,14 & 0 & 0,26 \\
\hline$\rho_{I}$ & Inv. Priv. & B & 0,5 & 0,25 & 0,32 & 0,08 & 0,55 & 0,30 & 0,07 & 0,52 \\
\hline
\end{tabular}




\begin{tabular}{|cc|ccc|ccc|ccc|}
$\rho_{w}$ & Markup Salários & B & 0,5 & 0,25 & 0,32 & 0,03 & 0,57 & 0,31 & 0,03 & 0,56 \\
$\rho_{p}$ & Markup Preços & B & 0,5 & 0,25 & 0,30 & 0,01 & 0,56 & 0,26 & 0,01 & 0,50 \\
$\rho_{G}$ & Cons. Púb. & B & 0,5 & 0,25 & 0,80 & 0,65 & 0,95 & 0,83 & 0,69 & 0,97 \\
$\rho_{I_{G}}$ & Inv. Púb. & B & 0,5 & 0,25 & 0,81 & 0,67 & 0,95 & 0,81 & 0,68 & 0,94 \\
$\rho_{T}$ & Transf. & B & 0,5 & 0,25 & 0,86 & 0,77 & 0,96 & 0,88 & 0,79 & 0,97 \\
$\rho_{\tau^{c}}$ & Trib. Cons. & B & 0,5 & 0,25 & 0,77 & 0,62 & 0,93 & 0,64 & 0,45 & 0,85 \\
$\rho_{\tau^{l}}$ & Trib. Trab. & B & 0,5 & 0,25 & 0,64 & 0,46 & 0,83 & 0,45 & 0,22 & 0,67 \\
$\rho_{\tau^{k}}$ & Trib. Cap. & B & 0,5 & 0,25 & 0,50 & 0,29 & 0,71 & 0,40 & 0,19 & 0,61 \\
\hline \multicolumn{7}{|c|}{ Desvio-padrão dos Choques } \\
\hline$\sigma_{m}^{2}$ & Monet. & Gl & 0,01 & Inf. & 0,003 & 0,002 & 0,003 & 0,003 & 0,002 & 0,003 \\
$\sigma_{A}^{2}$ & Tecn. & Gl & 0,01 & Inf. & 0,009 & 0,002 & 0,017 & 0,007 & 0,002 & 0,012 \\
$\sigma_{b}^{2}$ & Pref. & Gl & 0,01 & Inf. & 0,009 & 0,007 & 0,012 & 0,009 & 0,007 & 0,011 \\
$\sigma_{I}^{2}$ & Inv. Priv. & Gl & 0,01 & Inf. & 0,016 & 0,011 & 0,020 & 0,016 & 0,012 & 0,021 \\
$\sigma_{w}^{2}$ & Markup Salários & Gl & 0,01 & Inf. & 0,006 & 0,003 & 0,010 & 0,006 & 0,003 & 0,009 \\
$\sigma_{p}^{2}$ & Markup Preços & Gl & 0,01 & Inf. & 0,005 & 0,003 & 0,006 & 0,005 & 0,004 & 0,007 \\
$\sigma_{G}^{2}$ & Cons. Púb. & Gl & 0,01 & Inf. & 0,029 & 0,024 & 0,035 & 0,030 & 0,024 & 0,035 \\
$\sigma_{I_{G}}^{2}$ & Inv. Púb. & Gl & 0,01 & Inf. & 0,083 & 0,070 & 0,096 & 0,083 & 0,070 & 0,096 \\
$\sigma_{T}^{2}$ & Transf. & Gl & 0,01 & Inf. & 0,029 & 0,024 & 0,033 & 0,029 & 0,024 & 0,033 \\
$\sigma_{\tau^{c}}^{2}$ & Trib. Cons. & Gl & 0,01 & Inf. & 0,011 & 0,009 & 0,013 & 0,010 & 0,008 & 0,011 \\
$\sigma_{\tau^{l}}^{2}$ & Trib. Trab. & Gl & 0,01 & Inf. & 0,004 & 0,004 & 0,005 & 0,011 & 0,009 & 0,013 \\
$\sigma_{\tau^{k}}^{2}$ & Trib. Cap. & Gl & 0,01 & Inf. & 0,011 & 0,009 & 0,013 & 0,013 & 0,011 & 0,015 \\
\hline
\end{tabular}

Fonte: Elaboração própria. Nota: B: beta. G: gama. Gl: gama invertida. N: normal. Inf.: infinito. O intervalo de credibilidade se refere aos $5^{\circ}$ e $95^{\circ}$ percentis.

Para os parâmetros a seguir, seguem-se Castro et al. (2011). O custo de ajustamento do investimento $(\varphi)$ tem uma distribuição gama com média 4 e desviopadrão 1,5. O grau de indexação dos preços $\left(\gamma_{p}\right)$ assume uma distribuição beta com média 0,65 e desvio-padrão 0,2 , enquanto o grau de indexação dos salários $\left(\gamma_{w}\right)$, uma distribuição beta com média 0,65 e desvio-padrão 0,15. A probabilidade de uma firma intermediária não ser sorteada para poder reajustar seu preço $\left(\varpi_{p}\right)$ assume uma distribuição beta com média 0,65 e desvio-padrão 0,1 , ao passo que a probabilidade de uma família ricardiana não ser sorteada para poder reajustar seu salário $\left(\varpi_{w}\right)$ tem uma distribuição beta com média 0,75 e desvio-padrão 0,1. O grau de persistência de formação de hábito $(h)$ assume uma distribuição beta com média 0,85 e desvio-padrão 0,05 .

Embora Castro et al. (2011) calibrem o parâmetro de fração de famílias não ricardianas $(v)$ em 0,4, opta-se por estimá-lo. Para esse parâmetro, atribui-se uma distribuição beta com média 0,4 e desvio-padrão 0,15. 
A escolha das distribuições dos parâmetros da regra monetária também segue Castro et al. (2011). O parâmetro de suavização da taxa de juros nominal $(\rho)$ se caracteriza por uma distribuição beta com média 0,6 e desvio-padrão 0,15 . O parâmetro de reação à inflação $\left(\rho_{\Pi}\right)$ tem uma distribuição normal com média 2 e desvio-padrão 0,35 , enquanto o parâmetro de reação ao produto $\left(\rho_{Y}\right)$ assume uma distribuição gama com média 0,25 e desvio-padrão 0,1 .

Quando a política fiscal se caracteriza por instrumentos fiscais de gastos diminuindo (aumentando) e de alíquotas tributárias ${ }^{26}$ aumentando (diminuindo) em resposta a uma elevação (queda) do produto, ela é chamada de anticíclica e contribui para suavizar o ciclo econômico. Quando os instrumentos fiscais não reagem ao produto, a política fiscal é acíclica. Por fim, quando os instrumentos fiscais de gastos aumentam (diminuem) e de alíquotas tributárias diminuem (aumentam) em resposta a uma elevação (queda) do produto, a política fiscal é pró-cíclica e contribui para amplificar o ciclo econômico. A literatura internacional aponta que a política fiscal é anticíclica ou acíclica em países desenvolvidos, ao passo que ela é pró-cíclica em países em desenvolvimento (e.g., Talvi e Vegh (2005), Alesina et al. (2008), Ilzetzki e Vegh (2008), Vegh e Vuletin (2012)). Em particular, a literatura nacional encontra evidências de a política fiscal brasileira ser pró-cíclica (e.g., Mendonça et al. (2009), Rocha (2009), Rocha e Giuberti (2008), Gadelha e Divino (2013a) e Gadelha e Divino (2013b) ${ }^{27}$ ).

Herbst e Schorfheide (2016, cap. 6) ressaltam a importância da escolha adequada das priors dos parâmetros de reação dos instrumentos fiscais ao produto. Eles estimam

\footnotetext{
${ }^{26}$ Vegh e Vuletin (2012) destacam a importância de distinguir entre mudanças nos instrumentos da política fiscal que de fato refletem as intenções dos policymakers e mudanças nos resultados da política fiscal. As alíquotas tributárias representam melhor o comportamento discricionário da política fiscal que as receitas e outras medidas baseadas nas receitas, que não estão sob o controle dos policymakers e variam endogenamente com o produto e outros fatores como a disposição dos agentes a cometer evasão tributária, capacidade de subornar os encarregados pela tributação e mudanças na distribuição de renda. ${ }^{27}$ Gadelha e Divino (2013b) é o único estudo que, além de encontrar evidências de a política fiscal brasileira ser pró-cíclica, busca compreender os motivos teóricos de tal comportamento. Suas estimações respaldam os argumentos sobre variabilidade da base tributária (pressões políticas por mais gastos públicos aumentam nas expansões econômicas, porque a base tributária e, por conseguinte, a arrecadação elevamse), corrupção (quando a arrecadação aumenta devido ao período expansivo da economia, cidadãos de países em que é forte a sensação de corrupção exigem dos governantes certos aumentos dos gastos públicos ou cortes dos impostos por temerem que a arrecadação extra seja desperdiçada) e economia informal (países com uma economia informal maior têm uma variabilidade da base tributária maior, amplificando o efeito do primeiro argumento), porém não corroboram aquelas sobre restrição ao crédito internacional (países em desenvolvimento são mais sujeitos a restrições ao crédito internacional em tempos de retração econômica, em que a escassez de oferta de crédito limita os gastos públicos).
} 
o mesmo modelo de Leeper et al. (2010) com a mesma base de dados, porém estabelecem priors mais difusas com suporte em valores positivos e negativos - mais precisamente, substituem a distribuição gama de Leeper et al. (2010) com desvio-padrão variando de 0,05 a 0,3 a depender do parâmetro por uma distribuição normal com desviopadrão 1, embora mantenham as mesmas médias -, encontrando evidências de que a política fiscal estadunidense de gastos é pró-cíclica e não anticíclica como forçadamente mostram os resultados de Leeper et al. (2010), cujos achados se devem à escolha das priors com suporte apenas em valores positivos, fazendo com que as posteriors necessariamente só tenham massa de probabilidade em valores positivos. ${ }^{28}$

Por isso, diferentemente de Leeper et al. (2010), para os coeficientes de reação ao produto dos instrumentos fiscais $\left(\phi_{Y, G}, \phi_{Y, I_{G}}, \phi_{Y, T}, \phi_{Y, \tau^{c}}, \phi_{Y, \tau^{l}}, \phi_{Y, \tau^{k}}\right)$, decide-se não restringir o domínio a valores positivos e adota-se uma postura agnóstica ao escolher uma distribuição normal com média 0 e desvio-padrão 1, tal como fazem Herbst e Schorfheide (2016, cap.6). Assim, tais coeficientes podem assumir valores positivos (comportamento anticíclico), nulo (comportamento acíclico) e negativos (comportamento pró-cíclico), permitindo aos dados falarem o comportamento fiscal com relativa folga.

No que tange aos parâmetros de reação à dívida pública $\left(\phi_{b, G}, \phi_{b, I_{G}}, \phi_{b, T}, \phi_{b, \tau} c\right.$, $\left.\phi_{b, \tau^{l}}, \phi_{b, \tau^{k}}\right)$, opta-se por distribuições difusas que abarquem um conjunto considerável de valores positivos a fim de deixar os dados indicarem quais instrumentos fiscais são mais fortemente acionados para estabilizar a dívida pública, tendo em vista que não existe uma literatura consolidada apontando para um certo comportamento. Assim, tal como Leeper et al. (2010), adota-se uma distribuição gama com média 0,4 e desvio-padrão 0,2, de modo a abarcar aproximadamente valores entre 0 e 1,25.

${ }^{28}$ Gadelha e Divino (2013a) estimam um modelo DSGE e encontram evidências de a política fiscal brasileira ser pró-cíclica, porém seus resultados são sujeitos a críticas que o presente trabalho busca contornar: (i) mesmo parâmetro de cada regra fiscal capta a reação ao produto e à dívida, não permitindo distinguir se a resposta é em relação ao produto ou à dívida; (ii) priors das regras fiscais centradas em valores positivos altos com desvios-padrão pequenos, embora tenham distribuição normal, são muito apertadas e tendem a gerar posteriors concentradas nas mesmas regiões; (iii) aplicação de filtro HP para estacionarizar os dados não é aconselhável porque esse método se baseia em informações passadas e futuras, sendo preferível o filtro HP one-sided ou a primeira diferença; e (iv) estimações dos parâmetros fiscais associados às alíquotas tributárias seriam mais informativas se obtidas com dados de alíquotas efetivas no lugar de receitas tributárias por representarem diretamente as alíquotas do modelo. 
Os parâmetros que dizem respeito aos choques são escolhidos com base em Castro et al. (2011). Os coeficientes de persistência dos choques autorregressivos $\left(\rho_{A}\right.$, $\left.\rho_{b}, \rho_{I}, \rho_{w}, \rho_{p}, \rho_{G}, \rho_{I_{G}}, \rho_{T}, \rho_{\tau^{c}}, \rho_{\tau^{l}}, \rho_{\tau^{k}}\right)$ têm distribuição beta com média 0,5 e desviopadrão 0,25 . Já para todos os desvios-padrão dos choques $\left(\sigma_{b}^{2}, \sigma_{I}^{2}, \sigma_{w}^{2}, \sigma_{A}^{2}, \sigma_{p}^{2}, \sigma_{G}^{2}, \sigma_{I_{G}}^{2}\right.$, $\left.\sigma_{T}^{2}, \sigma_{\tau^{c}}^{2}, \sigma_{\tau^{l}}^{2}, \sigma_{\tau^{k}}^{2}, \sigma_{m}^{2}\right)$, são atribuídas distribuições gama inversa com média 0,01 e desviopadrão infinito.

\subsection{Resultados das Estimações com Foco nas Regras Fiscais}

Utiliza-se o programa Dynare para efetuar o processo de estimação bayesiana. ${ }^{29}$ Como a base de dados A usa as séries de alíquotas tributárias de Azevedo e Fasolo (2015) e a base de dados B utiliza as séries de alíquotas tributárias de Almeida et al. (2017), faz-se uma estimação com cada base, gerando a "estimação A" e a "estimação B", embora ambas tenham as mesmas priors. Em cada estimação, são geradas 5 cadeias com 1 milhão de sorteios cada uma, obtendo-se uma taxa média de aceitação de aproximadamente $23 \%$, e são descartados $50 \%$ dos sorteios iniciais. ${ }^{30}$

A Tabela 3 apresenta a média e o intervalo de credibilidade (5ํ e 95ํㅜ percentis) das posteriors dos parâmetros das estimações A e B. ${ }^{31}$ Como pode ser notado, para os parâmetros que não dizem respeito às regras fiscais, as médias das posteriors das duas estimações são bem parecidas. Por isso, comparam-se os resultados da estimação $A$ desses parâmetros com aqueles obtidos por Castro et al. (2011) e as mesmas observações se aplicam aos resultados da estimação B.

A média da posterior do custo de ajustamento do investimento privado $(\varphi)$ é de 6,48, que contrasta substancialmente com o valor de 3,42 de Castro et al. (2011). Já a média da posterior da persistência de formação de hábito $(h)$ de 0,86 é maior que o valor de 0,74 achado por Castro et al. (2011). Como mencionado anteriormente, estima-se a

${ }^{29}$ Para mais detalhes sobre o processo de estimação bayesiana de modelos DSGE e aquele usado especificamente pelo Dynare, ver Apêndice 3.

${ }^{30}$ Os gráficos dos diagnósticos de convergência univariada e multivariada indicam haver convergência das estimações.

31 O Apêndice 4 apresenta os gráficos das priors e posteriors das estimações A e B. Como é possível observar pelas posteriors, os dados foram informativos para a maioria dos parâmetros, já que muitas posteriors tiveram suas massas de probabilidade menos dispersas relativamente às das priors ou se concentraram em valores distintos dos iniciais. Cabe ressaltar que esse é o caso de todos os parâmetros das regras fiscais. 
fração de famílias não ricardianas $(v)$, obtendo-se a média de 0,27 , que não dá respaldo ao valor calibrado de 0,4 em Castro et al. (2011).

No que concerne aos parâmetros de rigidez nominal, as médias das posteriors dos parâmetros de Calvo para preços $\left(\varpi_{p}\right)$ e para salários $\left(\varpi_{w}\right)$ são, respectivamente, de 0,66 e 0,78 . No contexto do modelo, isso significa que, em média, os preços e os salários são reajustados otimamente a cada 2,27 e 4,55 trimestres, respectivamente. Para esses parâmetros, Castro et al. (2011) encontram valores de 0,74 e 0,75, respectivamente. Já as médias das posteriors dos parâmetros de indexação dos preços $\left(\gamma_{p}\right)$ e dos salários $\left(\gamma_{w}\right)$ assumem valores de 0,37 e 0,61, respectivamente, enquanto Castro et al. (2011) acham os valores de 0,33 e 0,49.

Para a regra monetária, as médias das posteriors dos parâmetros de suavização da taxa de juros nominal $(\rho)$, de reação à inflação $\left(\rho_{\Pi}\right)$ e de reação ao produto $\left(\rho_{Y}\right)$ apresentam valores de 0,89, 2,23 e 0,11, ao passo que Castro et al. (2011) chegam a $0,79,2,43$ e 0,16, respectivamente. Logo, o presente trabalho encontra evidências de uma política monetária mais acomodatícia e um pouco menos avesso a variações da inflação e do produto.

No que tange aos parâmetros de resposta ao produto das regras fiscais, salientase que valores positivos, nulo e negativos indicam, respectivamente, comportamento anticíclico, acíclico e pró-cíclico do instrumento fiscal. Nota-se que as médias das posteriors das estimações A e B são negativas, com exceção das transferências em ambas as estimações e do tributo do trabalho na estimação $B$. No entanto, também é importante analisar onde ocorre a concentração da massa de probabilidade das posteriors com o objetivo de entender melhor quanta incerteza permeia os resultados, o que pode ser feito olhando para as posteriors dos parâmetros de resposta ao produto na Figura 3 e para os intervalos de credibilidade. 
Figura 3 - Priors e Posteriors dos Parâmetros Fiscais de Resposta ao Produto

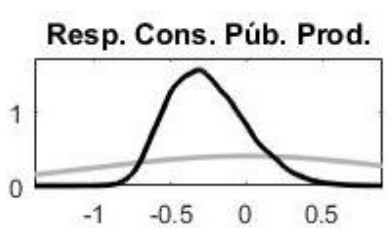

Resp. Trib. Cons. Prod.

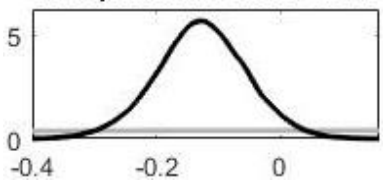

Resp. Cons. Púb. Prod.

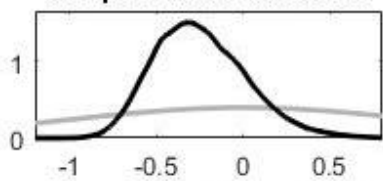

Resp. Trib. Cons. Prod.

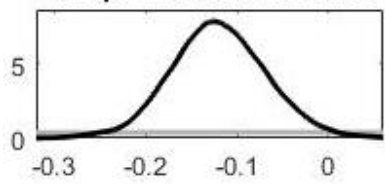

Estimação A

Resp. Inv. Púb. Prod.

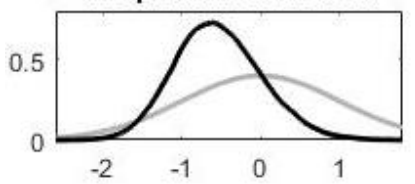

Resp. Trib. Trab. Prod.

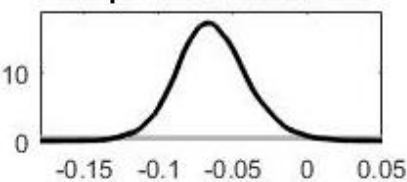

Estimação B

Resp. Inv. Púb. Prod.

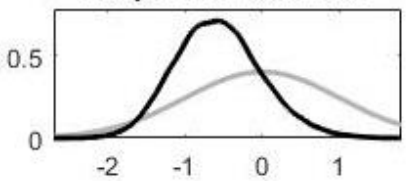

Resp. Trib. Trab. Prod.

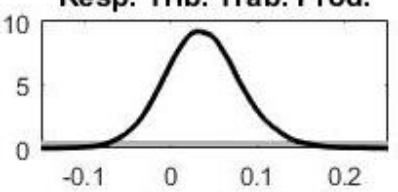

Resp. Transf. Prod.

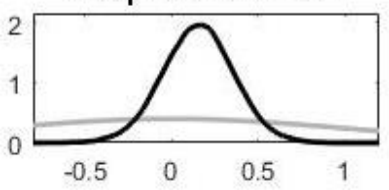

Resp. Trib. Cap. Prod.

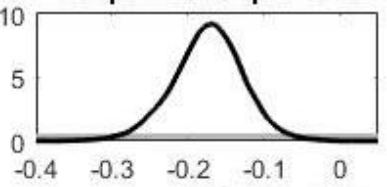

Resp. Transf. Prod.

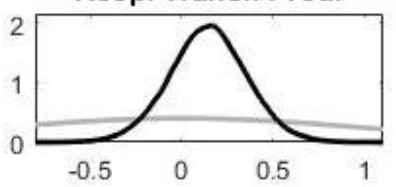

Resp. Trib. Cap. Prod.

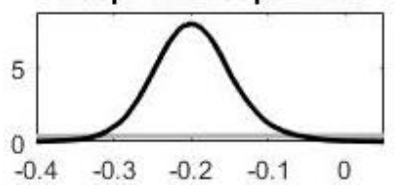

Fonte: Elaboração própria. Nota: As priors e as posteriors estão nas cores cinza e preto, respectivamente. Os gráficos das respostas fiscais (principalmente, dos tributos) são ampliados para melhorar a visualização, uma vez que as posteriors se mostram bem concentradas relativamente às priors, que são difusas. Ressalta-se que os dados são informativos em todos os casos, já que todas as posteriors são bem distintas das priors.

Do lado dos instrumentos de gastos, a resposta do consumo público ao produto $\left(\phi_{Y, G}\right)$ apresenta média de -0,26 na estimação $A$ e de $-0,25$ na estimação B. Em ambas as estimações, ocorre uma concentração da massa de probabilidade da posterior na região negativa como se vê pelos gráficos das posteriors.

A resposta do investimento púbico ao produto $\left(\phi_{Y, I_{G}}\right)$ tem média de $-0,54$ na estimação A e de -0,59 na estimação B. Em ambas as estimações, uma boa parte da massa de probabilidade se concentra na região negativa, o que se constata visualmente pelos gráficos. Esses resultados vão na direção do que se encontra na literatura nacional, ou seja, de que o consumo público e o investimento público são pró-cíclicos.

Em contraste, as transferências reagem menos ao produto, já que o parâmetro de resposta ao produto $\left(\phi_{Y, T}\right)$ tem média de 0,15 na estimação $\mathrm{A}$ e $\mathrm{B}$. Em ambas as estimações, a massa de probabilidade não se concentra tanto na região positiva como 
se vê pelos gráficos das posteriors. Como ela está mais dispersa que nos casos do consumo público e investimento público, fica mais difícil dizer com relativa precisão se o comportamento das transferências é anticíclico ou acíclico. Assim, parece mais seguro falar que as transferências são levemente anticíclicas ou acíclicas, o que pode estar relacionado, no primeiro caso, aos componentes de abono e seguro-desemprego, mais ligados ao papel de estabilizadores automáticos, enquanto, no segundo caso, à rigidez dos benefícios previdenciários e assistenciais, que compõem uma parte significativa das transferências e têm crescido independentemente das condições da atividade econômica.

Do lado dos instrumentos de tributos, a resposta da alíquota sobre o consumo ao produto $\left(\phi_{Y, \tau^{c}}\right)$ tem média de $-0,13$ na estimação $A$ e de $-0,12$ na estimação $B$, enquanto a resposta da alíquota sobre a renda do capital ao produto $\left(\phi_{Y, \tau^{k}}\right)$ apresenta média de 0,17 na estimação $A$ e $-0,20$ na estimação $B$. Em todos esses casos, a massa de probabilidade da posterior encontra-se bem concentrada na região negativa como se constata pelo gráfico e pelo fato de o intervalo de credibilidade não conter o valor zero. Isso evidencia que as alíquotas sobre o consumo e a renda do capital são pró-cíclicas.

Já a resposta da alíquota sobre a renda do trabalho ao produto $\left(\phi_{Y, \tau}\right)$ tem média de $-0,06$ na estimação $A$ e de 0,03 na estimação $B$. No primeiro caso, a massa de probabilidade se concentra bastante na região negativa e o intervalo de credibilidade não contém o valor zero. Porém, no segundo caso, ela se concentra apenas um pouco na região positiva como se vê pelo gráfico. Dessa forma, a estimação $A$ encontra evidências de a alíquota sobre a renda do trabalho ser pró-cíclica, porém a estimação B aponta para um comportamento levemente anticíclico ou acíclico.

No que tange aos parâmetros de resposta à dívida pública dos instrumentos fiscais de gastos, as repostas do consumo público $\left(\phi_{b, G}\right)$, investimento público $\left(\phi_{b, I_{G}}\right)$ e transferências $\left(\phi_{b, T}\right)$ têm, respectivamente, médias de $0,25,0,32$ e 0,20 na estimação $A$ e de $0,21,0,29$ e 0,19 na estimação $B$. Em ambas as estimações, o investimento público é o gasto que mais contribui para a estabilização da dívida e as transferências são o gasto que menos ajuda a estabilizar a dívida. Isso pode se dever ao fato de que o investimento público no Brasil é o gasto mais discricionário e, logo, sujeito a cortes 
quando da necessidade de ajustes fiscais, enquanto as transferências, sobretudo a parcela previdenciária, são os gastos mais rígidos.

Do lado da tributação, as respostas à dívida pública das alíquotas sobre o consumo $\left(\phi_{b, \tau^{c}}\right)$, a renda do trabalho $\left(\phi_{b, \tau^{l}}\right)$ e a renda do capital $\left(\phi_{b, \tau^{k}}\right)$ têm, respectivamente, médias de 0,20,0,07 e 0,09 na estimação $A$, de forma que a alíquota tributária sobre o consumo é a mais acionada para estabilizar a dívida pública. Isso parece fazer sentido para o Brasil, em que uma parcela significativa da arrecadação reside em impostos sobre o consumo. Já na estimação $B$, as médias são, respectivamente, de 0,13, 0,10 e 0,16 e, logo, indicam que há uma contribuição mais equânime entre as alíquotas tributárias para a estabilização da dívida pública.

Em vista dos resultados obtidos nas estimações $A$ e $B$, que usam bases de dados para alíquotas tributárias distintas como exercício de robustez, nota-se que, do lado dos gastos, as duas estimações apontam na mesma direção e mostram que o consumo público e o investimento público são pró-cíclicos, enquanto as transferências são acíclicas ou levemente anticíclicas. Já do lado dos tributos, as alíquotas tributárias sobre o consumo e a renda do capital são pró-cíclicas nas duas estimações, porém a estimação A indica que a alíquota sobre a renda do trabalho é pró-cíclica, ao passo que a estimação B mostra que ela é acíclica ou levemente anticíclica. Assim, a política fiscal brasileira é, em geral, pró-cíclica e contribui para amplificar o ciclo econômico. Por fim, as estimações A e $B$ evidenciam que, do lado dos gastos, o investimento público contribui mais para estabilizar a dívida pública e as transferências ajudam menos. Do lado dos tributos, a estimação A mostra evidências de a alíquota sobre o consumo ter papel proeminente na estabilização da dívida pública, enquanto a estimação $B$ encontra evidências de as três alíquotas contribuírem mais equanimemente para estabilizá-la.

Destarte, o exercício de robustez indica que as estimações dos parâmetros das regras fiscais de tributos são sensíveis às séries de alíquotas tributárias, porque, embora as estimações $A$ e $B$ encontrem evidências de que as alíquotas tributárias sobre 0 consumo e a renda do capital sejam pró-cíclicas, a estimação A mostra um comportamento pró-cíclico da alíquota sobre a renda do trabalho e a estimação $B$, um comportamento um pouco anticíclico ou acíclico, e ainda os resultados de resposta à dívida pública são diferentes. Isso provavelmente se deve à maneira de categorizar os 
diferentes impostos no momento de construir as bases tributárias, à metodologia de desagregação temporal para transformar algumas séries de baixa para alta frequência e à dificuldade de capturar e sintetizar agregadamente nessas séries toda a estrutura tributária de uma economia, ainda mais a brasileira, que é marcada por um sistema tributário bem complexo com inúmeros tributos e regimes especiais, além da dificuldade de coleta de dados fiscais. 


\section{Resultados do Modelo: Dinâmica, Multiplicadores Fiscais e Sensibilidade}

Este capítulo dedica-se aos resultados do modelo. Primeiro, analisam-se a dinâmica das principais variáveis macroeconômicas frente aos diversos choques fiscais, enfatizando como se manifesta no modelo o comportamento pró-cíclico da política fiscal, a partir dos gráficos das funções impulso-resposta, bem como a contribuição de cada choque para a flutuação das variáveis crescimento do produto, superávit primário e dívida pública a partir da decomposição da variância do erro de previsão.

Segundo, calculam-se os multiplicadores fiscais cumulativos a valor presente, usando a taxa de juros do modelo.

Por último, a fim de verificar quão sensíveis são os resultados dos multiplicadores fiscais aos parâmetros de elasticidade do produto em relação ao capital público $\left(\alpha_{G}\right)$, fração de famílias não ricardianas $(v)$, suavização da taxa de juros nominal da regra monetária $(\rho)$, elasticidade do custo de ajustamento da utilização do capital privado $(\kappa)$ e ao comportamento (pró-cíclico, acíclico ou anticíclico) da política fiscal, realizam-se exercícios de sensibilidade dos multiplicadores fiscais variando um desses parâmetros de cada vez e, no último caso, os parâmetros das políticas fiscais. ${ }^{32}$

\subsection{Choques Fiscais de Gastos e Tributos}

O modelo consegue capturar o comportamento da política fiscal, em geral, prócíclico e ajuda no entendimento de como a economia brasileira se comporta quando da ocorrência de choques fiscais. Um choque fiscal num dado instrumento estimula a atividade econômica e esse efeito positivo é magnificado pelos demais instrumentos que reagem endogenamente de maneira pró-cíclica de acordo com as regras fiscais. Porém, a adoção dessa política fiscal pró-cíclica expansionista acarreta inicialmente uma elevação da dívida pública, que posteriormente leva a autoridade fiscal a mudar a política fiscal de modo a aumentar seu superávit primário com diminuição de gastos e aumento de tributos conforme a reação endógena à dívida pública das regras fiscais ganha

32 Os valores que esses parâmetros assumem costumam ser relevantes para os resultados dos multiplicadores fiscais como mostram Zubairy (2014), Moura (2015) e Bhattarai e Trzeciakiewicz (2017). 
relevância. Como a dívida pública demora para ser estabilizada, o arrocho fiscal é mantido por um tempo considerável, afetando negativamente o produto. ${ }^{33}$

No caso do choque positivo do consumo público (Figura 4), as famílias ricardianas anteveem que o governo elevará a tributação para satisfazer seu orçamento intertemporal e isso gera um efeito riqueza negativo que as leva a diminuir seu consumo, seu investimento privado e seu tempo de lazer, que em contrapartida significa aumentar sua oferta de trabalho. Já as famílias não ricardianas aumentam seu consumo em resposta ao aumento da sua renda disponível, causada pela maior renda do trabalho. $\mathrm{O}$ aumento na oferta de trabalho impulsiona o crescimento do produto. Embora as famílias ricardianas componham a maior parcela na economia, o aumento do consumo das famílias não ricardianas é mais que suficiente para compensar a queda do consumo das famílias ricardianas de modo que o consumo privado agregado se eleva. Além disso, devido ao caráter pró-cíclico da política fiscal, o investimento público aumenta, bem como as alíquotas tributárias diminuem, contribuindo para intensificar o crescimento do produto e da dívida pública - embora as transferências sejam levemente anticíclicas, seu impacto é bem pequeno. Por outro lado, o aumento do retorno do capital é maior que a queda do salário e faz o custo marginal das firmas subir, pressionando para cima a inflação, o que em conjunto com um produto elevado leva a autoridade monetária a subir a taxa de juros nominal.

Passado o período inicial, o investimento público diminui e as alíquotas tributárias, sobretudo a incidente sobre o consumo, elevam-se para ampliar o superávit público a fim de fazer frente à escalada da dívida pública e permanecem acima do seu valor inicial por um tempo considerável em razão da morosidade da volta da dívida pública para seu valor de estado estacionário. Em particular, o consumo das famílias ricardianas cai ainda mais com a forte subida da alíquota tributária sobre o consumo, que conjuntamente com a queda da renda disponível diminui o consumo das famílias não ricardianas. O aumento

\footnotetext{
${ }^{33}$ Os gráficos das funções impulso-resposta mostram para o modelo $A$ o desvio percentual das variáveis em relação ao estado estacionário depois da ocorrência de um choque fiscal temporário de $1 \%$. A explicação do mecanismo de reação da economia no modelo da estimação $B$ é em essência a mesma. A principal diferença é que, na estimação $A$, todas as alíquotas tributárias são pró-cíclicas e a alíquota sobre o consumo tem papel proeminente na estabilização da dívida pública, enquanto, na estimação $\mathrm{B}$, a alíquota sobre a renda do trabalho é levemente anticíclica e todas as alíquotas tributárias ajudam de forma mais homogênea na estabilização da dívida pública.
} 
da alíquota tributária sobre a renda do trabalho e a queda do salário desestimulam a oferta de trabalho, enquanto o aumento da alíquota tributária sobre a renda do capital desincentiva o investimento privado. Essa política de oneração tributária faz o produto permanecer um pouco abaixo do seu valor de estado estacionário.

Figura 4 - Choque do Consumo Público
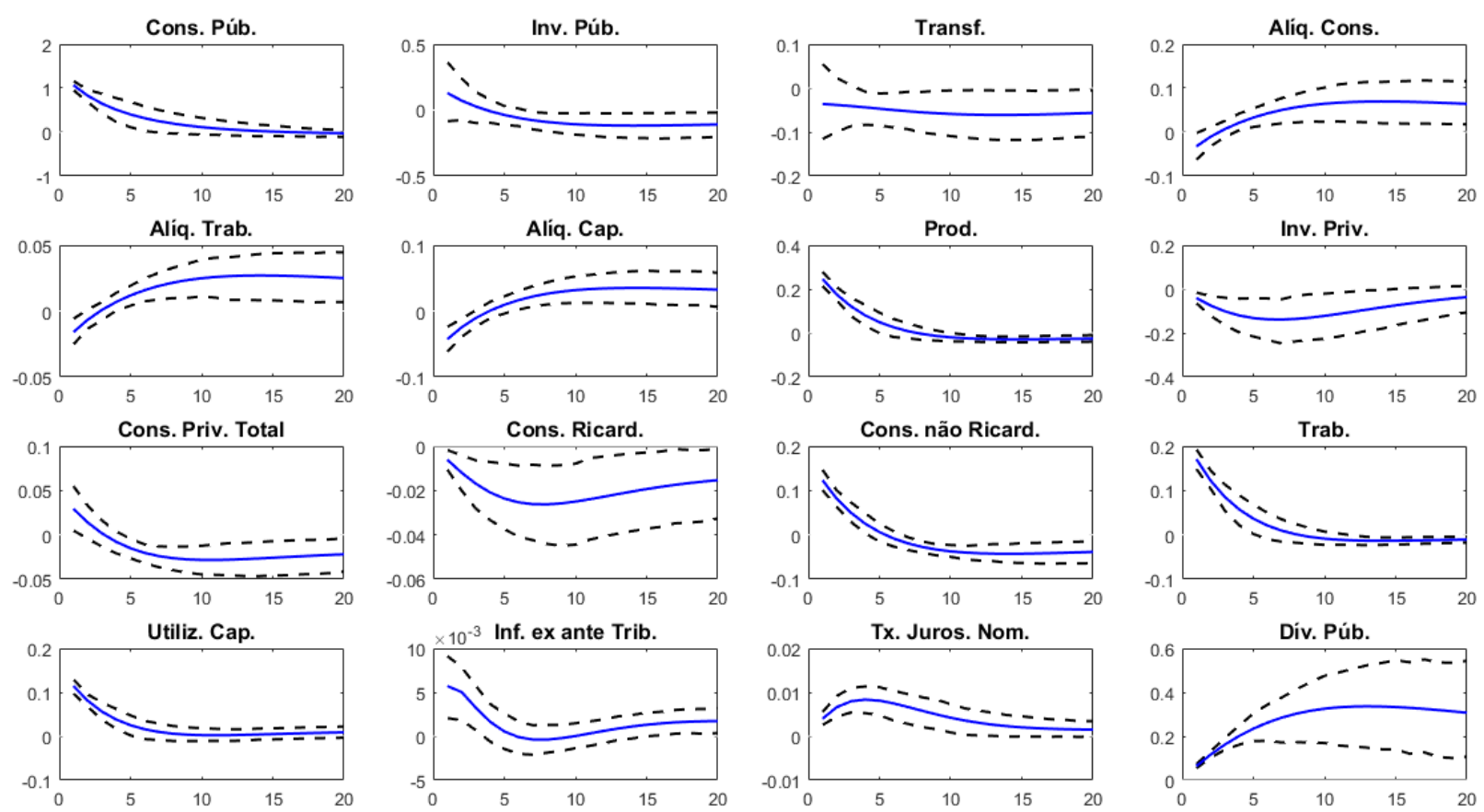

Fonte: Elaboração própria. Nota: A linha cheia azul é o valor médio e as linhas tracejadas pretas são os valores dos $5^{\circ}$ e $95^{\circ}$ percentis baseados na posterior. O eixo horizontal representa trimestres.

No caso do choque positivo do investimento público (Figura 5), os efeitos são parecidos com os do choque do consumo público. Uma diferença é que agora o consumo público se eleva em reação ao aumento inicial do produto no lugar do investimento público do caso anterior. Outra diferença é que o aumento do investimento público é maior e, à medida que o investimento público se reverte em capital público, a produtividade marginal dos fatores privados (trabalho e capital privado) eleva-se. Assim, o salário e o retorno do capital aumentam, pressionando para cima o custo marginal e a inflação, o que em conjunto com um produto acima do seu estado estacionário incita a autoridade monetária a subir a taxa de juros nominal. Ademais, ocorre um efeito crowding out do investimento público sobre o investimento privado. Posteriormente, como 
resultado da política fiscal pró-cíclica expansionista, a dívida pública se eleva e obriga a autoridade fiscal a diminuir o consumo público e a aumentar as alíquotas tributárias, sobretudo a incidente sobre o consumo, por um tempo longo em razão da dificuldade de trazer a dívida pública para seu valor de estado estacionário.

Figura 5 - Choque do Investimento Público
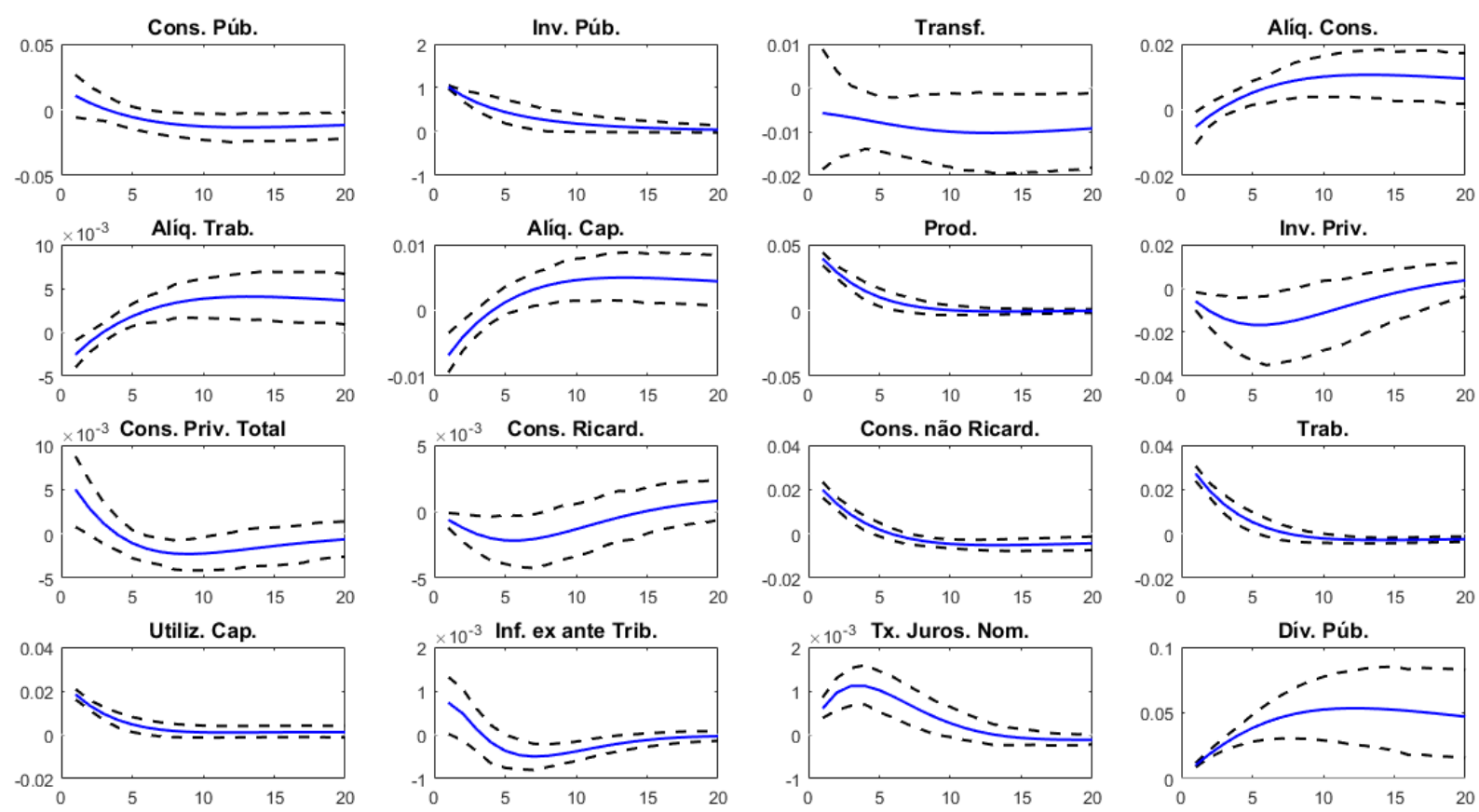

Fonte: Elaboração própria. Nota: A linha cheia azul é o valor médio e as linhas tracejadas pretas são os valores dos $5^{\circ}$ e $95^{\circ}$ percentis baseados na posterior. O eixo horizontal representa trimestres.

Já no caso do choque positivo das transferências (Figura 6), também os resultados são semelhantes aos do choque do consumo público. Porém, agora os três instrumentos fiscais de gastos aumentam, com o consumo público e o investimento público elevandose em resposta ao crescimento inicial do produto. Outra diferença é que o aumento das transferências é consideravelmente alto, gerando um efeito positivo, maior e mais persistente sobre o consumo das famílias não ricardianas e resultando num aumento do consumo agregado que demora mais para cair. Depois do período inicial com políticas pró-cíclicas expansionistas, a escalada da dívida pública força a autoridade fiscal a reverter sua política fiscal, que passa a consistir de gastos menores e alíquotas tributárias maiores, sobretudo a incidente sobre o consumo, por um tempo significativo. 
Figura 6 - Choque das Transferências
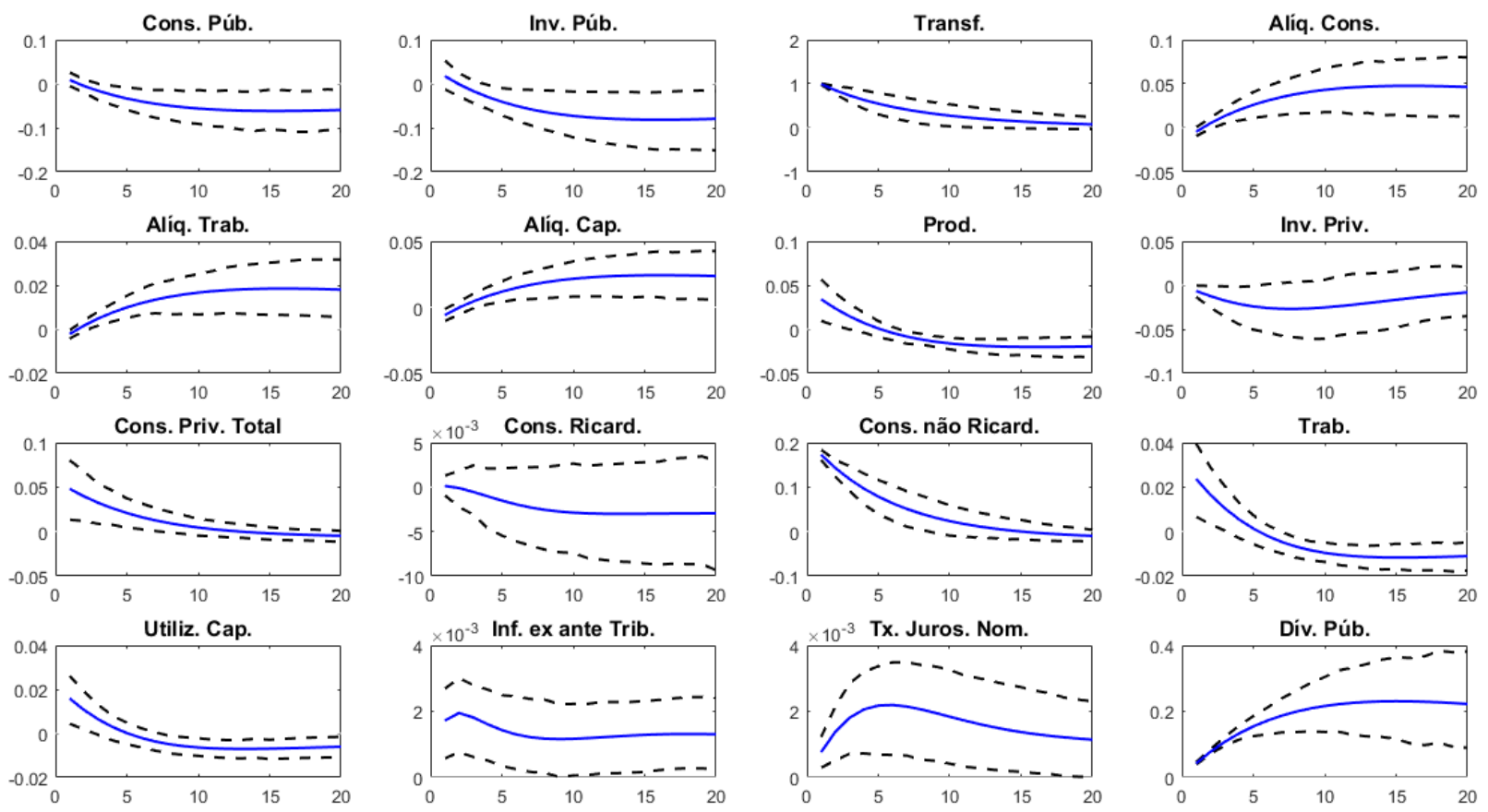

Fonte: Elaboração própria. Nota: A linha cheia azul é o valor médio e as linhas tracejadas pretas são os valores dos $5^{\circ}$ e $95^{\circ}$ percentis baseados na posterior. O eixo horizontal representa trimestres.

No caso do choque negativo da alíquota tributária sobre o consumo (Figura 7), as famílias ricardianas e não ricardianas aumentam o consumo, estimulando o crescimento do produto. A autoridade fiscal, então, promove políticas fiscais pró-cíclicas expansionistas ao aumentar o consumo público e o investimento público (embora reduzam um pouco as transferências) e ao diminuir as alíquotas tributárias do trabalho e do capital. Por um lado, o aumento dos gastos públicos gera um efeito riqueza negativo sobre as famílias ricardianas, que diminuem seu consumo e aumentam sua oferta de trabalho. Por outro lado, a diminuição das alíquotas estimula as famílias ricardianas a ofertarem trabalho e a investirem (no final, o investimento cai por causa do aumento da taxa de juros) e as famílias não ricardianas a consumir mais em razão do aumento da renda disponível. O resultado do aumento do trabalho é uma elevação do produto. $O$ custo marginal das firmas aumenta devido à subida do retorno do capital ser maior que a queda no salário e pressiona para cima a inflação, que em conjunto com a atividade econômica em alta leva a autoridade monetária a subir a taxa de juros nominal. 
Posteriormente, a combinação de elevação de gastos públicos com diminuição de alíquotas tributárias gera um aumento da dívida pública, o que faz a autoridade fiscal adotar uma política de corte dos gastos e elevação das alíquotas, por um tempo longo, já que a dívida demora para retornar para seu valor de estado estacionário. Com essa reversão da política tributária, a oferta de trabalho e os investimentos privados são desincentivados, levando o produto a permanecer um pouco abaixo de seu valor de estado estacionário.

Figura 7 - Choque do Tributo do Consumo
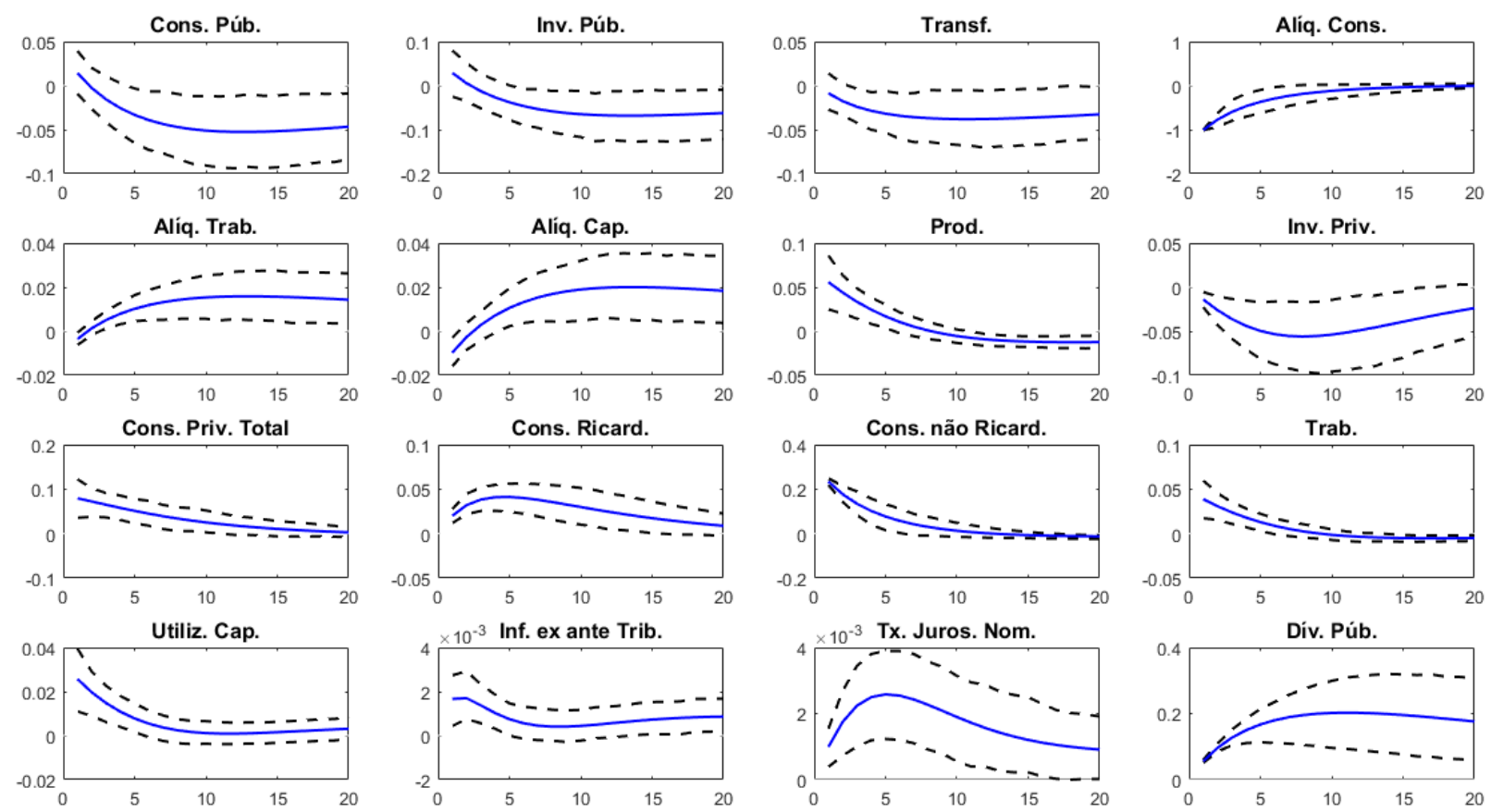

Fonte: Elaboração própria. Nota: A linha cheia azul é o valor médio e as linhas tracejadas pretas são os valores dos $5^{\circ}$ e $95^{\circ}$ percentis baseados na posterior. O eixo horizontal representa trimestres.

No caso do choque negativo da alíquota tributária sobre a renda do trabalho (Figura 8), as famílias ricardianas aumentam seu consumo, seu investimento e sua oferta de trabalho via efeito riqueza positivo. As famílias não ricardianas também elevam seu trabalho e, devido ao aumento na sua renda disponível, elas consomem mais. Assim, o consumo agregado aumenta e o produto também. Com o aumento inicial da atividade econômica, a autoridade fiscal amplia o consumo público e o investimento público, contrai levemente as transferências e diminui as alíquotas tributárias sobre o consumo e 0 
capital. Como a elevação do consumo público e investimento público prepondera em relação às transferências, ocorre um efeito riqueza negativo que leva as famílias ricardianas a diminuírem seu consumo e investimento e aumentarem sua oferta de trabalho. As famílias não ricardianas consomem mais com o aumento da sua renda disponível. A inflação diminui com a queda do custo marginal das firmas, que se deparam com um salário caindo mais que o aumento do retorno do capital, e leva a autoridade monetária a afrouxar sua política monetária ao reduzir a taxa de juros nominal.

Com a elevação da dívida pública causada pelas políticas fiscais pró-cíclicas expansionistas, a autoridade fiscal se vê forçada a diminuir os gastos e a elevar as alíquotas tributárias, sobretudo a incidente sobre o consumo. Como a dívida pública volta lentamente para seu valor de estado estacionário, as alíquotas permanecem por um tempo substancial acima de seus valores de estado estacionário, fazendo o produto também ficar abaixo de seu valor estado estacionário.

Figura 8 - Choque do Tributo do Trabalho
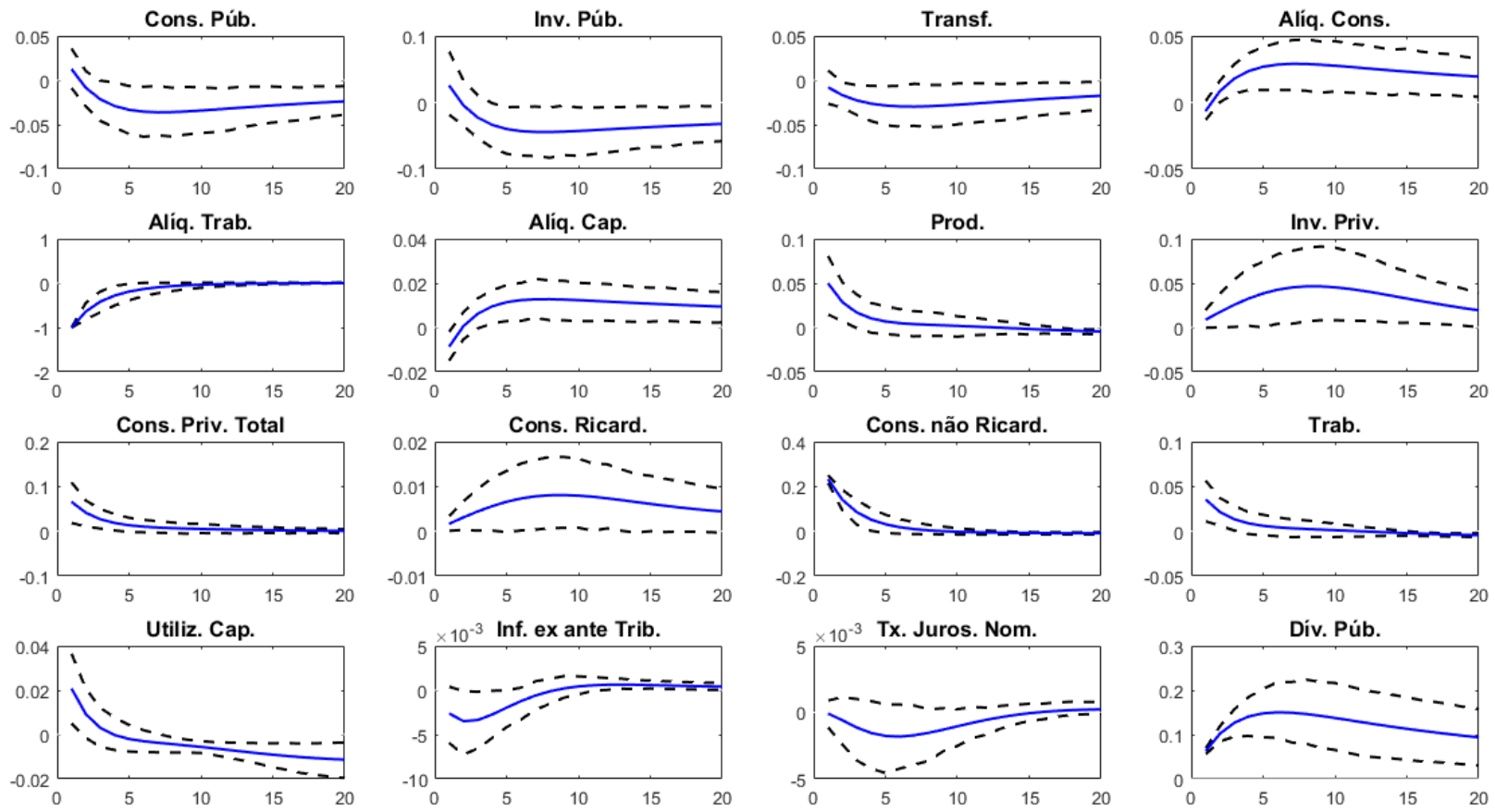

Fonte: Elaboração própria. Nota: A linha cheia azul é o valor médio e as linhas tracejadas pretas são os valores dos $5^{\circ}$ e $95^{\circ}$ percentis baseados na posterior. O eixo horizontal representa trimestres. 
Por fim, no caso do choque negativo da alíquota tributária sobre a renda do capital (Figura 9), as famílias ricardianas aumentam seu consumo e seu investimento, porém diminuem sua oferta de trabalho, porque torna-se mais vantajoso alugar capital privado e aumentar seu investimento. Com a queda da renda disponível em razão de o aumento do salário não suplantar a diminuição do trabalho, as famílias não ricardianas diminuem seu consumo. O consumo agregado diminui um pouco e começa a elevar-se à medida que o consumo das famílias não ricardianas aumenta em consequência da elevação das horas trabalhadas. Embora incialmente o trabalho empregado caia, o aumento na utilização do capital privado leva ao crescimento do produto, que por sua vez incita a autoridade fiscal a praticar políticas fiscais pró-cíclicas expansionistas que se traduzem em aumento do consumo público e do investimento público, leve queda das transferências e diminuição das alíquotas tributárias sobre o consumo e a renda do trabalho. A queda conjunta do salário e do retorno do capital provoca a diminuição do custo marginal, que pressiona a inflação para baixo e faz a autoridade monetária afrouxar a política monetária com a diminuição da taxa de juros nominal.

A adoção de políticas fiscais pró-cíclicas expansionistas provoca a elevação da dívida pública, o que induz a autoridade fiscal a mudar sua política fiscal, diminuindo os gastos e elevando as alíquotas tributárias, sobretudo a incidente sobre o consumo, que permanecem altas por um tempo considerável devido à dificuldade de trazer a dívida pública para seu valor de estado estacionário. Isso, então, desestimula o consumo e o investimento, além de fazer o produto permanecer abaixo de seu valor de estado estacionário. 
Figura 9 - Choque do Tributo do Capital
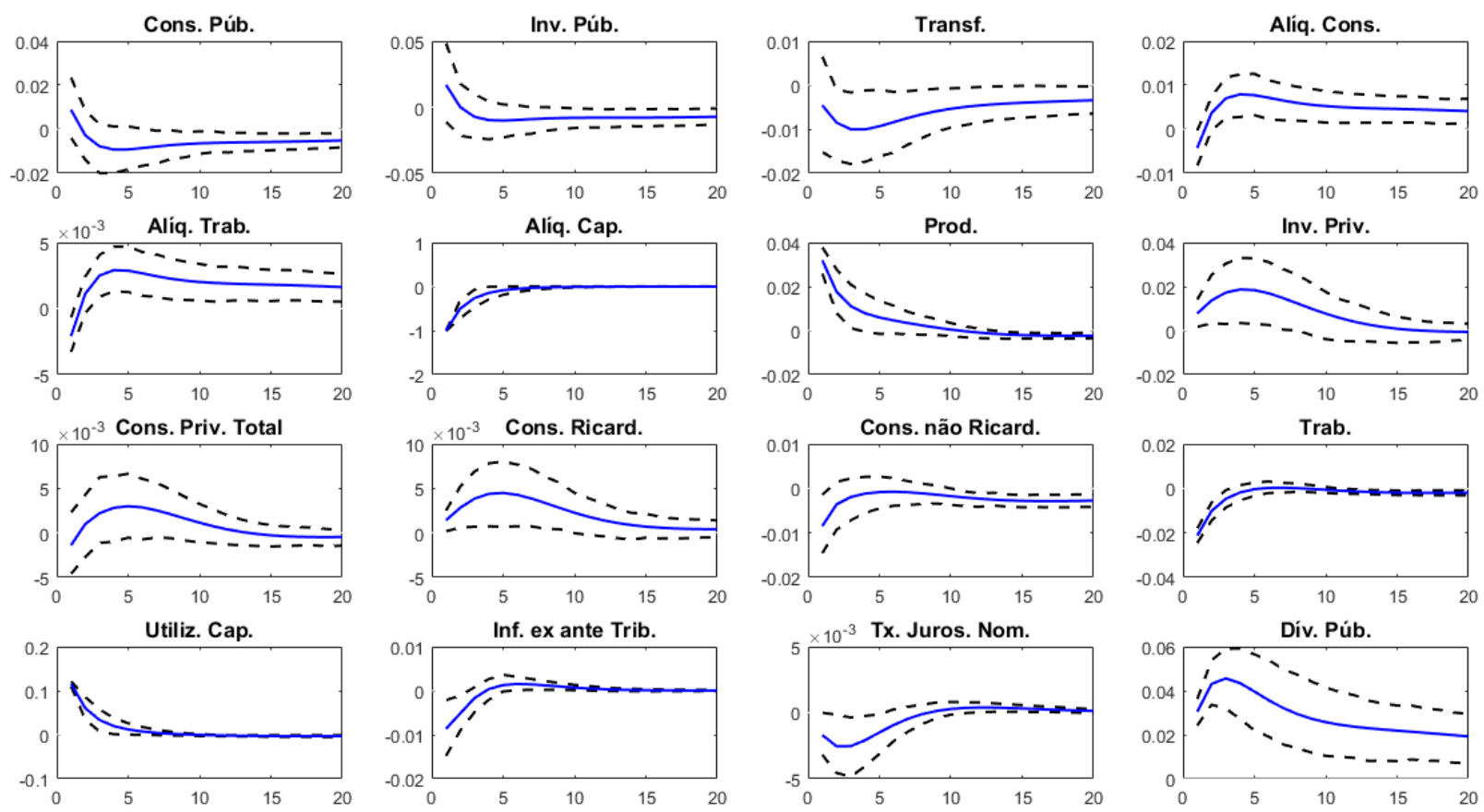

Fonte: Elaboração própria. Nota: A linha cheia azul é o valor médio e as linhas tracejadas pretas são os valores dos $5^{\circ}$ e $95^{\circ}$ percentis baseados na posterior. O eixo horizontal representa trimestres.

Esta subseção também reporta na Tabela 4 a decomposição do erro de previsão da variância das principais variáveis macroeconômicas citadas nos debates fiscais: crescimento do produto, razão superávit primário-produto e razão dívida pública-produto. A decomposição da variância permite estudar em que medida a variação média de cada variável pode ser explicada por cada um dos choques do modelo para diferentes horizontes de tempo.

É interessante notar que os choques fiscais são relevantes para explicar as variações das três variáveis em todos os horizontes de tempo (inclusive, no horizonte curto de 4 trimestres e mesmo no horizonte longo de 20 trimestres), o que reforça a importância do estudo da política fiscal para compreender melhor as origens das flutuações da atividade econômica e dos principais indicadores fiscais. Considerando a média das estimações, os choques fiscais são responsáveis por $21 \%$ no horizonte curto e $19 \%$ no horizonte longo da variação do crescimento do produto; por $63 \%$ no horizonte curto e $49 \%$ no horizonte longo da variação da razão superávit primário-produto; e por $5 \%$ no horizonte curto e $21 \%$ no horizonte longo da variação da razão dívida pública- 
produto. Devido à desagregação dos instrumentos fiscais, é possível ver que os choques de gastos são mais importantes que os de tributos, sendo o choque do consumo público o que mais contribui para a flutuação dessas variáveis.

Os resultados também revelam quais são as contribuições dos choques não fiscais. No caso do crescimento do produto, os choques de preferência e investimento privado são os mais importantes em todos os períodos. Nos casos da razão superávit primário-produto e da razão dívida pública-produto, nenhum dos choques não fiscais predomina, ou seja, a importância deles muda bastante ao longo do tempo.

Tabela 4 - Decomposição da Variância

\begin{tabular}{|c|c|c|c|c|c|c|c|c|c|c|c|c|}
\hline & \multicolumn{4}{|c|}{ Crescimento do Produto } & \multicolumn{4}{|c|}{ Razão Superávit Primário-Produto } & \multicolumn{4}{|c|}{ Razão Dívida Púb.-Produto } \\
\hline Trimestre & $1 \mathrm{1T}$ & $4 \mathrm{~T}$ & $20 \mathrm{~T}$ & Inf. & $1 \mathrm{~T}$ & $4 \mathrm{~T}$ & $20 \mathrm{~T}$ & Inf. & $1 \mathrm{~T}$ & $4 \mathrm{~T}$ & $20 \mathrm{~T}$ & Inf. \\
\hline \multicolumn{13}{|c|}{ Estimação A - Choques Fiscais } \\
\hline Cons.Púb. & 13,70 & 12,17 & 10,93 & 10,88 & 30,45 & 25,65 & 17,63 & 15,44 & 5,91 & 1,66 & 5,77 & 7,87 \\
\hline Inv.Púb. & 6,14 & 5,37 & 4,79 & 4,77 & 13,13 & 11,28 & 7,91 & 6,88 & 2,65 & 0,72 & 2,29 & 2,84 \\
\hline Transf. & 0,49 & 0,45 & 0,41 & 0,41 & 17,48 & 16,86 & 12,34 & 11,16 & 0,10 & 1,32 & 4,45 & 7,25 \\
\hline Trib.Cons. & 0,14 & 0,12 & 0,11 & 0,11 & 3,40 & 2,58 & 1,69 & 1,39 & 0,02 & 0,15 & 0,37 & 0,48 \\
\hline Trib.Tr & 0,03 & 0,0 & 0,03 & 0,03 & 0,94 & 0,58 & 0,36 & 0,27 & 0,01 & 0,05 & 0,04 & 0,04 \\
\hline Trib.Cap. & 0,05 & 0,04 & 0,04 & 0,04 & 0,55 & 0,27 & 0,16 & 0,12 & 0 & 0,02 & 0,01 & 0,01 \\
\hline Total & 20,55 & 3,18 & 6,31 & 16,24 & 65,95 & 57,22 & 40,09 & 35,26 & 8,69 & 3,92 & 12,93 & 18,49 \\
\hline \multicolumn{13}{|c|}{ Estimação A - Demais Choques } \\
\hline Monet. & 2,84 & 3,68 & 3,80 & 3,80 & 0,28 & 0,55 & 13,61 & 17,22 & 4,14 & 34,62 & 33,28 & 28,58 \\
\hline Tecn. & 2,01 & 3,68 & 3,47 & 3,47 & 5,56 & 2,80 & 2,31 & 2,26 & 7,35 & 2,44 & 1,86 & 2,47 \\
\hline Pref. & 37,27 & 31,70 & 29,21 & 29,08 & 12,97 & 11,25 & 6,99 & 5,12 & 42,99 & 27,16 & 3,73 & 2,51 \\
\hline Inv.Priv. & 24,45 & 20,18 & 19,32 & 19,23 & 0,56 & 0,75 & 1,16 & 1,59 & 21,66 & 17,93 & 3,05 & 2,41 \\
\hline $\begin{array}{l}\text { Markup } \\
\text { Salários }\end{array}$ & 2,31 & 13,58 & 18,79 & 19,13 & 6,84 & 8,91 & 19,65 & 24,57 & 12,25 & 10,81 & 34,06 & 36,29 \\
\hline $\begin{array}{l}\text { Markup } \\
\text { Preços }\end{array}$ & 10,57 & 9 & 9,11 & 9,07 & 7,84 & 18,52 & 16,19 & 13,98 & 2,94 & 3,11 & 11,08 & 9,27 \\
\hline Total & 79,45 & 81,82 & 83,70 & 83,78 & 34,05 & 42,78 & 59,91 & 64,74 & 91,33 & 96,07 & 87,06 & 81,53 \\
\hline \multicolumn{13}{|c|}{ Estimação B - Choques Fiscais } \\
\hline Cons.Púb. & 18,80 & 18,32 & 17,39 & 17,35 & 31,66 & 30,33 & 25,95 & 24,74 & 8,76 & 2,66 & 13,17 & 17,64 \\
\hline Inv.P & 4,23 & 4,10 & 3,86 & 3,85 & 6,76 & 6,32 & 5,36 & 4,95 & 1,99 & 0,58 & 2,23 & 2,57 \\
\hline & 0,57 & 0,5 & 0,60 & 0,60 & 25,55 & 26,77 & 23,92 & 22,90 & 0,23 & 30 & 12,47 & 18,43 \\
\hline Trib. & 0,09 & & 0,09 & 0,09 & 2,35 & 1,49 & 1,11 & 0,8 & 0,01 & 0,13 & 0,21 & 0,22 \\
\hline Trib.Trab. & 0,13 & 0,17 & 0,16 & 0,16 & 5,31 & 2,69 & 1,93 & 1,48 & 0,05 & 0,31 & 0,19 & 0,15 \\
\hline Trib.Cap. & 0,06 & 0,07 & 0,07 & 0,07 & 0,66 & 0,31 & 0,22 & 0,17 & 0 & 0,03 & 0,01 & 0,01 \\
\hline Total & 23,88 & 23,34 & 22,17 & 22,12 & 72,29 & 67,91 & 58,49 & 55,13 & 11,04 & 7,01 & 28,28 & 39,02 \\
\hline \multicolumn{13}{|c|}{ Estimação B - Demais Choques } \\
\hline Monet. & 1,75 & 2,56 & 2,74 & 2,75 & 0,24 & 0,44 & 7,77 & 11,59 & 2,67 & 25,73 & 31,09 & 25,08 \\
\hline Tecn. & 1,53 & 3,38 & 3,43 & 3,45 & 6,58 & 3,42 & 3,52 & 3,66 & 7,02 & 2,77 & 3,17 & 3,96 \\
\hline Pref. & 36,70 & 34,22 & 33,05 & 32,99 & 12,22 & 11,34 & 8,32 & 6,30 & 45,08 & 32,19 & 5,17 & 2,98 \\
\hline Inv.Priv. & 29,99 & 27,51 & 27,51 & 27,46 & 1,21 & 1,68 & 1,89 & 2,19 & 29,21 & 26,82 & 5,26 & 3,66 \\
\hline $\begin{array}{l}\text { Markup } \\
\text { Salários }\end{array}$ & 0,60 & 3,72 & 5,44 & 5,59 & 1,84 & 2,39 & 6,92 & 9,45 & 2,56 & 2,76 & 15,71 & 16,64 \\
\hline $\begin{array}{l}\text { Markup } \\
\text { Preços }\end{array}$ & 5,54 & 5,27 & 5,66 & 5,65 & 5,61 & 12,83 & 13,09 & 11,70 & 2,42 & 2,72 & 11,33 & 8,66 \\
\hline Total & 76,11 & 76,66 & 77,83 & 77,89 & 27,70 & 32,10 & 41,51 & 44,89 & 88,96 & 92,99 & 71,73 & 60,98 \\
\hline
\end{tabular}


Fonte: Elaboração própria. Nota: Inf. significa infinito e refere-se à decomposição assintótica.

\subsection{Multiplicadores Fiscais de Gastos e Tributos}

Para sintetizar o efeito quantitativo de um instrumento fiscal sobre a atividade econômica ao longo do tempo, usa-se o multiplicador fiscal cumulativo trazido a valor presente com a taxa de juros do modelo:

$$
\frac{\sum_{i=0}^{n}\left(\prod_{j=0}^{i} R_{t+j}^{-1}\right) \Delta Y_{t+i}}{\sum_{i=0}^{n}\left(\prod_{j=0}^{i} R_{t+j}^{-1}\right) \Delta X_{t+i}}
$$

onde $Y_{t}$ é o produto, $X_{t}$ é o instrumento fiscal e $R_{t}$ é a taxa de juros bruta do modelo. ${ }^{34}$ Os multiplicadores fiscais de gastos e tributos são computados como desvios do estado estacionário, sendo que para as alíquotas tributárias são usados os valores das respectivas arrecadações tributárias.

Consideram-se, para cada gasto e tributo, um choque de magnitude igual à respectiva razão gasto-produto e arrecadação-produto no estado estacionário. O modelo é calibrado com os valores das médias das distribuições a posteriori encontradas nas estimações A e B, dando origem à "calibração A" e "calibração B", respectivamente. Sob as calibrações A e B, a Figura 10 apresenta a dinâmica dos multiplicadores fiscais e a Tabela 5 reporta os valores para alguns períodos.

${ }^{34}$ Como já mencionado, esse multiplicador fiscal tem sido amplamente adotado pela literatura, porque sintetiza o efeito do choque fiscal sobre o produto ao longo do tempo. Para exemplificar, faz-se o cálculo desse multiplicador para $n=2$ a partir das FIRs do modelo log-linearizado, notando que $\Delta$ é o desvio em relação ao estado estacionário, $\hat{Y}_{t}=\frac{Y_{t}-Y}{Y} \Rightarrow \Delta Y_{t}=Y \hat{Y}_{t}, \hat{X}_{t}=\frac{X_{t}-X}{X} \Rightarrow \Delta X_{t}=X \hat{X}_{t}$ e $\hat{R}_{t}=\frac{R_{t}-R}{R} \Rightarrow R_{t}=R\left(1+\hat{R}_{t}\right)$ :

$$
\frac{\sum_{i=0}^{2}\left(\Pi_{j=0}^{i} R_{t+j}^{-1}\right) \Delta Y_{t+i}}{\sum_{i=0}^{2}\left(\Pi_{j=0}^{i} R_{t+j}^{-1}\right) \Delta X_{t+i}}=\frac{\Delta Y_{t}+R_{t+1}^{-1} \Delta Y_{t+1}+R_{t+2}^{-1} R_{t+1}^{-1} \Delta Y_{t+2}}{\Delta X_{t}+R_{t+1}^{-1} \Delta X_{t+1}+R_{t+2}^{-1} R_{t+1}^{-1} \Delta X_{t+2}}=\frac{Y\left(\hat{Y}_{t}+\left[R\left(1+\hat{R}_{t+1}\right)\right]^{-1} \widehat{Y}_{t+1}+\left[R^{2}\left(1+\hat{R}_{t+2}\right)\left(1+\hat{R}_{t+1}\right)\right]^{-1} \widehat{Y}_{t+2}\right)}{X\left(\hat{X}_{t}+\left[R\left(1+\hat{R}_{t+1}\right)\right]^{-1} \hat{X}_{t+1}+\left[R^{2}\left(1+\hat{R}_{t+2}\right)\left(1+\hat{R}_{t+1}\right)\right]^{-1} \hat{X}_{t+2}\right)} .
$$


Figura 10 - Gráficos dos Multiplicadores Fiscais

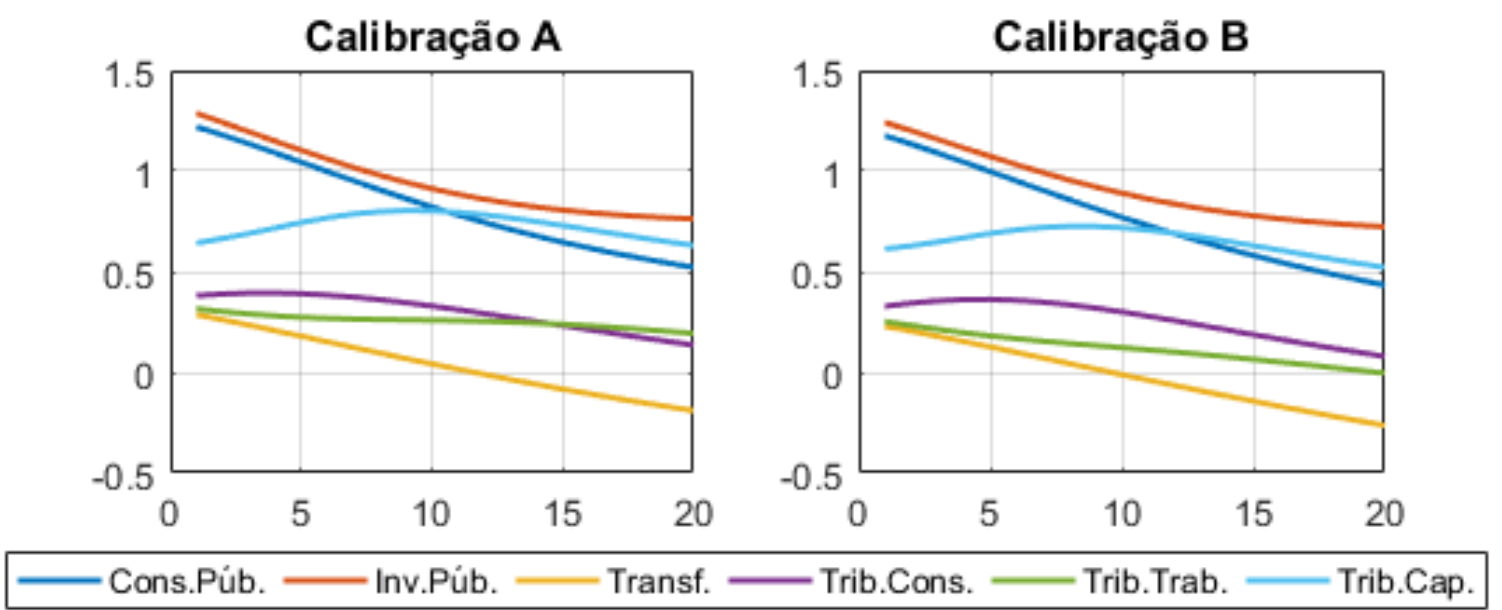

Fonte: Elaboração própria. Nota: O eixo horizontal representa trimestres.

Tabela 5 - Valores dos Multiplicadores Fiscais

\begin{tabular}{|c|c|c|c|c|}
\hline Instrumento Fiscal & 10 Tri. & 4\% Tri. & $12^{\circ}$ Tri. & $20^{\circ}$ Tri. \\
\hline \multicolumn{5}{|c|}{ Calibração A } \\
\hline Cons. Púb. & 1,22 & 1,09 & 0,74 & 0,52 \\
\hline Inv. Púb. & 1,29 & 1,15 & 0,86 & 0,76 \\
\hline Transf. & 0,29 & 0,21 & $-0,01$ & $-0,19$ \\
\hline Trib. Cons. & 0,38 & 0,39 & 0,29 & 0,14 \\
\hline Trib. Trab. & 0,32 & 0,28 & 0,25 & 0,19 \\
\hline Trib. Cap. & 0,64 & 0,72 & 0,78 & 0,63 \\
\hline \multicolumn{5}{|c|}{ Calibração B } \\
\hline Cons. Púb. & 1,18 & 1,04 & 0,69 & 0,43 \\
\hline Inv. Púb. & 1,24 & 1,12 & 0,84 & 0,72 \\
\hline Transf. & 0,23 & 0,15 & $-0,07$ & $-0,26$ \\
\hline Trib. Cons. & 0,33 & 0,36 & 0,26 & 0,08 \\
\hline Trib. Trab. & 0,25 & 0,20 & 0,10 & 0 \\
\hline Trib. Cap. & 0,61 & 0,67 & 0,69 & 0,52 \\
\hline
\end{tabular}

Fonte: Elaboração própria.

A dinâmica dos multiplicadores fiscais de gastos e tributos ao longo do tempo é parecida sob as calibrações $A$ e $B$, embora menos no caso dos tributos, o que se deve às calibrações distintas para os parâmetros das regras fiscais de tributos, que são baseadas nas estimações com as bases de dados $A$ e $B$, em que as alíquotas advêm de estudos diferentes. Os multiplicadores de gastos e do tributo do trabalho decaem 
ininterruptamente, enquanto os multiplicadores do tributo do consumo e do capital se elevam até atingir um pico e caem.

Sob as calibrações A e B, o multiplicador fiscal do investimento público (vermelho) é o maior em todos os horizontes de tempo, assumindo valores maiores que a unidade inicialmente, porém caindo continuamente até ficar abaixo da unidade. Isso revela a importância do investimento público como um instrumento fiscal que impulsiona a atividade econômica diretamente no curto prazo por ser um componente da demanda agregada e indiretamente no longo prazo por elevar a produtividade da economia quando da maturação do capital público.

O segundo maior multiplicador é o do consumo público (azul escuro) até o 11ํㅜ período, depois do qual o multiplicador do tributo do capital (azul claro) passa a superálo até o último período. Essa mudança de relevância do multiplicador ao longo do tempo pode ser explicada por um raciocínio análogo ao do investimento público, já que no curto prazo o consumo público provoca um impacto direto e forte sobre a demanda agregado, mas a redução do tributo do capital estimula acumulação de capital privado, que ao maturar no longo prazo aumenta a produtividade da economia.

Por outro lado, o multiplicador fiscal das transferências (amarelo) é o menor em todos os horizontes. As transferências incentivam apenas temporariamente o consumo das famílias não ricardianas, que compõem uma fração pequena do total das famílias, além de não impactar de modo efetivo e duradouro a produtividade da economia.

Voltando a uma das motivações do trabalho, os resultados dos multiplicadores indicam que, sob a perspectiva da preservação da atividade econômica, principalmente num período de desaceleração, os policymakers deveriam evitar cortes de investimento público e privilegiar cortes de transferências no recente ajuste fiscal. Ressalta-se a ressalva de que, além da preservação da atividade econômica, é importante considerar outros aspectos do contexto brasileiro na escolha da forma do ajuste, como a rigidez orçamentária que faz o investimento público ser o gasto mais discricionário e, portanto, mais sujeito a cortes e o papel relevante das transferências no combate às desigualdades sociais.

Também é interessante olhar para os multiplicadores fiscais no contexto da política fiscal brasileira adotada a partir da eclosão da recente crise econômica internacional. A 
fim de atenuar os impactos recessivos da crise, o governo brasileiro implementou um pacote de estímulos fiscais composto principalmente por desonerações tributárias - do Imposto sobre Produtos Industrializados (IPI), do Imposto sobre Operações de Crédito, Câmbio e Seguros (IOF), da Contribuição sobre Intervenção no Domínio Econômico (Cide), de tributos da cesta básica e da folha salarial -, subsídios e investimentos públicos. ${ }^{35}$

Apesar de nos primeiros anos terem êxito em termos de impedir uma redução maior da atividade econômica, os estímulos fiscais começaram a se mostrar ineficazes, sobretudo a partir de 2010-11. De acordo com uma literatura sobre esse período da política fiscal brasileira (e.g., Afonso e Gobetti (2015), Gobetti e Orair (2015), Gobetti et al. (2016) e Orair (2016)), isso se deveu, em que pesem outros fatores, à mudança da composição relativa dos instrumentos fiscais. No início, a política fiscal foi eficaz porque se concentrou no investimento público, porém sua capacidade de impulsionar a economia diminuiu sensivelmente quando o foco foi sendo redirecionado do investimento público para desonerações tributárias e subsídios. Além disso, o espaço fiscal para fazer uso de políticas expansionistas ficou cada vez menor à medida que a desaceleração econômica diminuiu a arrecadação tributária e os gastos com benefícios sociais e de pessoal mantiveram seu crescimento forte e rígido.

Essa interpretação acerca da perda de eficácia da política fiscal ganha respaldo à luz dos multiplicadores fiscais obtidos pelo presente trabalho. O multiplicador do investimento público é maior que os multiplicadores do tributo do consumo (associado ao $\mathrm{IPI}, \mathrm{IOF}^{36}$, Cide e tributos da cesta básica), do tributo do trabalho (ligado à forma de tributação da folha salarial) e do tributo do capital (vinculado também ao IOF), além de ser também maior que os multiplicadores do consumo público (associado aos gastos de pessoal) e das transferências (ligado aos gastos com benefícios sociais).

\footnotetext{
${ }^{35}$ Os estímulos fiscais para mitigar a desaceleração econômica desse período foram pontuais, o que, portanto, não nulifica as evidências encontradas para um período amplo de que a política fiscal brasileira é, em geral, pró-cíclica nem invalida uma análise desses estímulos com base nos multiplicadores fiscais. ${ }^{36}$ As bases de dados A e B consideram que o IOF é, respectivamente, um tributo do consumo e do capital, em razão da classificação diferenciada de Azevedo e Fasolo (2015) e Almeida et al. (2017).
} 
A título de comparação, as Tabela 6 e Tabela 7 reportam, respectivamente, os multiplicadores fiscais de estudos nacionais e internacionais ${ }^{37}$ que se utilizam de modelos DSGE. Como se pode notar pela divergência dos valores, não existe um consenso na literatura nacional nem na internacional.

Os valores dos multiplicadores fiscais do presente trabalho encontram semelhanças com alguns dos estudos. Em relação à literatura nacional, os multiplicadores do consumo público e investimento público aproximam-se dos de Moura (2015) no $1^{\circ}$ e $12^{\circ}$ trimestres. O multiplicador das transferências assemelha-se com o de Cavalcanti e Vereda (2015), chegando inclusive a atingir valores negativos. Por outro lado, os multiplicadores dos tributos são bastante diferentes dos de Costa Jr. et al. (2017), que é o único estudo nacional com o qual se pode comparar.

Tabela 6 - Valores dos Multiplicadores Fiscais de Estudos Nacionais

\begin{tabular}{|c|c|c|c|c|}
\hline Instrumento Fiscal & $1^{\circ}$ Tri. & 4o Tri. & $12^{\circ}$ Tri. & 20ํㅜㄱi. \\
\hline \multicolumn{5}{|c|}{ Barro e Lima (2013) } \\
\hline Cons. Púb. & & 0,44 e 0,29 & 0,45 e 0,30 & 0,46 e 0,31 \\
\hline \multicolumn{5}{|c|}{ Cavalcanti e Vereda (2015) } \\
\hline Inv. Púb. & & $-0,14$ e 0,55 & $-0,30$ e 0,40 & 0,04 e 0,63 \\
\hline Transf. & & 0,25 e 0,38 & $-0,12$ e 0,03 & $-0,21$ e $-0,06$ \\
\hline \multicolumn{5}{|c|}{ Moura (2015) } \\
\hline Cons. Púb. & 1,28 & 0,93 & 0,74 & 0,69 \\
\hline Inv. Púb. & 1,35 & 1,05 & 1,08 & 1,28 \\
\hline \multicolumn{5}{|c|}{ Costa Jr. et al. (2017) } \\
\hline Cons. Púb. & 0,06 & 0,04 & 0,04 & 0,04 \\
\hline Inv. Púb. & 0 & 0 & 0 & 0 \\
\hline Trib. Cons. & 0,09 & 0,12 & 0,09 & 0,10 \\
\hline Trib. Trab. & 0,01 & 0,01 & 0,01 & 0,01 \\
\hline Trib. Cap. & 0 & 0 & 0 & 0 \\
\hline
\end{tabular}

Já em relação à literatura internacional, o multiplicador do consumo público comporta-se como o de Zubairy (2014) inicialmente, porém diminui mais aceleradamente.

37 A escolha dos estudos internacionais guia-se pela relevância, semelhança do arcabouço dos instrumentos fiscais e disponibilidade dos valores dos multiplicadores reportados. 
O multiplicador do investimento público passa a aproximar-se do de Bhattarai e Trzeciakiewicz (2017) em horizontes distantes, enquanto o multiplicador das transferências parece com que o de Bhattarai e Trzeciakiewicz (2017), mas cai acentuadamente no último horizonte. O multiplicador do tributo do consumo não encontra paralelo. O multiplicador do tributo do trabalho sob a calibração $A$ assemelha-se ao de Forni et al. (2009) e Bhattarai e Trzeciakiewicz (2017), mas o mesmo multiplicador sob a calibração $B$ não encontra um estudo análogo. O multiplicador do tributo do capital sob a calibração A não se aproxima de nenhum estudo, porém o mesmo multiplicador sob a calibração B aproxima-se do de Bhattarai e Trzeciakiewicz (2017) nos horizontes longos.

Tabela 7 - Valores dos Multiplicadores Fiscais de Estudos Internacionais

\begin{tabular}{|c|c|c|c|c|}
\hline Instrumento Fiscal & 1으. Tri. & $4 \div$ Tri. & $12^{\circ}$ Tri. & $20^{\circ}$ Tri. \\
\hline \multicolumn{5}{|c|}{ Leeper et al. (2010) - EUA } \\
\hline Cons. Púb. & 0,64 e 0,59 & 0,43 e 0,32 & 0,33 e 0,14 & 0,20 e $-0,21$ \\
\hline Transf. & $-0,02$ e $-0,07$ & $-0,16$ e $-0,19$ & $-0,28$ e $-0,33$ & $-0,46$ e $-0,64$ \\
\hline Trib. Trab. & 0,19 e 0,14 & 0,19 e 0,12 & 0,19 e 0,04 & 0,19 e $-0,22$ \\
\hline Trib. Cap. & 0,18 e 0,14 & 0,26 e 0,20 & 0,33 e 0,18 & 0,50 e $-0,42$ \\
\hline \multicolumn{5}{|c|}{ Zubairy (2014) - EUA } \\
\hline Cons. Púb. & 1,07 & 1,06 & 0,90 & 0,72 \\
\hline Trib. Trab. & 0,13 & 0,32 & 0,68 & 0,85 \\
\hline Trib. Cap. & 0,34 & 0,43 & 0,52 & 0,46 \\
\hline \multicolumn{5}{|c|}{ Forni et al. (2009) - União Europeia } \\
\hline Cons. Púb. & 1,21 & 0,85 & 0,35 & \\
\hline Transf. & 0,42 & 0,31 & 0,12 & \\
\hline Trib. Cons. & 0,53 & 0,60 & 0,51 & \\
\hline Trib. Trab. & 0,39 & 0,31 & 0,23 & \\
\hline Trib. Cap. & 0,33 & 0,35 & 0,52 & \\
\hline \multicolumn{5}{|c|}{ Bhattarai e Trzeciakiewicz (2017) - Reino Unido } \\
\hline Cons. Púb. & 0,97 & 0,76 & 0,44 & 0,25 \\
\hline Inv. Púb. & 1,08 & 0,96 & 0,78 & 0,72 \\
\hline Transf. & 0,30 & 0,23 & 0,05 & $-0,09$ \\
\hline Trib. Cons. & 0,49 & 0,56 & 0,46 & 0,30 \\
\hline Trib. Trab. & 0,35 & 0,31 & 0,24 & 0,17 \\
\hline Trib. Cap. & 0,44 & 0,53 & 0,60 & 0,52 \\
\hline
\end{tabular}

Fonte: Elaboração própria. Nota: Os valores de Leeper et al. (2010) são referentes aos $1^{\circ}, 5^{\circ}, 10^{\circ}$ e $25^{\circ}$ trimestres e são obtidos quando todos os instrumentos fiscais e quando só os tributos do trabalho e capital reagem à dívida pública. Alguns valores estão em branco por falta de informação do estudo. 


\subsection{Exercícios de Sensibilidade dos Multiplicadores Fiscais}

A Figura 11 mostra a dinâmica dos multiplicadores fiscais quando o parâmetro da elasticidade do produto em relação ao capital público $\left(\alpha_{G}\right)$ assume os valores de 0 (azul), 0,02 (preto) e 0,04 (vermelho). À medida que $\alpha_{G}$ aumenta, o estoque de capital público tem um efeito positivo maior sobre a produtividade marginal dos fatores privados (trabalho e capital privado).

Os gráficos mostram que $\alpha_{G}$ só afeta de maneira relevante o multiplicador fiscal do investimento público e sua relação é positiva e crescente ao longo do tempo, ou seja, não só um aumento em $\alpha_{G}$ eleva o multiplicador do investimento público, como também essa elevação é tanto maior quanto mais longo é o horizonte de tempo. Esse resultado faz sentido já que o efeito do investimento público sobre a produtividade da economia leva um certo tempo para maturar e aumentar a acumulação do estoque de capital público, que é disponibilizado para as firmas.

É interessante notar que, quando $\alpha_{G}=0,02$, obtêm-se exatamente os multiplicadores encontrados sob a calibração $A$ do presente trabalho, que segue Moura (2015) ao adotar $\alpha_{G}=0,02$, que é uma calibração "conservadora" escolhida para mostrar que, mesmo para um valor pequeno, o multiplicador do investimento público é relevante. Como os multiplicadores do investimento público para o $20^{\circ}$ trimestre podem ultrapassar o valor da unidade para calibrações de $\alpha_{G}$ um pouco maiores que 0,02 (ver o gráfico para 0,04 na Figura 11), é plausível argumentar que o multiplicador do investimento público pode assumir valores maiores que a unidade na economia brasileira mesmo para períodos longos, o que dá respaldo ao mesmo multiplicador encontrado por Moura (2015). 
Figura 11 - Sensibilidade à Elasticidade do Produto em relação ao Capital Público
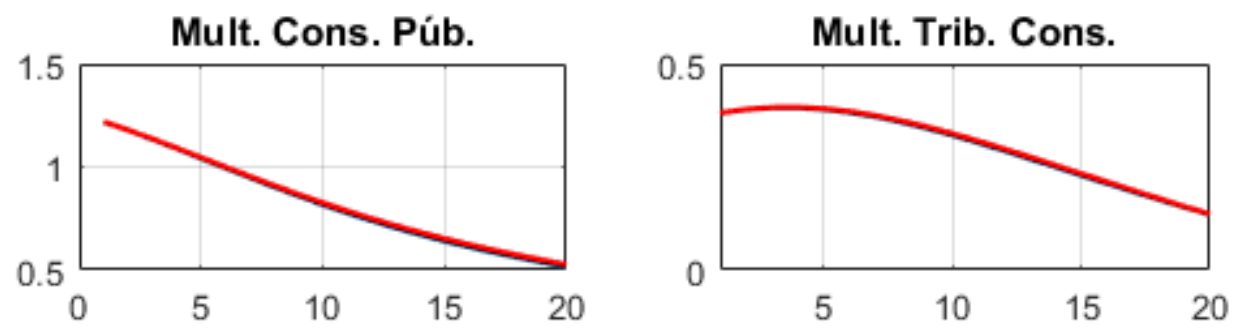

Mult. Inv. Púb.

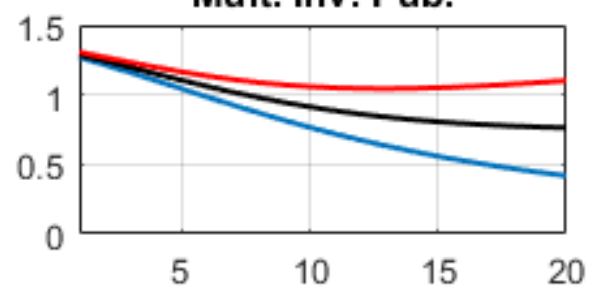

Mult. Trib. Trab.

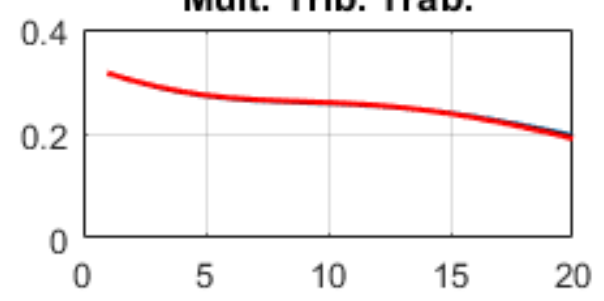

Mult. Transf.

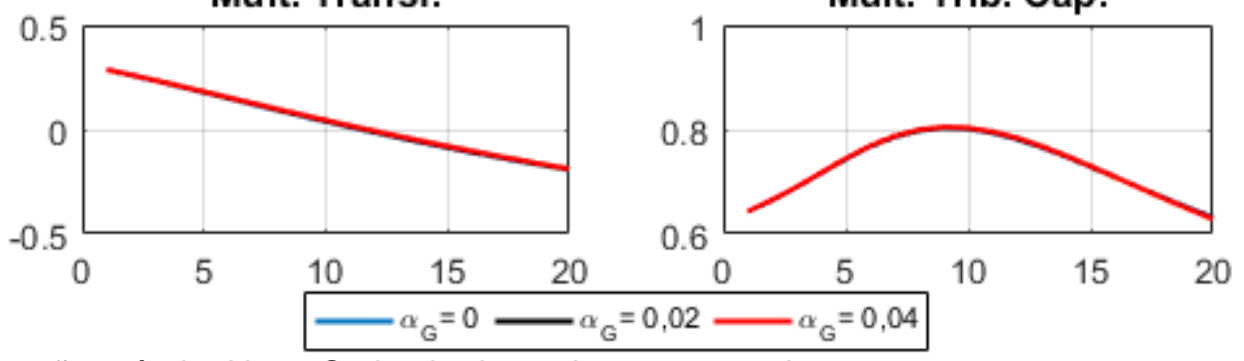

Fonte: Elaboração própria. Nota: $\mathrm{O}$ eixo horizontal representa trimestres.

A Figura 12 apresenta o comportamento dos multiplicadores fiscais quando o parâmetro da fração de famílias não ricardianas $(v)$ assume os valores de 0 (azul), 0,25 (preto) e 0,50 (vermelho). Quanto maior é o valor de $v$, tanto maior é a fração de famílias que não têm acesso aos mercados de ativos e só consomem sua renda corrente líquida de tributos advinda da venda de trabalho e transferências públicas e, logo, tanto menor é a fração de famílias que têm acesso aos mercados de ativos e realocam seus recursos intertemporalmente para suavizar seu consumo ao longo do tempo quando da ocorrência de políticas fiscais, tendendo a atenuar seus efeitos. Esse parâmetro é importante para o entendimento do consumo privado agregado, sendo tradicionalmente um dos principais responsáveis por permitir aos modelos DSGE gerarem o efeito crowding in do gasto público sobre o consumo privado agregado, devido ao fato de o aumento do consumo das famílias não ricardianas suplantar a queda do consumo das famílias ricardianas após um choque do gasto público. 
Com exceção do caso do tributo do capital, um aumento de $v$ provoca uma elevação dos multiplicadores. Os multiplicadores dos gastos públicos e dos tributos do consumo e trabalho são maiores porque um valor maior de $v$ implica que o efeito do choque sobre o consumo das famílias não ricardianas é maior, uma vez que é maior a parcela das famílias que elevam seu consumo quando da elevação da renda líquida, proporcionada principalmente pelo aumento da renda do trabalho no caso dos choques do consumo público, investimento público e tributo do trabalho, pelo aumento das transferências no caso do choque das transferências e pela queda dos preços dos bens de consumo no caso do choque do tributo do consumo. Só o multiplicador do tributo do capital tem uma relação diferente, ou seja, seu valor é menor quando $v$ aumenta. Isso se deve ao fato de que, num cenário de $v$ alto, é menor a fração das famílias que detêm o capital privado e, por isso, é menor o impacto da queda do tributo do capital privado sobre o investimento e o empréstimo do capital privado, que se reflete num produto menor.

Figura 12 - Sensibilidade à Fração de Famílias não Ricardianas

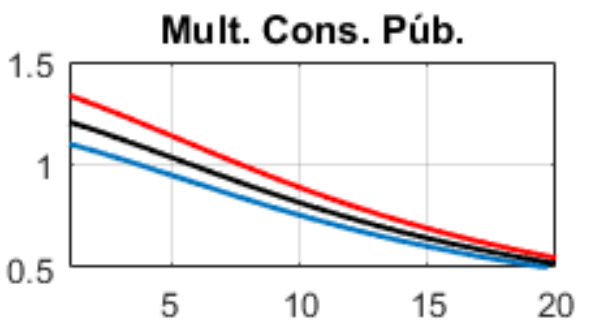

Mult. Trib. Cons.

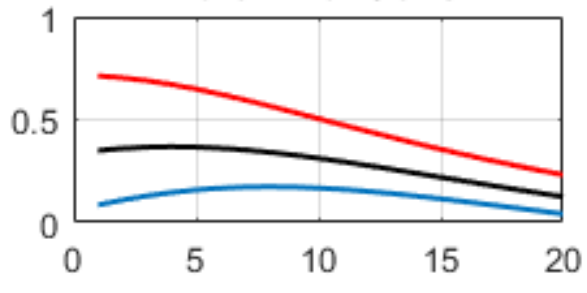

Mult. Inv. Púb.

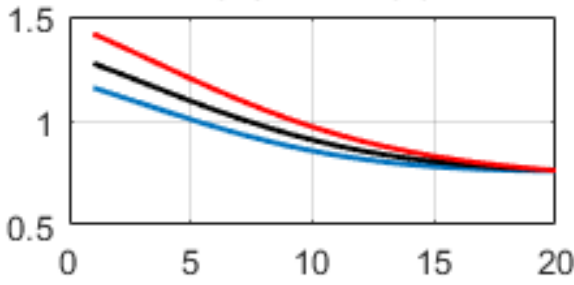

Mult. Trib. Trab.

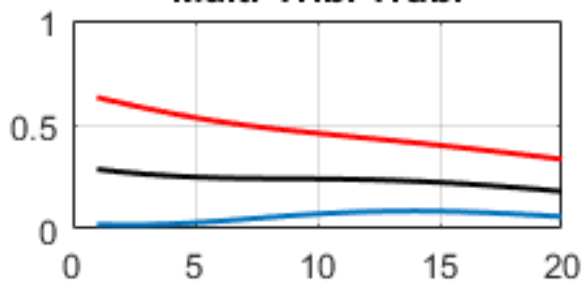

Mult. Transf.

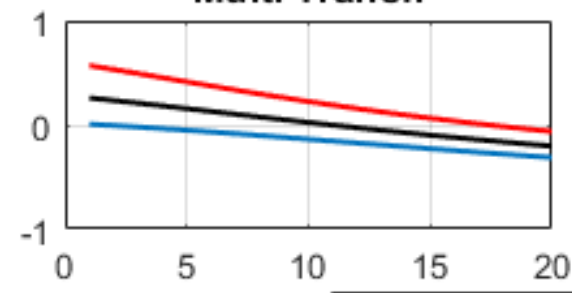

Mult. Trib. Cap.

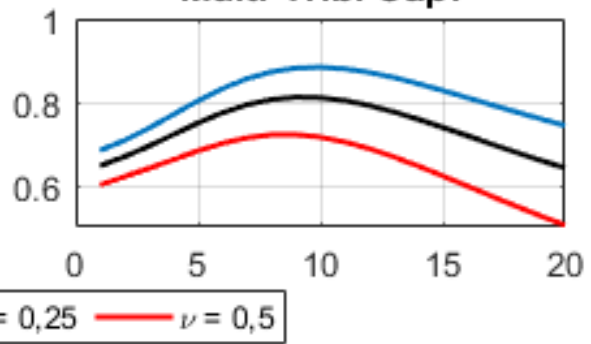

Fonte: Elaboração própria. Nota: O eixo horizontal representa trimestres. 
A Figura 13 mostra a dinâmica dos multiplicadores fiscais quando o parâmetro de suavização da taxa de juros nominal da regra monetária $(\rho)$ assume os valores de 0,5 (azul), 0,7 (preto) e 0,9 (vermelho). Um valor maior de $\rho$ significa que a política monetária é mais acomodatícia, ou seja, a autoridade monetária modifica mais suavemente a taxa de juros em resposta a mudanças da inflação e do produto.

Os gráficos dos multiplicadores revelam que apenas o multiplicador do tributo do capital é afetado de modo significativo, aumentando para valores altos de $\rho$ nos períodos mais distantes. Como o choque negativo do tributo do capital gera uma queda da inflação, uma autoridade monetária que derruba lentamente a taxa de juros, por seguir uma regra monetária com um $\rho$ alto, provoca um aumento do produto que se materializa com mais vigor no futuro.

Figura 13 - Sensibilidade à Suavização da Taxa de Juros da Regra Monetária

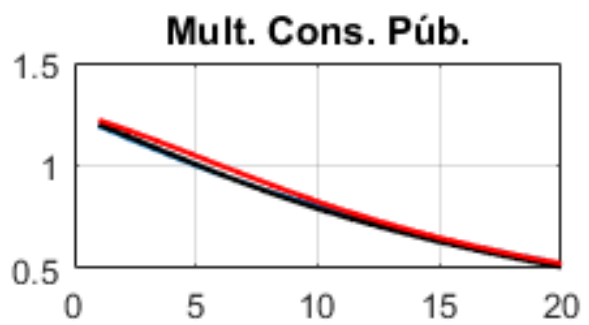

Mult. Inv. Púb.

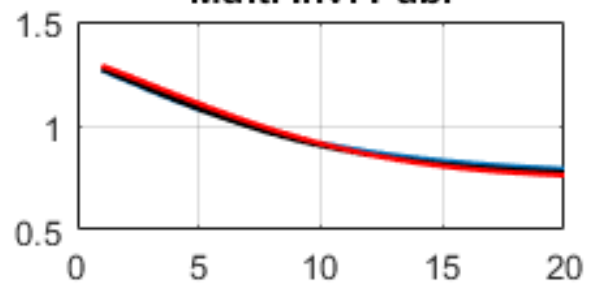

Mult. Transf.

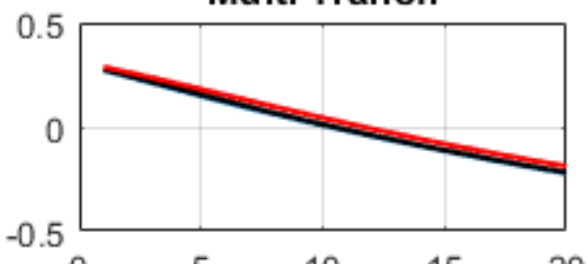

Mult. Trib. Cons.

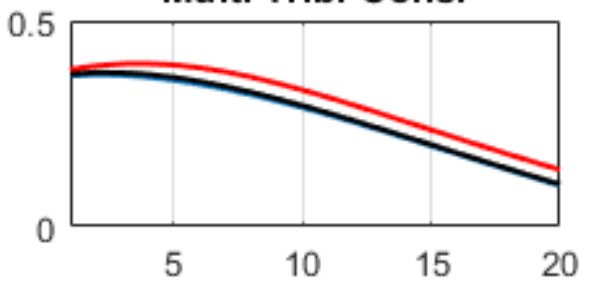

Mult. Trib. Trab.

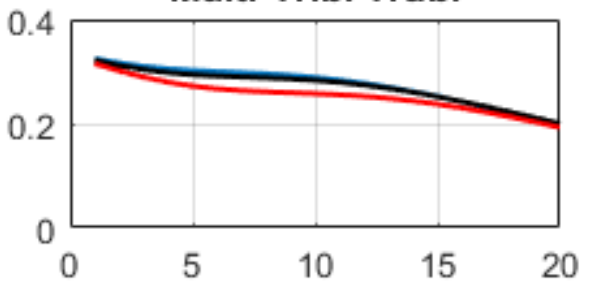

Mult. Trib. Cap.

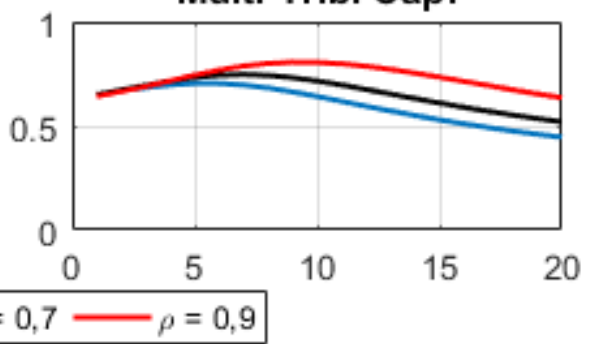

Fonte: Elaboração própria. Nota: $\mathrm{O}$ eixo horizontal representa trimestres.

A Figura 14 apresenta o comportamento dos multiplicadores fiscais quando o parâmetro da elasticidade do custo de ajustamento da utilização do capital privado $(\kappa)$ 
assume os valores de 0,3 (azul), 0,5 (preto) e 0,7 (vermelho). Quanto maior o valor de $\kappa$, tanto mais custoso é provocar mudanças da utilização do capital privado e, logo, tanto menor é a variação da utilização do capital em resposta a variações do retorno do capital líquido do tributo do capital.

Apenas 0 gráfico do multiplicador do tributo do capital modifica-se significativamente com a mudança de $\kappa$, sendo que o multiplicador diminui à medida que $\kappa$ cresce. Isso acontece porque um valor maior de $\kappa$ significa que as famílias ricardianas que desejam aumentar a utilização do estoque de capital privado após um choque gerar uma queda do tributo do capital deparam-se com custos maiores que as desincentivam a alugar capital privado para as firmas, o que se reflete num produto menor.

Figura 14 - Sensibilidade à Elasticidade do Custo de Ajustamento da Utilização do Capital Privado
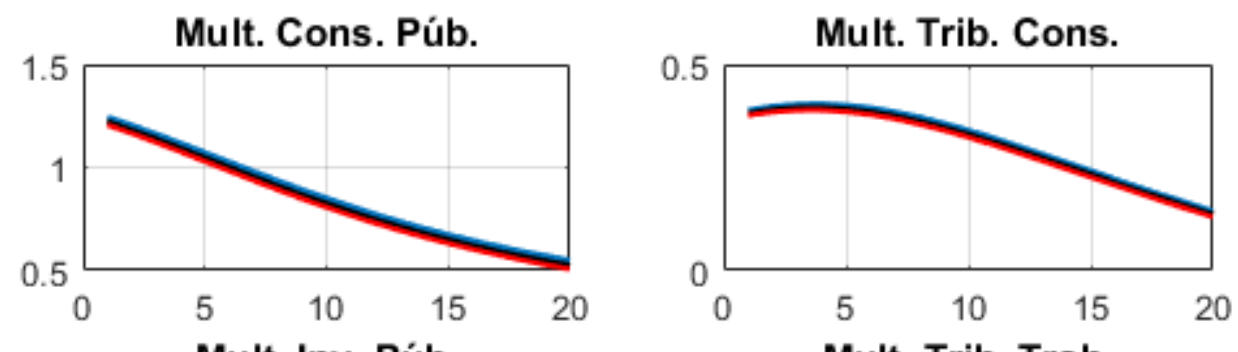

Mult. Inv. Púb.

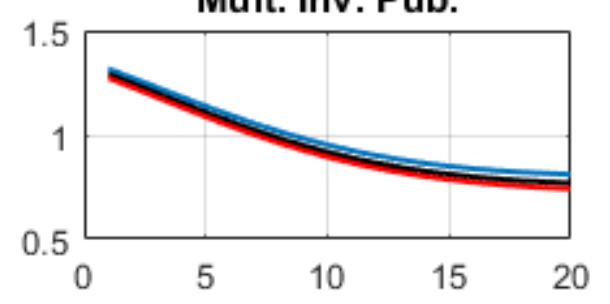

Mult. Trib. Trab.

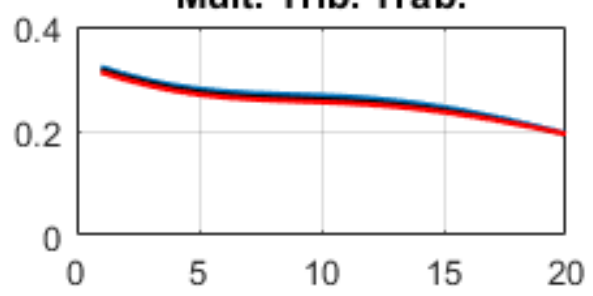

Mult. Transf.

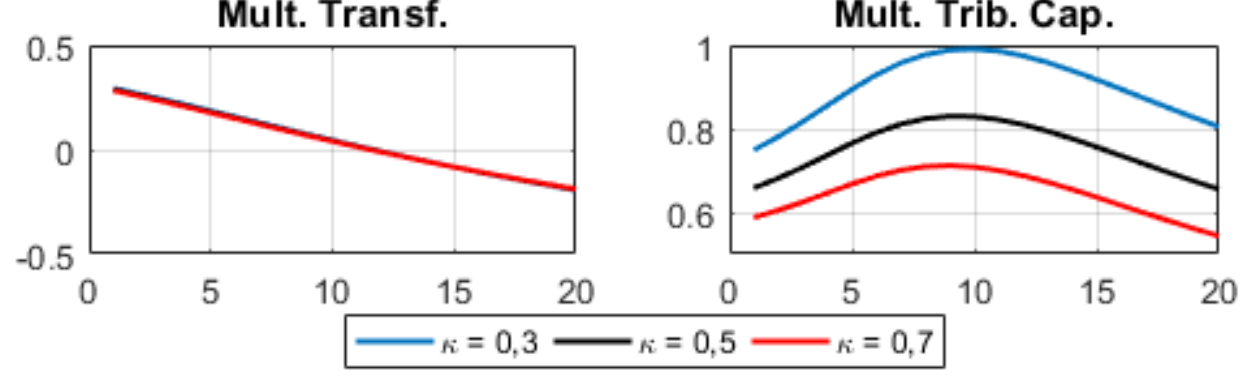

Fonte: elaboração própria. Nota: $\mathrm{O}$ eixo horizontal representa trimestres.

Uma questão ainda não abordada pela literatura é como os multiplicadores fiscais são afetados pelo comportamento (anticíclico, acíclico ou pró-cíclico) da política fiscal. A 
Figura 15 apresenta a dinâmica dos multiplicadores quando todos os parâmetros de resposta ao produto $\left(\phi_{Y, G}, \phi_{Y, I_{G}}, \phi_{Y, T}, \phi_{Y, \tau^{c}}, \phi_{Y, \tau^{l}}, \phi_{Y, \tau^{k}}\right)$ assumem os valores de -0,3 (azul), 0 (preto) e 0,3 (vermelho), ou seja, todos os parâmetros fiscais relacionados ao produto assumem os mesmos valores e variam de modo a refletir os comportamentos pró-cíclico (azul), acíclico (preto) e anticíclico (vermelho), respectivamente.

Os gráficos mostram que os multiplicadores são maiores quando a política fiscal é pró-cíclica e menores quando ela é anticíclica, sobretudo para horizontes curtos de tempo. Esse resultado ocorre porque, quando a política fiscal é pró-cíclica, o efeito positivo sobre o produto de um choque de um certo instrumento fiscal é magnificado pela reação dos demais instrumentos, que tendem a também aumentar o produto. Destarte, é importante analisar se o comportamento da política fiscal é pró-cíclico, acíclico ou anticíclico quando se estudam multiplicadores fiscais. Os estudos de economias caracterizadas por políticas fiscais pró-cíclicas - como os países em desenvolvimento, inclusive o Brasil - que não levam esse comportamento fiscal em consideração tendem a obter multiplicadores fiscais subestimados. 
Figura 15 - Sensibilidade ao Comportamento da Política Fiscal

Mult. Cons. Púb.

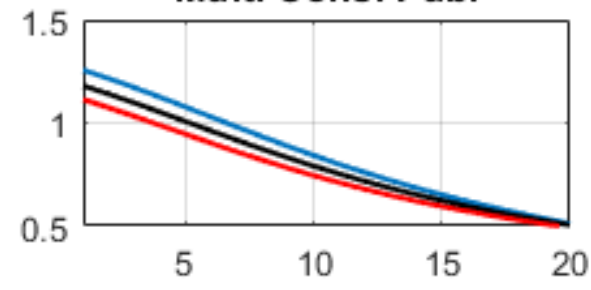

Mult. Inv. Púb.

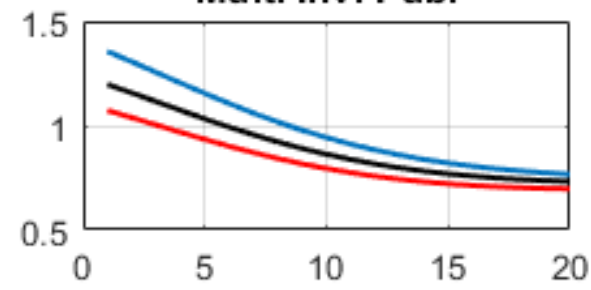

Mult. Transf.

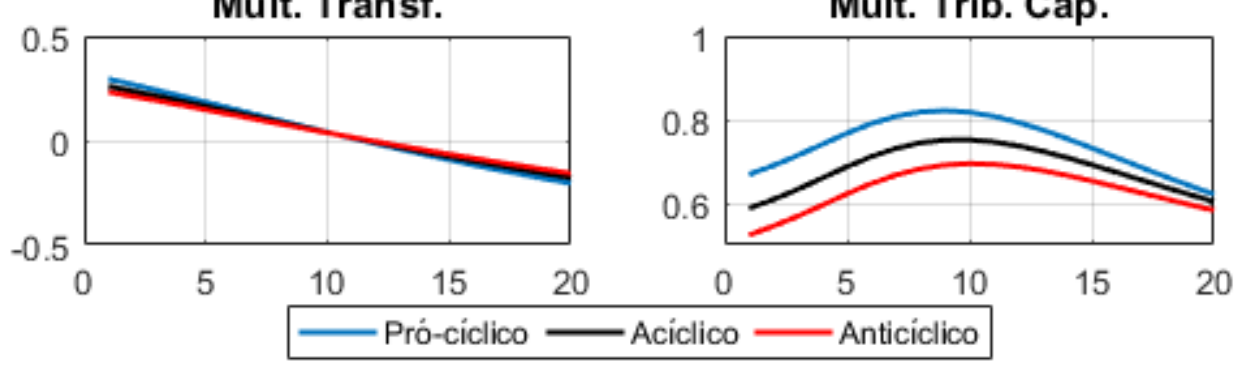

Mult. Trib. Cons.

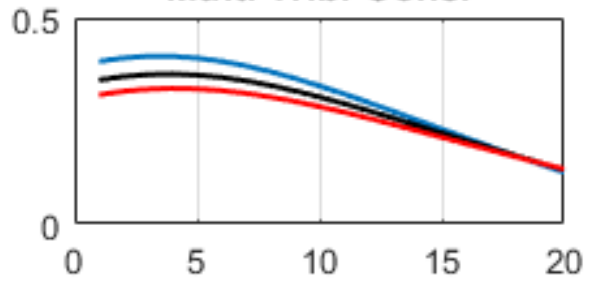

Mult. Trib. Trab.

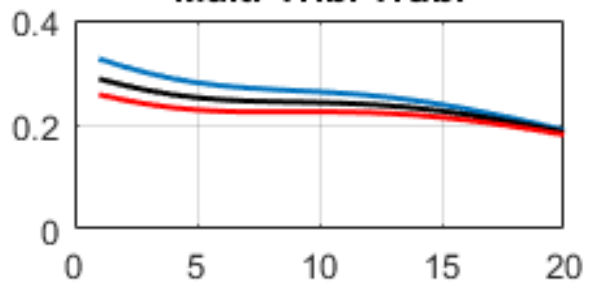

0

Mult. Trib. Cap.

Fonte: Elaboração própria. Nota: Todos os parâmetros fiscais de resposta ao produto $\left(\phi_{Y, G}, \phi_{Y, I_{G}}, \phi_{Y, T}\right.$, $\left.\phi_{Y, \tau^{c}}, \phi_{Y, \tau^{l}}, \phi_{Y, \tau^{k}}\right)$ assumem os valores de -0,3 (azul), 0 (preto) e 0,3 (vermelho). O eixo horizontal representa trimestres. 


\section{Conclusão}

Dois são os principais objetivos relativos à política fiscal brasileira que guiaram o presente trabalho. Em primeiro plano, estudar o impacto da política fiscal brasileira sobre a atividade econômica via multiplicadores fiscais desagregados, de forma a munir os policymakers com informações mais precisas a respeito de quais instrumentos fiscais são mais eficazes e dos efeitos sobre o produto de suas escolhas de corte de gastos e/ou aumento de tributos necessários ao recente ajuste fiscal. Em segundo plano, verificar se o comportamento da política fiscal é anticíclico, acíclico ou pró-cíclico, tendo em consideração que em tese uma política fiscal anticíclica é preferível, pois ajuda na estabilização do ciclo econômico, embora a literatura encontre um comportamento prócíclico em países em desenvolvimento, inclusive no Brasil.

Para atingir tais objetivos, o trabalho estimou com técnicas bayesianas um modelo DSGE com um rico arcabouço de instrumentos fiscais de gastos e tributos desagregados em consumo público, investimento público, transferências e alíquotas tributárias sobre o consumo, a renda do trabalho e a renda do capital. Foram usadas, em particular, duas bases distintas de alíquotas efetivas, que são os dados tributários que mais se aproximam das alíquotas tributárias do modelo e que ainda nenhuma outra pesquisa fez uso, o que permitiu realizar duas estimações como exercício de robustez.

Os multiplicadores fiscais obtidos mostram que o impacto dinâmico da política fiscal sobre o produto varia de acordo com o instrumento fiscal. Em ambas as estimações e em todos os horizontes de tempo, o multiplicador do investimento público é o maior, enquanto o das transferências é o menor. Isso ocorre sobretudo porque o investimento público impulsiona a atividade econômica inicialmente ao expandir a demanda agregada e também posteriormente quando a maturação do capital público aumenta a produtividade geral da economia, ao passo que as transferências têm apenas um impacto positivo, pequeno e não duradouro sobre o consumo agregado.

Esses resultados dos multiplicadores indicam que, sob a perspectiva da preservação da atividade econômica, sobretudo num período de desaceleração, os policymakers deveriam evitar cortes de investimento público e privilegiar cortes de transferências no recente ajuste fiscal. Porém, é preciso considerar outros aspectos do contexto brasileiro na escolha da forma do ajuste que vão além da preservação da 
atividade econômica, como a rigidez orçamentária que faz o investimento público ser o gasto mais discricionário e, logo, mais sujeito a cortes e o papel relevante das transferências na diminuição das desigualdades sociais. Ademais, esses resultados estão em consonância com uma literatura que advoga que a política fiscal brasileira em 2010-11 perdeu eficácia em razão da mudança da composição relativa dos instrumentos fiscais, em que o investimento público foi perdendo espaço para desonerações tributárias e subsídios, além dos gastos sociais e de pessoal.

Já as estimações das regras fiscais evidenciam que a política fiscal é, em geral, pró-cíclica, amplificando o ciclo econômico. Do lado dos gastos, as duas estimações evidenciam que o consumo público e o investimento público são pró-cíclicos, indo na mesma direção da literatura, e que as transferências são levemente anticíclicas ou acíclicas, o que pode se dever, no primeiro caso, aos componentes de abono e segurodesemprego, mais associados com o papel de estabilizadores automáticos, e, no segundo caso, à rigidez dos benefícios previdenciários e assistenciais, que compõem uma parcela significativa das transferências e que têm crescido independentemente das condições da atividade econômica. Já do lado dos tributos, as duas estimações indicam que as alíquotas tributárias sobre o consumo e a renda do capital são pró-cíclicas, porém uma estimação indica que a alíquota sobre a renda do trabalho é pró-cíclica, ao passo que a outra estimação aponta que ela é levemente anticíclica ou acíclica.

Além disso, cabe destacar outros resultados interessantes. As estimações das regras fiscais também mostram que, em termos de contribuição para a estabilização da dívida pública, o investimento público é o gasto mais cortado, enquanto as transferências são o gasto mais poupado. Isso pode ser explicado pelo fato de, no Brasil, o investimento público ser a despesa pública mais discricionária e as transferências serem as mais rígidas, sobretudo a parcela previdenciária e assistencial. Ainda, uma estimação indica que a alíquota sobre o consumo é a mais acionada para ajudar a controlar a dívida pública, o que parece fazer sentido quando se lembra que uma parte relevante da arrecadação brasileira depende de impostos sobre o consumo, embora a outra estimação aponte que a contribuição das alíquotas é mais equânime. Tendo em vista que a resposta do tributo do trabalho ao produto e as respostas dos tributos à dívida pública são 
diferentes nas duas estimações, os resultados dos parâmetros das regras fiscais de tributos tendem a ser sensíveis aos dados de alíquotas efetivas.

O modelo consegue capturar o comportamento, em geral, pró-cíclico da política fiscal brasileira e permite compreender o mecanismo de reação da economia frente aos choques fiscais. Devido à pró-ciclicidade da política fiscal, quando um dos instrumentos fiscais sofre um choque que impulsiona a economia, o efeito é magnificado pelos demais instrumentos inicialmente. No entanto, à medida que essa política fiscal pró-cíclica expansionista eleva a dívida pública, a autoridade fiscal é induzida a praticar um arrocho fiscal, composto por diminuição de gastos e aumento de tributos, por um período considerável devido à morosidade da estabilização da dívida pública, afetando negativamente o produto.

Ademais, o modelo revela que os choques fiscais são responsáveis por uma parcela relevante da explicação da variação do crescimento do produto, razão superávit primário-produto e razão dívida pública-produto, o que ressalta a importância do estudo da política fiscal para a compreensão das flutuações da economia brasileira e dos principais indicadores fiscais.

Dentre os exercícios de sensibilidade dos multiplicadores fiscais, dois merecem destaque. O multiplicador do investimento público não atinge valores maiores que a unidade tal como acontece com esse mesmo multiplicador calculado por Moura (2015) adotando uma elasticidade do produto em relação ao capital público pequena, porém passa a assumir valores maiores que a unidade quando se adota um valor um pouco maior para esse parâmetro. Devido à falta de consenso na literatura sobre o valor desse parâmetro na economia brasileira, não se descarta a possibilidade de o multiplicador do investimento público ser maior que a unidade. O segundo exercício a ser destacado aborda a questão ainda não explorada na literatura de como o comportamento (anticíclico, acíclico ou pró-cíclico) da política fiscal afeta os multiplicadores, ilustrando que os multiplicadores são maiores quando a política fiscal é pró-cíclica e menores quando ela é anticíclica, o que significa que os estudos de economias caracterizadas por políticas fiscais pró-cíclicas - como os países em desenvolvimento, inclusive o Brasil que não levam esse comportamento fiscal em consideração tendem a obter multiplicadores fiscais subestimados. 
Por fim, apesar de o modelo DSGE adotado dar passos importantes no aspecto fiscal, principalmente na desagregação dos instrumentos fiscais de gastos e tributos e na possibilidade de a política fiscal ser anticíclica, acíclica ou pró-cíclica, algumas possíveis extensões que tendem a afetar os multiplicadores fiscais merecem ser observadas, como incluir um setor externo, a possibilidade de mudanças de regime (expansão ou contração) e um limite fiscal de tributação que os agentes aceitam, além de usar séries de alíquotas efetivas mais extensas. Uma economia mais aberta com uma alta propensão a importar e com um regime de câmbio mais flexível tem multiplicadores fiscais menores devido aos vazamentos de demanda e aos movimentos cambiais que atenuam o efeito das políticas fiscais discricionárias domésticas. Esse aspecto não parece ser tão relevante para economias relativamente fechadas como é o caso da brasileira. Os multiplicadores fiscais são maiores em períodos de contração econômica que em períodos de expansão, uma vez que no primeiro caso há maior capacidade ociosa, que potencializa a política fiscal ao diminuir o efeito crowding out. Um país com uma dívida pública alta e em que os agentes não admitem mais aumentos na tributação para estabilizar a dívida enfrenta incertezas que podem colocar em xeque a capacidade de a política fiscal ser usada para impulsionar a atividade econômica. 


\section{Referências}

AFONSO, J. R. R.; GOBETTI, S. W. Impactos das Reformas Tributárias e dos Gastos Públicos sobre o Cresciento e os Investimentos: $O$ Caso do Brasil. Série Macroeconomia do Desenvolvimento $\mathbf{N}^{\circ} 167$, p. 42, 2015.

ALESINA, A.; CAMPANTE, F. R.; TABELLINI, G. Why Is Fiscal Policy Often Procyclical? Journal of the European Economic Association, v. 6, n. 5, p. 1006-1036, 2008.

ALMEIDA, V. et al. Alíquotas tributárias efetivas médias na economia brasileira: Uma abordagem macroeconômica. Revista Brasileira de Economia, v. 71, n. 2, p. 153-175, 2017.

AZEVEDO, C. F.; FASOLO, A. M. Alíquotas Efetivas dos Impostos sobre o Consumo e a Renda dos Fatores: uma estimação em frequência trimestral para o Brasil. Concurso de Monografia em Finanças Públicas - $3^{\circ}$ Lugar, 2015.

BARROS, J. C. DE M.; LIMA, E. C. R. Estímulos Fiscais e a Interação entre as Políticas Monetária e Fiscal no Brasil. 41 Encontro Nacional de Economia, 2013.

BATINI, N. et al. Fiscal Multipliers: Size, Determinants, and Use in Macroeconomic Projections. Technical Notes and Manuals - Fiscal Affairs Department - International Monetary Fund, p. 1-30, 2014.

BENIGNO, P.; WOODFORD, M. Optimal monetary and fiscal policy: A linear-quadratic approach. National Bureau of Economic Research Working Paper 9905, v. 18, p. $271-$ 364, 2003.

BERNSTEIN, J.; ROMER, C. The Job Impact of the American Recovery and Reinvestment Plan. [s.l: s.n.]. Disponível em: <https://www.economy.com/markzandi/documents/The_Job_Impact_of_the_American_Recovery_and_Reinvestment_Pla n.pdf>.

BHATTARAI, K.; TRZECIAKIEWICZ, D. Macroeconomic impacts of fiscal policy shocks in the UK: A DSGE analysis. Economic Modelling, v. 61, n. October, p. 321-338, 2017.

CALVO, G. Staggered Prices in a Utility Maximizing Framework. Journal of Monetary Economics, v. 12, n. 1978, p. 383-398, 1983.

CAMPBELL, J. Y.; MANKIW, N. G. Consumption, Income and Interest Rates: Reinterpreting the Time Series Evidence. In: BLANCHARD, O. J.; FISCHER, S. (Eds.). . NBER Macroeconomics Annual 1989. [s.I.] MIT Press, 1989. v. 4p. 185-246.

CASTRO, M. R. DE et al. SAMBA: Stochastic Analytical Model with a Bayesian Approach. Banco Central do Brasil Working Paper Series n.239, p. 1-138, 2011.

CAVALCANTI, M. A. F. H.; VEREDA, L. Propriedades Dinâmicas de um Modelo DSGE com Parametrizações Alternativas para o Brasil. Texto para Discussão IPEA n. 1588, 2011.

CAVALCANTI, M. A. F. H.; VEREDA, L. Fiscal Policy Multipliers in a DSGE Model for Brazil. Brazilian Review of Econometrics, v. 35, n. 2, p. 197, 2015.

CHEN, W. Master Thesis: Fiscal Policy in An Estimated Dynamic Stochastic 
General Equilibrium Model. [s.I.] Humboldt University of Berlin, 2007.

CHRISTIANO, L.; EICHENBAUM, M.; REBELO, S. When Is the Government Spending Multiplier Large? Journal of Political Economy, v. 119, n. 1, p. 78-121, 2011.

CHRISTIANO, L. J.; EICHENBAUM, M.; EVANS, C. L. Nominal Rigidities and the Dynamic Effects of a Shock to Monetary Policy. Journal of Political Economy, v. 113, n. 1, p. 1-45, fev. 2005.

COGAN, J. F. et al. New Keynesian versus Old Keynesian Government Spending Multipliers. European Central Bank Working Paper Series n.1090, p. 1-27, 2009.

COSTA JÚNIOR, C. J.; CINTADO, A. C. G.; SAMPAIO, A. V. Post-2008 Brazilian fiscal policy : an interpretation through the analysis of fiscal multipliers. Estudos Econômicos, v. 47, n. 1, p. 93-124, 2017.

DRAUTZBURG, T.; UHLIG, H. Fiscal stimulus and distortionary taxation. Review of Economic Dynamics, v. 18, n. 4, p. 894-920, 2015.

ERCEG, C. J.; GUERRIERI, L.; GUST, C. Expansionary fiscal shocks and the US trade deficit. International Finance, v. 8, n. 3, p. 363-397, 2005.

ERCEG, C. J.; HENDERSON, D. W.; LEVIN, A. T. Optimal Monetary Policy With Staggered Wage and Price Contracts. Journal of monetary Economics, v. 46, n. 2, p. 281-313, 2000.

FORNI, L.; MONTEFORTE, L.; SESSA, L. The general equilibrium effects of fiscal policy: Estimates for the Euro area. Journal of Public Economics, v. 93, n. 3-4, p. 559-585, 2009.

GADELHA, S. R. DE B.; DIVINO, J. A. Estímulo Fiscal, Impostos Distorcivos e Ciclo Econômico Brasileiro. Texto para Discussão Tesouro Nacional n014, $2013 a$.

GADELHA, S. R. DE B.; DIVINO, J. A. Uma Análise da Ciclicidade da Política Fiscal Brasileira. Estudos Econômicos, v. 43, p. 711-743, 2013b.

GALÍ, J.; VALLÉS, J.; LÓPEZ-SALIDO, J. D. Understanding the Effects of Government Spending. Journal of the European Economic Association, v. 5, n. 1, p. 227-270, 2007.

GOBETTI, S. W.; ORAIR, R. O. Flexibilização Fiscal: Novas Evidências e Desafios. Texto para Discussão IPEA n. 2132, 2015.

GOBETTI, S. W.; ORAIR, R. O.; SIQUEIRA, F. DE F. Política Fiscal e Ciclo Econômico: uma análise baseada em multiplicadores do gasto público. XXI Prêmio Tesouro Nacional - $2^{\circ}$ Lugar, 2016.

GRIFFOLI, T. M. An introduction to the solution \& estimation of DSGE models. Dynare User Guide, p. 1-94, 2013.

HERBST, E. P.; SCHORFHEIDE, F. Bayesian Estimation of DSGE Models. [s.I.] Princeton University Press, 2016.

ILZETZKI, E.; VEGH, C. A. Procyclica Fiscal Policy in Developing Countries: Truth or 
Fiction? National Bureau of Economic Research Working Paper 14191, p. 1-31, 2008. JUSTINIANO, A.; PRIMICERI, G. E.; TAMBALOTTI, A. Investment Shocks and Business CyclesFederal Reserve Bank of New York Staff Reports. [s.I: s.n.].

KLEIN, P. Using the generalized Schur form to solve a multivariate linear rational expectations model. Journal of Economic Dynamics and Control, v. 24, n. 10, p. 14051423, 2000.

LEEPER, E. M.; PLANTE, M.; TRAUM, N. Dynamics of fiscal financing in the United States. Journal of Econometrics, v. 156, n. 2, p. 304-321, 2010.

MANKIW, N. G. The Savers - Spenders Theory of Fiscal Policy. American Economic Review Paper and Proceedings, v. 90, n. 2, p. 120-25, 2000.

MENDONÇA, M. J.; MEDRANO, L. A.; SACHSIDA, A. Avaliando os Efeitos da Política Fiscal no Brasil: Resultados de um Procedimento de Identificação Agnóstica. Texto para Discussão IPEA n. 1377, 2009.

MOREIRA, T. B. S.; SOARES, F. A. R. A Crise Financeira Internacional e as Políticas Anticíclicas no Brasil. Prêmio Tesouro Nacional - 1 Lugar, p. 1-34, 2010.

MOUNTFORD, A.; UHLIG, H. What are the effects of fiscal policy shocks? Journal of Applied Econometrics, p. 960-992, 2009.

MOURA, G. V. Multiplicadores Fiscais e Investimento em Infraestrutura. Revista Brasileira de Economia, v. 69, n. 1, p. 75-104, 2015.

ORAIR, R. O. Investimento Público no Brasil: Trajetória e relações com o regime fiscal. Texto para Discussão IPEA n. 2215, 2016.

PIRES, M. C. DE C. Multiplicadores Fiscais: Uma Contribuição ao Debate sobre Políticas Fiscais Anticíclicas. Encontro Nacional de Economia, p. 1-16, 2009.

ROCHA, F. Política Fiscal Através do Ciclo e Operação dos Estabilizadores Fiscais. Revista Economia, v. 10, p. 483-499, 2009.

ROCHA, F.; GIUBERTI, A. C. Assimetria cíclica na política fiscal dos estados brasileiros. Pesquisa e Planejamento Econômico, v. 38, n. 2, p. 253-276, 2008.

SIMS, C. A. Solving Linear Rational Expectations Models. Computational Economics, v. 20, p. 1-20, 2002.

SMETS, F.; WOUTERS, R. An Estimated Dynamic Stochastic General Equilibrium Model of the Euro Area. Journal of the European Economic Association, v. 1, n. 5, p. 11231175, 2003.

SMETS, F.; WOUTERS, R. Shocks and Frictions in US Business Cycle: A Bayesian DSGE Approach. American Economic Review, v. 97, p. 586-606, 2007.

SPILIMBERGO, A.; SYMANSKY, S.; SCHINDLER, M. Fiscal multipliers. IMF staff position note, p. 1-14, 2009.

STAHLER, N.; THOMAS, C. FiMod - A DSGE model for fiscal policy simulations. 
Economic Modelling, v. 29, n. 2, p. 239-261, 2012.

TALVI, E.; VEGH, C. A. Tax base variability and procyclical fiscal policy in developing countries. Journal of Development Economics, v. 78, n. 1, p. 156-190, 2005.

UHLIG, H. A Toolkit for Analysing Nonlinear Dynamic Stochastic Models Easily. In: MARIMON, R.; SCOTT, A. (Eds.). . Computational Methods for the Study of Dynamic Economics. [s.I.] Oxford University Press, 2001. p. 30-61.

VEGH, C. A.; VULETIN, G. How is Tax Policy Conducted over the Business Cycle? National Bureau of Economic Research Working Paper 17753, p. 1-27, 2012.

VILLEMOT, S. Solving rational expectations models at first order: What dynare does. Dynare Working Papers Series n.2, n. 2, p. 1-9, 2011.

ZUBAIRY, S. On Fiscal Multipliers: Estimates from a Medium Scale DSGE Model On Fiscal Multipliers: Estimates from a Medium Scale DSGE Model. International Economic Review, v. 55, n. 1, p. 169-195, 2014. 


\section{Apêndices}

\subsection{Dados de Alíquotas Efetivas de Azevedo e Fasolo (2015)}

Azevedo e Fasolo (2015) estimam séries de tempo em frequência trimestral para as alíquotas efetivas dos impostos sobre o consumo, sobre a renda individual, sobre a renda do trabalho e sobre a renda do capital, o que requer antes a construção de séries acerca das bases tributárias e receitas tributárias. Esse esforço se traduz em uma importante contribuição para as pesquisas de macroeconomia empírica sobre política fiscal no Brasil, sobretudo as que se valem de modelos dinâmicos de equilíbrio geral, pois a forma de cálculo das séries tem por base um arcabouço tradicional desse tipo de modelo. A seguir, resume-se o procedimento para a construção das séries, adotando a mesma notação do artigo.

Existem quatro tipos de impostos: sobre o consumo, a renda do trabalho, a renda do capital e a renda individual (i.e., impostos incidentes igualmente sobre a renda do trabalho e do capital). As alíquotas efetivas dos impostos sobre o consumo $\left(\tau_{c}\right)$, a renda individual $\left(\tau_{y}\right)$, a renda do trabalho $\left(\tau_{l}\right)$ e a renda do capital $\left(\tau_{k}\right)$ são dadas por:

$$
\tau_{c}=\frac{T_{c}}{c_{t}+g_{t}} \quad \tau_{y}=\frac{T_{y}}{w_{t} h_{t}+r_{t}^{k} k_{t}} \quad \tau_{l}=\frac{T_{l}}{w_{t} h_{t}} \quad \tau_{k}=\frac{T_{k}}{r_{t}^{k} k_{t}}
$$

onde $T_{c}$ é a receita dos impostos sobre o consumo, $c_{t}+g_{t}$ a base tributária do consumo, $T_{y}$ a receita dos impostos sobre a renda individual, $w_{t} h_{t}+r_{t}^{k} k_{t}$ a base tributária da renda individual, sendo composta pela base tributária da renda do trabalho $\left(w_{t} h_{t}\right)$ e pela base tributária da renda do capital $\left(r_{t}^{k} k_{t}\right), T_{l}$ a receita dos impostos sobre a renda do trabalho e $T_{k}$ a receita dos impostos sobre a renda do capital. Por sua vez, $c_{t}$ é o consumo das famílias, $g_{t}$ o consumo público, $w_{t}$ o salário real, $h_{t}$ o montante de trabalho, $r_{t}^{k}$ a taxa de retorno real do capital, e $k_{t}$ o estoque de capital.

É importante observar que para calcular essas alíquotas são necessárias apenas as informações das receitas e bases tributárias, que não dependem do agente econômico sobre o qual o imposto incide.

As principais informações dos dados usados no cálculo das receitas tributárias estão resumidas na Tabela 8 . Esse conjunto de dados compõe $96,83 \%$ do total de receitas tributárias do Brasil. 
Tabela 8 - Impostos das Receitas Tributárias de Azevedo e Fasolo (2015)

\begin{tabular}{|ccccc|}
\hline Imposto & Classe & Jurisdição & Fonte de Dados & $\%$ Receita Total \\
\hline IPI, II, Cide, Cofins, IOF & $\tau_{c}$ & Federal & Ipeadata & $19,30 \%$ \\
\hline ICMS & $\tau_{c}$ & Estadual & Ipeadata & $22,60 \%$ \\
\hline ISS & $\tau_{c}$ & Municipal & SISTN-Finbra & $2,30 \%$ \\
\hline $\begin{array}{c}\text { IRPF, IRRF/Remessas, } \\
\text { IRRF/Outros }\end{array}$ & $\tau_{y}$ & Federal & Ipeadata & $2,90 \%$ \\
\hline FGTS & $\tau_{l}$ & Federal & website FGTS & $5,10 \%$ \\
\hline $\begin{array}{c}\text { IRRF/Trabalho, } \\
\text { PIS/PASEP }\end{array}$ & $\tau_{l}$ & Federal & Ipeadata & $8,10 \%$ \\
\hline Sistema S e SE & $\tau_{l}$ & Federal & BCB & $1,50 \%$ \\
\hline RGPS, CPSS/Federal & $\tau_{l}$ & Federal & Anexo Relatório do & $18,10 \%$ \\
\hline CPSS/Estadual & $\tau_{l}$ & Estadual & SISTN & $0,60 \%$ \\
\hline CPSS/Municipal & $\tau_{l}$ & Municipal & SISTN & $0,20 \%$ \\
\hline IRPJ, CSLL & $\tau_{k}$ & Federal & Ipeadata & $10,30 \%$ \\
\hline ITR, IRRF/Capital & $\tau_{k}$ & Federal & Ipeadata & $2,90 \%$ \\
\hline CPMF & $\tau_{k}$ & Federal & Ipeadata & $2,30 \%$ \\
\hline IPVA, ITCD & $\tau_{k}$ & Estadual & Ipeadata & $1,80 \%$ \\
\hline IPTU, ITBI & $\tau_{k}$ & Municipal & SISTN-Finbra & $1,80 \%$ \\
\hline
\end{tabular}

Fonte: Azevedo e Fasolo (2015, p. 28). Nota: A receita total mostra a participação média do conjunto de impostos no total de receitas tributárias no período 1999-2014.

A base tributária do consumo é calculada como a soma do consumo privado e consumo público, obtidos das Contas Nacionais Trimestrais do Instituto Brasileiro de Geografia e Estatística (CNT-IBGE), subtraídas a remuneração dos servidores públicos e a receita dos impostos sobre o consumo. A remuneração dos servidores públicos é estimada a partir de dados do Ipeadata para o âmbito federal e dados do Sistema de Coleta de Dados dos Entes da Federação (SISTN) e da Secretaria do Tesouro Nacional (STN) para o âmbito estadual e municipal.

A base tributária da renda individual, que consiste da soma da renda do trabalho e da renda do capital, é aproximada pelo valor adicionado a custo de fatores dado pela diferença entre a renda das CNT-IBGE e a estimativa de impostos líquidos sobre a produção, formada pela soma das receitas dos impostos IPI, ICMS, ISS, CIDE, II, IOF Cofins, Salário Educação e contribuições para o Sistema S. 
Para a base tributária da renda do trabalho, é usada uma aproximação da massa salarial composta por remunerações da força de trabalho e contribuições dos empregadores para o sistema de seguridade social. Os dados das remunerações da força de trabalho são obtidos com base em estimações da população ocupada total no Brasil a partir da Pesquisa Nacional por Amostra de Domicílios (PNAD) e da Pesquisa Mensal de Emprego (PME) e estimações dos salários médios no Brasil a partir da PNAD, da PME e do Censo Populacional.

Por fim, a base tributária da renda do capital é calculada como o resíduo obtido pela diferença entre o valor adicionado a custo de fatores e a renda do trabalho.

A Figura 16 mostra as séries estimadas das alíquotas tributárias de Azevedo e Fasolo (2015) dessazonalizadas usadas no presente trabalho.

Figura 16 - Alíquotas Dessazonalizadas de Azevedo e Fasolo (2015)

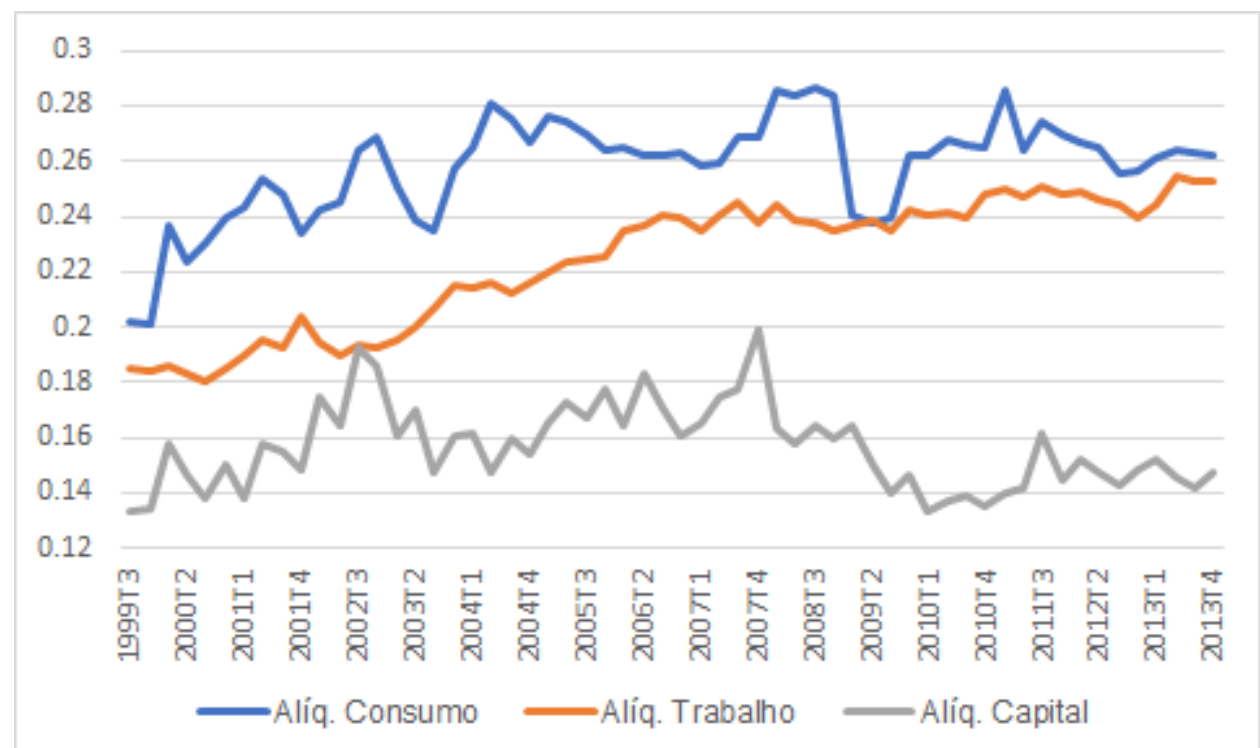

Fonte: Azevedo e Fasolo (2015).

\subsection{Dados de Alíquotas Efetivas de Almeida et al. (2017)}

Analogamente a Azevedo e Fasolo (2015), Almeida et al. (2017) estimam séries de tempo trimestrais para alíquotas efetivas incidentes sobre o consumo $\left(\tau_{c}\right)$, sobre a renda do trabalho $\left(\tau_{l}\right)$, sobre a renda do capital $\left(\tau_{k}\right)$ e sobre a renda total $\left(\tau_{h}\right)$, que é semelhante à alíquota sobre a renda individual de Azevedo e Fasolo (2015). Para tanto, 
também recorrem a estimações que têm por base um modelo de equilíbrio geral e dados de bases tributárias e receitas tributárias. A seguir, com a mesma notação do artigo, apresentam-se sucintamente as fórmulas para o cálculo das alíquotas tributárias e os dados usados:

$$
\begin{gathered}
\tau_{c}=\frac{5110+5121}{C+G-G_{w}-5110-5121} \quad \tau_{h}=\frac{1100}{\text { OSPUE }+P E I+W} \\
\tau_{l}=\frac{\tau_{h} W+2000+3000}{W+2200} \quad \tau_{k}=\frac{\tau_{h}(\text { OSPUE }+P E I)+1200+4100+4400}{O S}
\end{gathered}
$$

onde as receitas tributárias representadas por 1100, 1200, 2000, 2200, 3000, 4100, 4400, 5110 e 5121 e seus respectivos dados de impostos são dados pela Tabela 9, $C$ é o consumo das famílias, $G$ o consumo do governo (federal, estadual e municipal), $G_{w}$ a compensação de empregados pagos por fornecedores de serviços do governo, OSPUE o excedente operacional das empresas privadas (exceto corporações), PEI a renda das famílias derivada da propriedade e de empreendimentos de residentes, $W$ massa salarial real e $O S$ o excedente operacional total da economia.

A massa salarial real é obtida pela multiplicação entre o rendimento real efetivo médio e a população ocupada, correspondentes aos empregos do setor privado e com carteira assinada. $O$ excedente operacional total da economia tem como proxy 0 resultado da diferença entre o PIB a custos de fatores e a massa salarial real.

A Figura 17 apresenta as séries estimadas das alíquotas tributárias de Almeida et al. (2017) dessazonalizadas usadas no presente trabalho. 
Tabela 9 - Impostos das Receitas Tributárias de Almeida et al. (2017)

\begin{tabular}{|cccc|}
\hline Símbolo & Descrição & Imposto & Classe \\
\hline 1100 & $\begin{array}{c}\text { Tributação sobre a renda, lucro e } \\
\text { ganhos de capital de indivíduos }\end{array}$ & IRPF, IRRF/Remessas, IRRF/Outros & $\tau_{h}$ \\
\hline 1200 & $\begin{array}{c}\text { Tributação sobre a renda, lucro e } \\
\text { ganhos de capital de corporações }\end{array}$ & IRPJ, CSLL & $\tau_{k}$ \\
\hline 2000 & Total de contribuições sociais & $\begin{array}{c}\text { Contribuições e receitas de } \\
\text { parcelamento para a seguridade } \\
\text { social da União, Estados/DF e } \\
\text { municípios }\end{array}$ & $\tau_{l}$ \\
\hline 2200 & $\begin{array}{c}\text { Contribuições dos empregadores } \\
\text { para a seguridade social }\end{array}$ & $\begin{array}{c}\text { Contribuições patronais dos regimes } \\
\text { de previdência e dos empregadores } \\
\text { ao INSS, IRRF/Trabalho, PIS/PASEP }\end{array}$ & $\tau_{l}$ \\
\hline 3000 & $\begin{array}{c}\text { Tributação em folha de } \\
\text { pagamento e da força de trabalho }\end{array}$ & $\begin{array}{c}\text { SE, Sistema S, FGTS, Adicional da } \\
\text { Contribuição Previdenciária }\end{array}$ & $\tau_{l}$ \\
\hline 4100 & $\begin{array}{c}\text { Tributação incidente sobre a } \\
\text { propriedade imóvel }\end{array}$ & IPTU, IPVA, ITR, ITBI, ITCD & $\tau_{k}$ \\
\hline 4400 & $\begin{array}{c}\text { Tributação das transações } \\
\text { financeiras e de capital }\end{array}$ & $\begin{array}{c}\text { CPMF, IOF, IRRF/Capital, Imposto } \\
\text { sobre a exportação }\end{array}$ & $\tau_{k}$ \\
\hline 5110 & $\begin{array}{c}\text { Tributação sobre bens e serviços } \\
\text { em geral }\end{array}$ & Cide, Cofins, IPI, II & $\tau_{c}$ \\
\hline 5121 & Tributação específica & $\begin{array}{c}\text { Taxas federais, estaduais e } \\
\text { municipais, ICMS, ISS }\end{array}$ & $\tau_{c}$ \\
\hline
\end{tabular}

Fonte: Almeida et al. (2017, p. 158).

Figura 17 - Alíquotas Dessazonalizadas de Almeida et al. (2017)

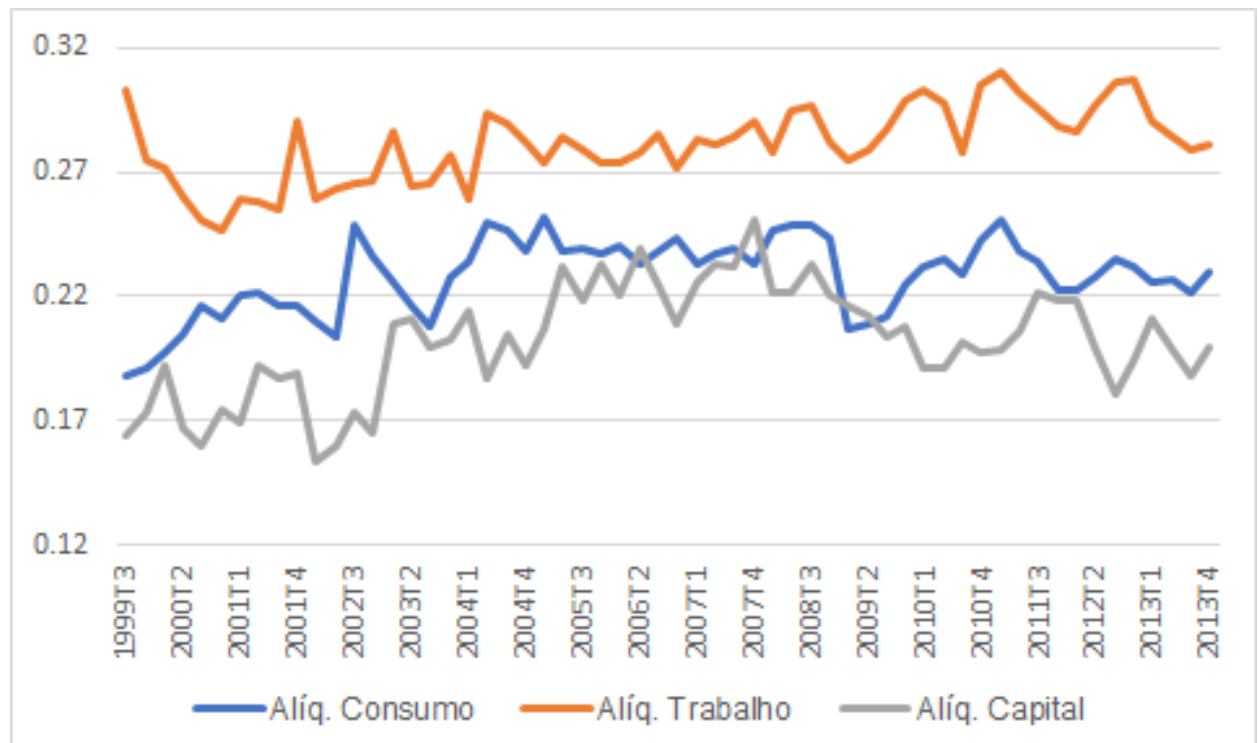

Fonte: Almeida et al. (2017). 


\subsection{Estimação Bayesiana de Modelos DSGE}

Faz-se uma exposição do algoritmo de Metropolis-Hastings usado para realizar estimação bayesiana de modelos DSGE com base em Herbst e Schorfheide (2016), bem como se comenta sucintamente o algoritmo específico no Dynare a partir de Griffoli (2013). O algoritmo de Metropolis-Hastings pertence ao grupo de algoritmos de cadeias de Markov de Monte Carlo (MCMC). Seu objetivo é construir uma cadeia de Markov tal que a distribuição estacionária associada à cadeia é única e igual à distribuição a posteriori de interesse.

Dado um vetor inicial para os parâmetros $\theta^{0}$, a iteração $i$ do algoritmo de Metropolis-Hastings, para $i=1, \ldots, N$, consiste nos seguintes passos:

$\left.1^{\circ}\right)$ Sorteie $\theta^{*}$ de uma distribuição proposta $q\left(\theta^{*} \mid \theta^{i-1}\right)$. Uma característica essencial da distribuição proposta é que seu suporte contenha o suporte da distribuição a posteriori de interesse.

No Dynare, o vetor inicial é a moda da distribuição a posteriori não normalizada, ou seja, é o vetor tal que maximiza $\ln \left(\theta \mid y_{1: T}\right)+\ln (\theta)$, que é obtido com o auxílio de um algoritmo de maximização aplicado a essa distribuição, que por sua vez pode ser encontrada depois de aplicar o filtro de Kalman, que faz parte de uma das etapas abaixo. Ademais, a distribuição proposta é uma distribuição normal multivariada $N\left(\theta^{i-1}, c \Sigma_{m}\right)$, onde $\Sigma_{m}$ é o inverso da hessiana da verossimilhança avaliada na moda da distribuição a posteriori e o fator de escala $c$ é o parâmetro de controle da taxa de aceitação (fração de parâmetros candidatos que são aceitos). Se o fator de escala é muito pequeno, a taxa de aceitação será muito alta e o algoritmo explorará lentamente a distribuição a posteriori de interesse, uma vez que ele poderá ficar preso ao redor de um máximo local. Por outro lado, se o fator de escala é muito grande, a taxa de aceitação será muito pequena e o algoritmo gastará muito tempo nas caudas da distribuição a posteriori de interesse.

$\left.2^{\circ}\right)$ Para $\theta^{*}$, estabeleça o sistema linear de expectativas racionais:

$$
\Gamma_{0}\left(\theta^{*}\right) E_{t} s_{t+1}=\Gamma_{1}\left(\theta^{*}\right) s_{t}+\Pi\left(\theta^{*}\right) \varepsilon_{t}
$$

onde $s_{t}$ é o vetor de variáveis endógenas log-linearizadas e $\varepsilon_{t}$ é o vetor de inovações estruturais (processos estocásticos exógenos). Resolva o sistema por um método apropriado e obtenha:

$$
s_{t}=\Phi_{1}\left(\theta^{*}\right) s_{t-1}+\Phi_{\varepsilon}\left(\theta^{*}\right) \varepsilon_{t}
$$


No Dynare, de acordo com Villemot (2011), o método implementado é uma variação de Uhlig (1999), Klein (2000) e Sims (2002). Basicamente, ele categoriza as variáveis endógenas em variáveis não pré-determinadas (também chamadas de variáveis que pulam ou variáveis forward-looking) e variáveis pré-determinadas (também chamadas de variáveis de estado ou variáveis backward-looking), e usa a decomposição generalizada de Schur (decomposição QZ) para resolver o sistema linear de expectativas racionais. Um resultado é que o modelo tem uma única solução localmente limitada se o número de variáveis não pré-determinadas for igual ao número de autovalores generalizados de $\Gamma_{0}^{-1} \Gamma_{1}$ que são em módulo maiores que um.

$\left.3^{\circ}\right)$ Escreva o modelo na representação de estado de espaço com a equação de transição, a equação de medida e a condição inicial dadas respectivamente por:

$$
\begin{gathered}
s_{t}=\Phi_{1}\left(\theta^{*}\right) s_{t-1}+\Phi_{\varepsilon}\left(\theta^{*}\right) \varepsilon_{t} \\
y_{t}=\Psi_{1}\left(\theta^{*}\right) z_{t}+\Psi_{2}\left(\theta^{*}\right) s_{t}+u_{t}
\end{gathered}
$$

$S_{0}$

onde $y_{t}$ é um vetor de variáveis observáveis, $z_{t}$ é um vetor de possíveis tendências determinísticas e $u_{t}$ é um vetor de erros de medida. Se as inovações estruturais e os erros de medida forem ruídos brancos gaussianos independentes tais que $\varepsilon_{t} \sim N\left(0, \Sigma_{\varepsilon}\right)$ e $u_{t} \sim N\left(0, \Sigma_{u}\right)$, então o filtro de Kalman linear gaussiano pode ser aplicado a fim de encontrar a verossimilhança $p\left(y_{1: T} \mid \theta^{*}\right)$ como descrito abaixo.

Primeiro, dado $s_{0} \sim N\left(\bar{s}_{0 \mid 0}, P_{0 \mid 0}\right)$, com $\bar{s}_{0 \mid 0}$ e $P_{0 \mid 0}$ correspondendo às distribuições invariantes associadas à lei de movimento de $s_{t}$, rode o filtro de Kalman, para $t=1, \ldots, T$, conforme os passos indicados na Tabela 10. 
Tabela 10 - Filtro de Kalman Linear Gaussiano

\begin{tabular}{|ccc|}
\hline Variável & Distribuição & Média e Variância \\
\hline$s_{t-1} \mid\left(y_{1: t-1}, \theta^{*}\right)$ & $N\left(\bar{s}_{t-1 \mid t-1}, P_{t-1 \mid t-1}\right)$ & Dado da iteração $i-1$ \\
\hline & & $\bar{s}_{t \mid t-1} \equiv E\left[s_{t} \mid y_{1: t-1}, \theta^{*}\right]=\Phi_{1} \bar{s}_{t-1 \mid t-1}$ \\
$s_{t} \mid\left(y_{1: t-1}, \theta^{*}\right)$ & $N\left(\bar{s}_{t \mid t-1}, P_{t \mid t-1}\right)$ & $P_{t \mid t-1} \equiv \operatorname{Var}\left[s_{t}-\bar{s}_{t-1} \mid y_{1: t-1}, \theta^{*}\right]=\Phi_{1} P_{t-1 \mid t-1} \Phi_{1}^{\prime}+$ \\
& & $\Phi_{\varepsilon} \Sigma_{\varepsilon} \Phi_{\varepsilon}^{\prime}$ \\
\hline$y_{t} \mid\left(y_{1: t-1}, \theta^{*}\right)$ & $N\left(\bar{y}_{t \mid t-1}, F_{t \mid t-1}\right)$ & $\bar{y}_{t \mid t-1} \equiv E\left[y_{t} \mid y_{1: t-1}, \theta^{*}\right]=\Psi_{1} z_{t}+\Psi_{2} \bar{s}_{t \mid t-1}$ \\
& & $F_{t \mid t-1} \equiv \operatorname{Var}\left[y_{t}-\bar{y}_{t \mid t-1} \mid y_{1: t-1}, \theta^{*}\right]=\Psi_{2} P_{t \mid t-1} \Psi_{2}^{\prime}+\Sigma_{u}$ \\
\hline & $N\left(\bar{s}_{t \mid t}, P_{t \mid t}\right)$ & $\bar{s}_{t \mid t} \equiv E\left[s_{t} \mid y_{1: t}, \theta^{*}\right]=\bar{s}_{t \mid t-1}+P_{t \mid t-1} \Psi_{2}^{\prime} F_{t \mid t-1}^{-1}\left(y_{t}-\bar{y}_{t \mid t-1}\right)$ \\
$s_{t} \mid\left(y_{1: t}, \theta^{*}\right)$ & $P_{t \mid t} \equiv \operatorname{Var}\left[s_{t}-\bar{s}_{t \mid t} \mid y_{1: t}, \theta^{*}\right]=P_{t \mid t-1}-$ \\
& $P_{t \mid t-1} \Psi_{2}^{\prime} F_{t \mid t-1}^{-1} \Psi_{2} P_{t \mid t-1}$ \\
&
\end{tabular}

Fonte: Adaptado de Herbst e Schorfheide (2016, p. 23).

Segundo, usando $\bar{y}_{t \mid t-1}$ e $F_{t \mid t-1}$ encontrados, calcule a verossimilhança dada por:

$$
\begin{gathered}
p\left(y_{1: T} \mid \theta^{*}\right)=\prod_{t=1}^{T} p\left(y_{t} \mid y_{1: t-1}, \theta^{*}\right)=\frac{1}{(2 \pi)^{T n / 2} \prod_{t=1}^{T} \operatorname{det}\left(F_{t \mid t-1}\right)^{1 / 2}} \exp \left\{-\frac{1}{2} \sum_{t=1}^{T}\left(y_{t}-\right.\right. \\
\left.\left.\bar{y}_{t \mid t-1}\right)^{\prime} F_{t \mid t-1}^{-1}\left(y_{t}-\bar{y}_{t \mid t-1}\right)\right\}
\end{gathered}
$$

Note que também é possível estimar as variâncias das inovações estruturais e dos erros de medida, bastando incluí-las em $\theta^{*}$.

4ํ) Com a verossimilhança em mãos, calcule a distribuição a posteriori não normalizada e a probabilidade de aceitação dadas, respectivamente, por:

$$
\begin{gathered}
p\left(\theta^{*} \mid y_{1: T}\right) \propto p\left(y_{1: T} \mid \theta^{*}\right) p\left(\theta^{*}\right) \\
\alpha \equiv \min \left\{1, \frac{p\left(\theta^{*} \mid y_{1: T}\right)}{p\left(\theta^{i-1} \mid y_{1: T}\right)} \frac{q\left(\theta^{i-1} \mid \theta^{*}\right)}{q\left(\theta^{*} \mid \theta^{i-1}\right)}\right\}=\min \left\{1, \frac{p\left(y_{1: T} \mid \theta^{*}\right) p\left(\theta^{*}\right)}{p\left(y_{1: T} \mid \theta^{i-1}\right) p\left(\theta^{i-1}\right)} \frac{q\left(\theta^{i-1} \mid \theta^{*}\right)}{q\left(\theta^{*} \mid \theta^{i-1}\right)}\right\}
\end{gathered}
$$

onde a probabilidade de aceitação é simplificada devido à densidade marginal dos dados $p\left(y_{1: T}\right)$ e $p\left(\theta^{i-1} \mid y_{1: T}\right) \propto p\left(y_{1: T} \mid \theta^{i-1}\right) p\left(\theta^{i-1}\right)$ é conhecido da iteração $i-1$. Então, estabeleça $\theta^{i}=\theta^{*}$ com probabilidade $\alpha$ e $\theta^{i}=\theta^{i-1}$ caso contrário. Uma possibilidade é sortear um valor $u$ de uma distribuição uniforme $U[0,1]$. Nesse caso, tem-se $\theta^{i}=\theta^{*}$ se $\alpha>u$ e $\theta^{i}=\theta^{i-1}$ caso contrário.

No Dynare, uma vez que a distribuição proposta é uma normal multivariada, que é simétrica, a probabilidade de aceitação é simplificada para $\alpha=\min \left\{1, \frac{p\left(y_{1: T} \mid \theta^{*}\right) p\left(\theta^{*}\right)}{p\left(y_{1: T} \mid \theta^{i-1}\right) p\left(\theta^{i-1}\right)}\right\}$. 


\subsection{Distribuições a Priori e a Posteriori}

As imagens a seguir dizem respeito à estimação A. A linha cinza é a distribuição a priori e alinha preta é a distribuição a posteriori. Para melhorar a visualização das distribuições a posteriori dos coeficientes fiscais, que são bem mais concentradas que as suas respectivas distribuições a priori, ampliaram-se as imagens.
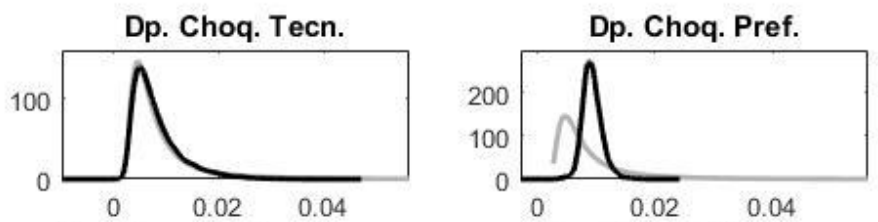

Dp. Choq. Markup Salários

Dp. Choq. Markup Preços
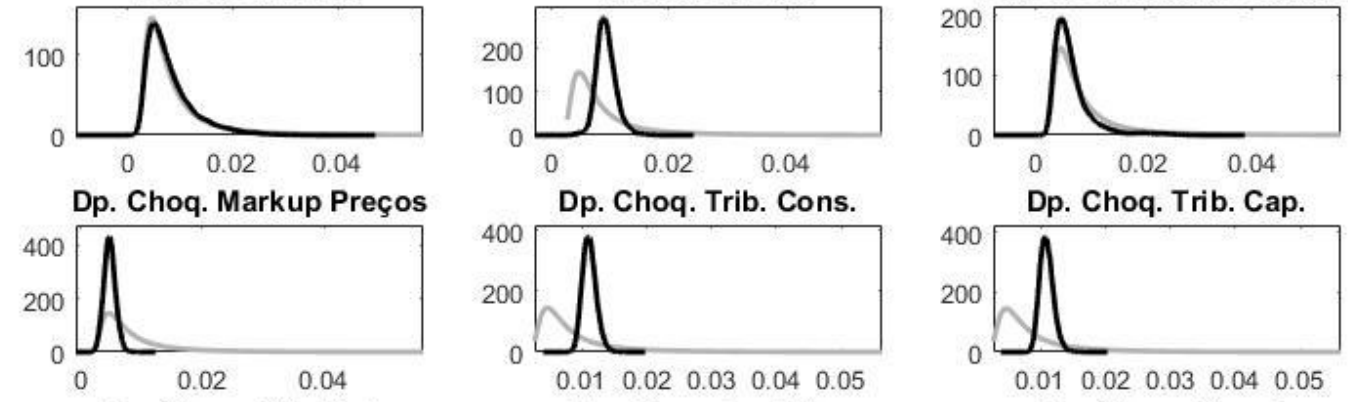

Dp. Choq. Trib. Trab

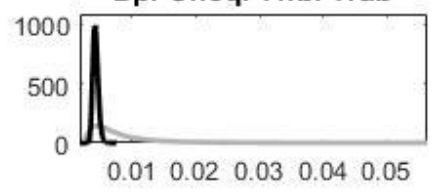

Dp. Choq. Inv. Priv.
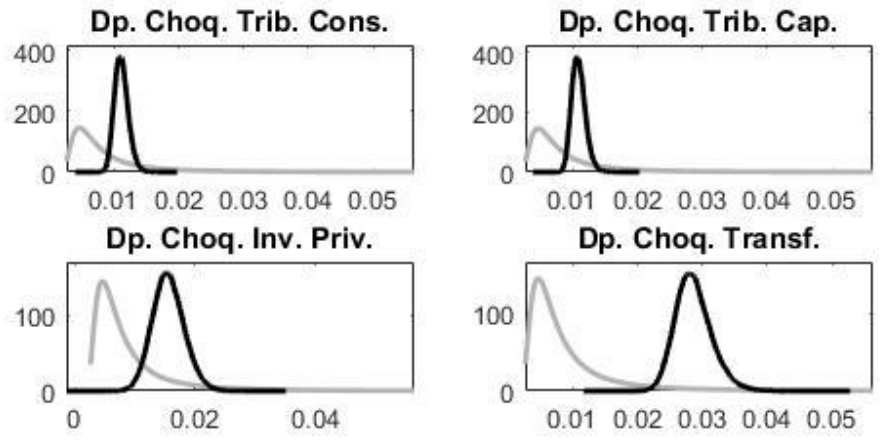

Dp. Choq. Transf.

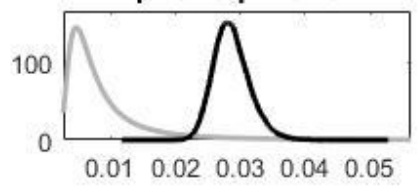

Dp. Choq. Inv. Púb.

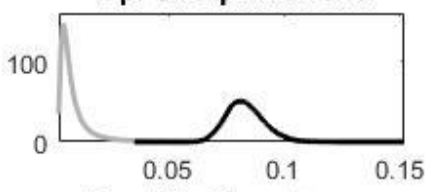

Dp. Choq. Monet.

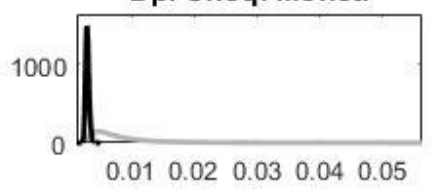

Dp. Choq. Cons. Púb.

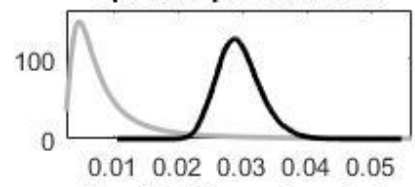

Persist. Choq. Tecn.

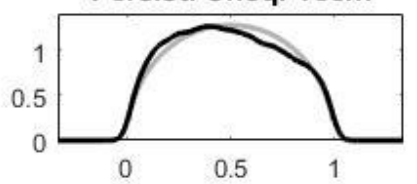

Persist. Choq. Pref.

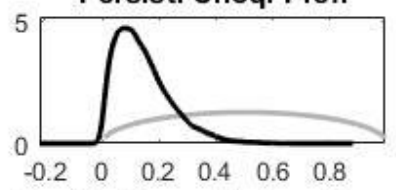

Persist. Choq. Inv. Priv.

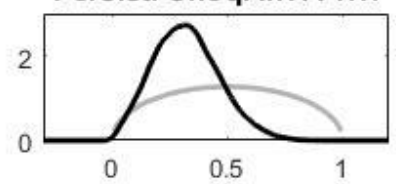

Persist. Choq. Markup Preços

Persist. Choq. Markup Salários
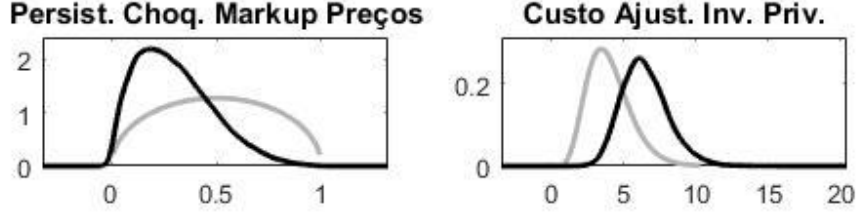

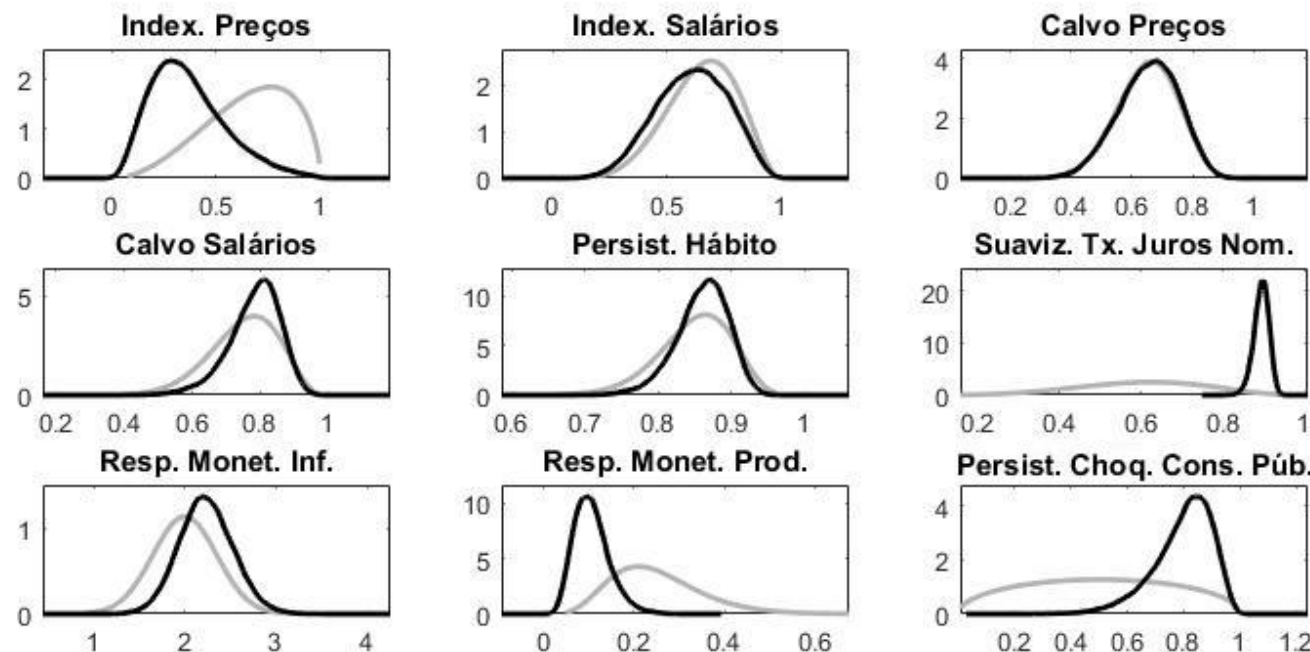

Persist. Choq. Cons. Púb.

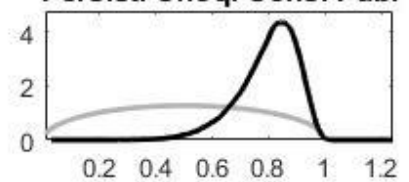

Persist. Choq. Inv. Púb.

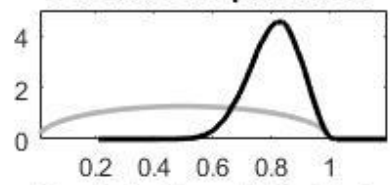

Persist. Choq. Transf.

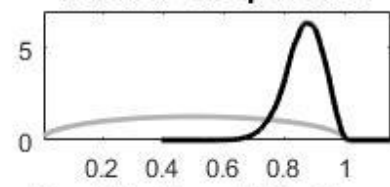

Persist. Choq. Trib. Cap.

Persist. Choq. Trib. Trab.

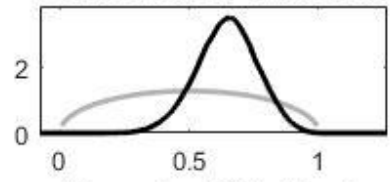

Persist. Choq. Trib. Cons.
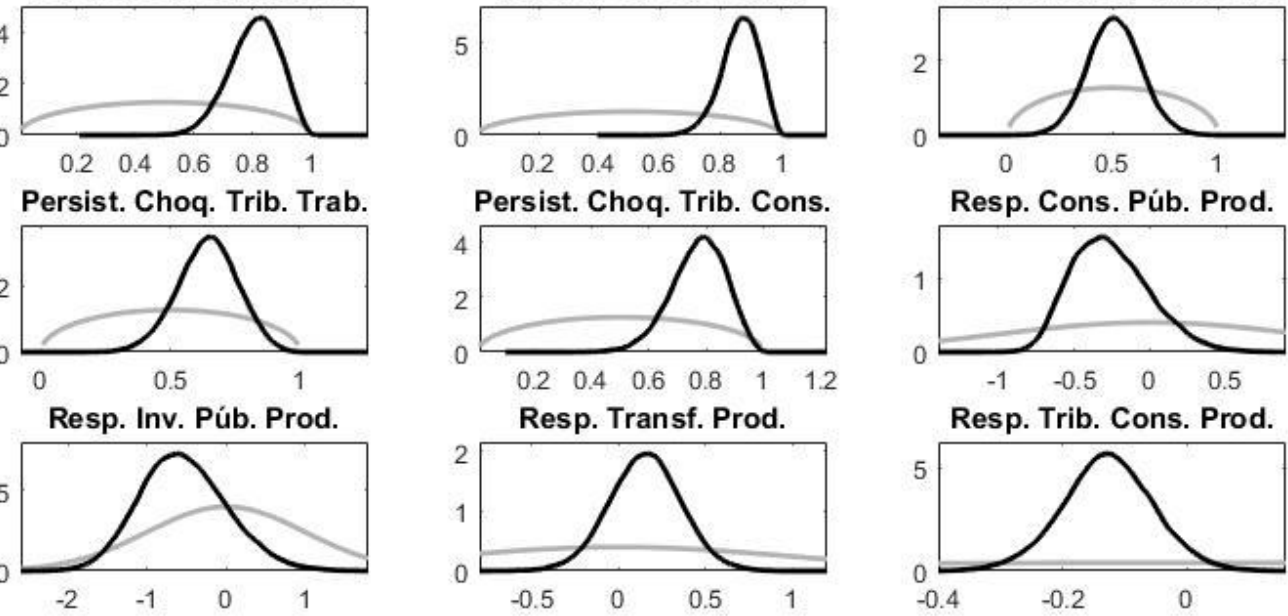

Resp. Cons. Púb. Prod.

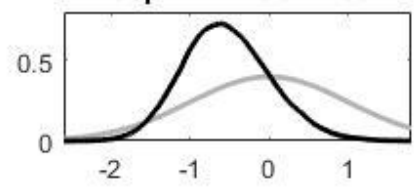

Resp. Trib. Cap. Prod.

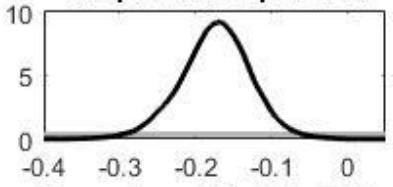

Resp. Trib. Trab. Prod.

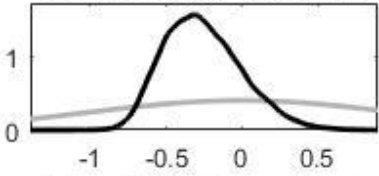

Resp. Trib. Cons. Prod.

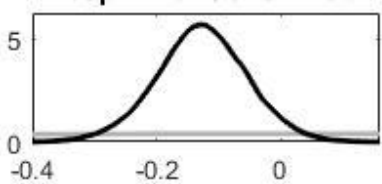

Resp. Inv. Púb. Dív. Púb.
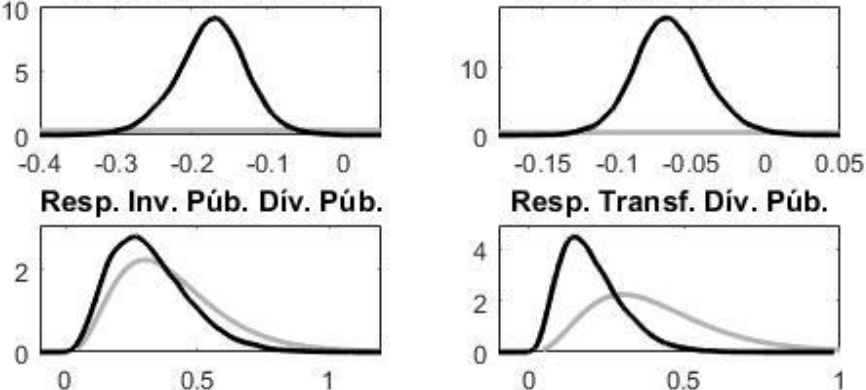

Resp. Cons. Púb. Dív. Púb.

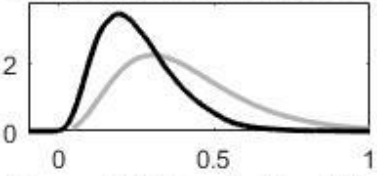

Resp. Transf. Div. Púb.

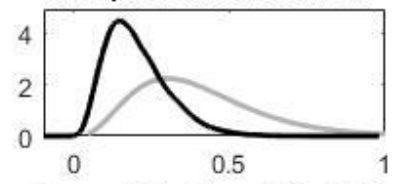

Resp. Trib. Cons. Dív. Púb.

Resp. Trib. Cap. Div. Púb.
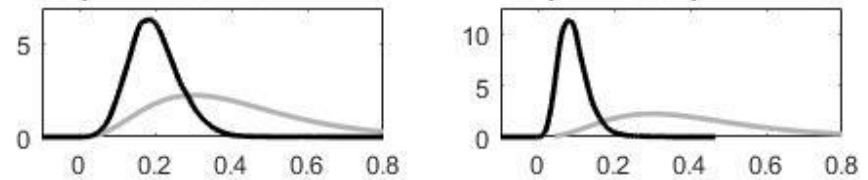

Resp. Trib. Trab. Dív. Púb.

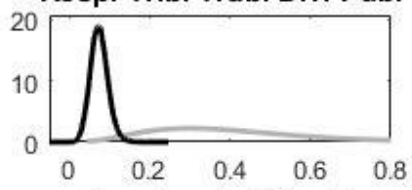

Fração não Ricard.

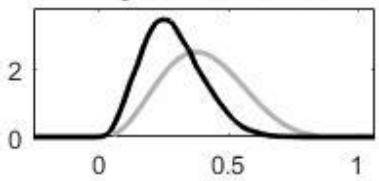


Por sua vez, as imagens a seguir dizem respeito à estimação $B$. A linha cinza é a distribuição a priori e alinha preta é a distribuição a posteriori. Para melhorar a visualização das distribuições a posteriori dos coeficientes fiscais, que são bem mais concentradas que as suas respectivas distribuições a priori, ampliaram-se as imagens.

Dp. Choq. Tecn.

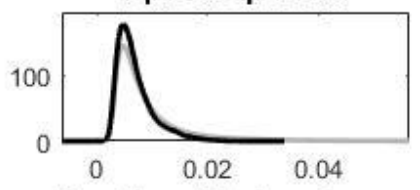

Dp. Choq. Markup Preços

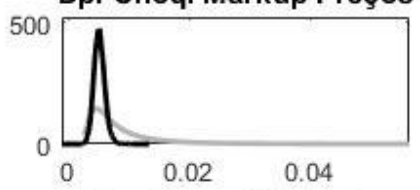

Dp. Choq. Trib. Trab

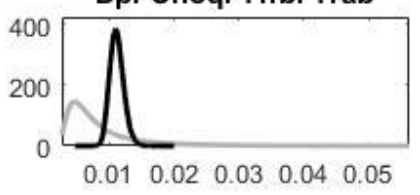

Dp. Choq. Inv. Púb.

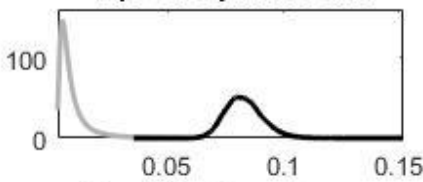

Persist. Choq. Tecn.

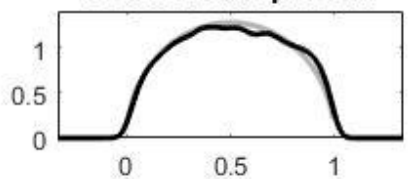

Persist. Choq. Markup Salários

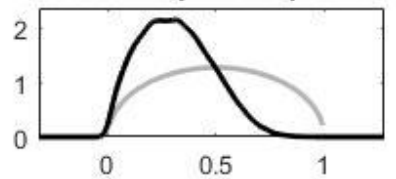

Dp. Choq. Pref.

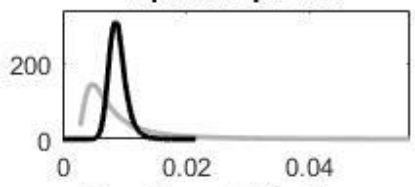

Dp. Choq. Trib. Cons.

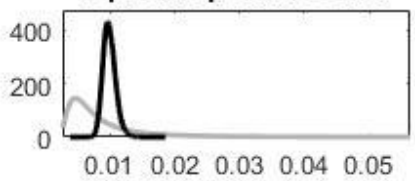

Dp. Choq. Inv. Priv.

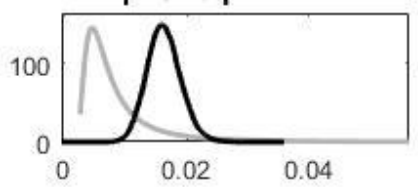

Dp. Choq. Monet.

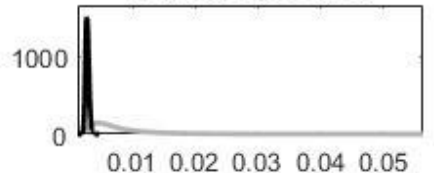

Persist. Choq. Pref.

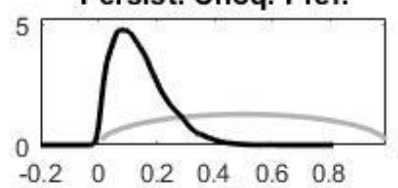

Persist. Choq. Markup Preços

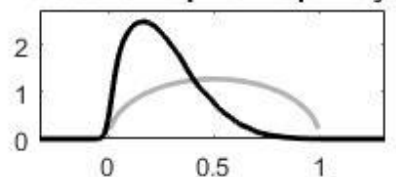

Dp. Choq. Markup Salários

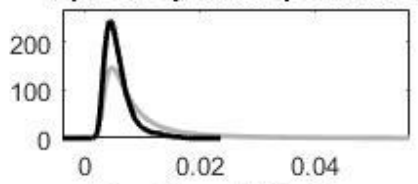

Dp. Choq. Trib. Cap.

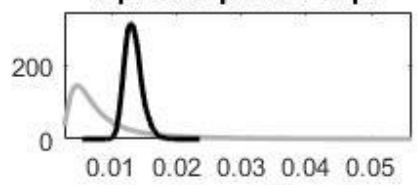

Dp. Choq. Transf.

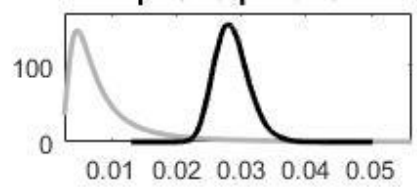

Dp. Choq. Cons. Púb.

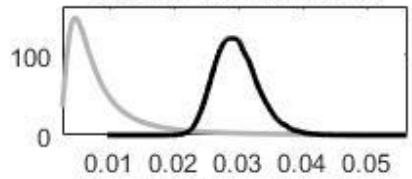

Persist. Choq. Inv. Priv.

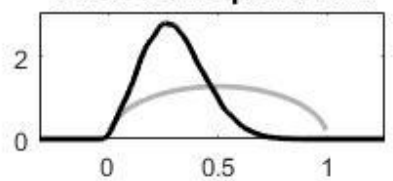

Custo Ajust. Inv. Priv.

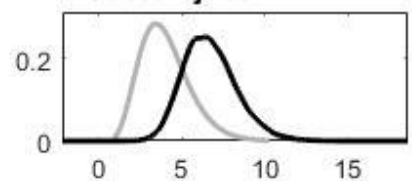



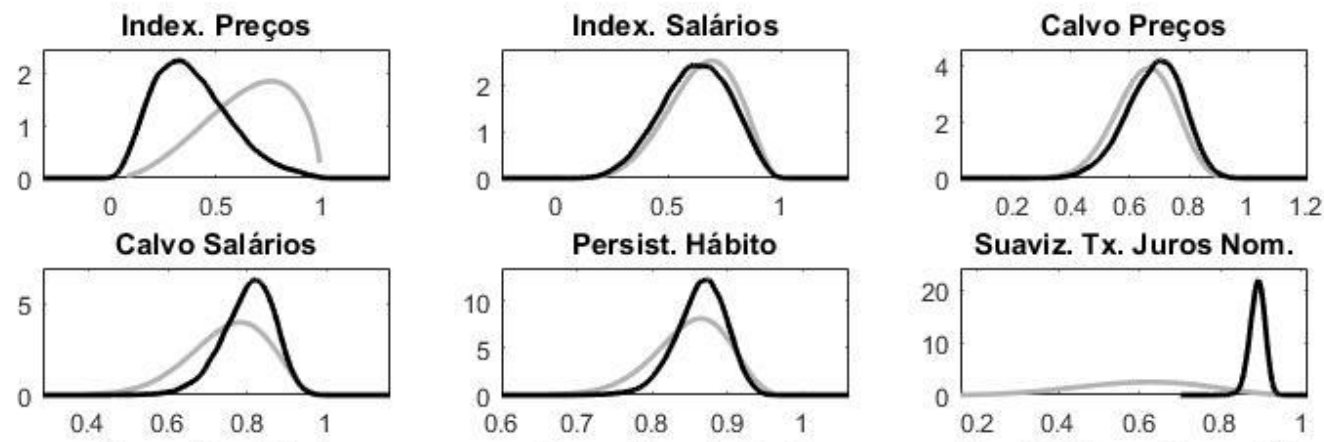

Suaviz. Tx. Juros Nom.

Resp. Monet. Inf.

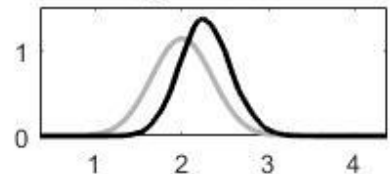

Resp. Monet. Prod.
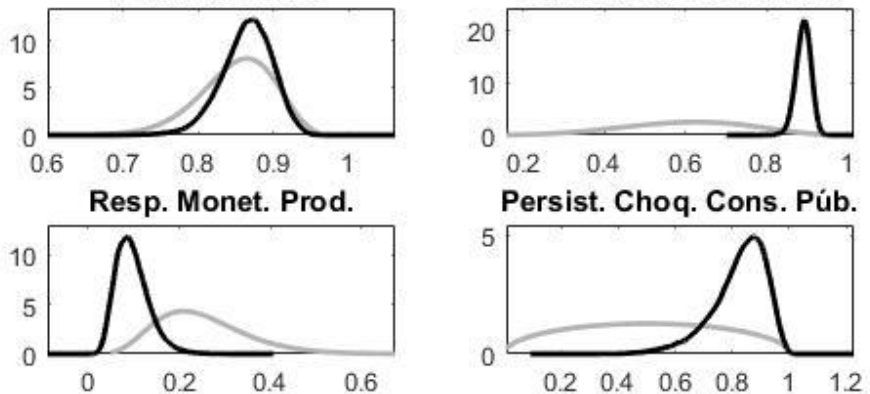

Persist. Choq. Inv. Púb.

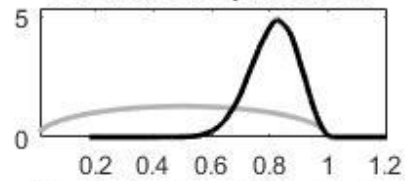

Persist. Choq. Transf.

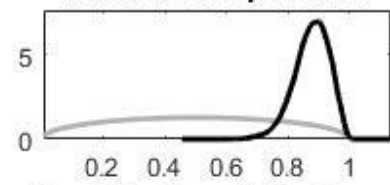

Persist. Choq. Trib. Cap.

Persist. Choq. Trib. Trab.
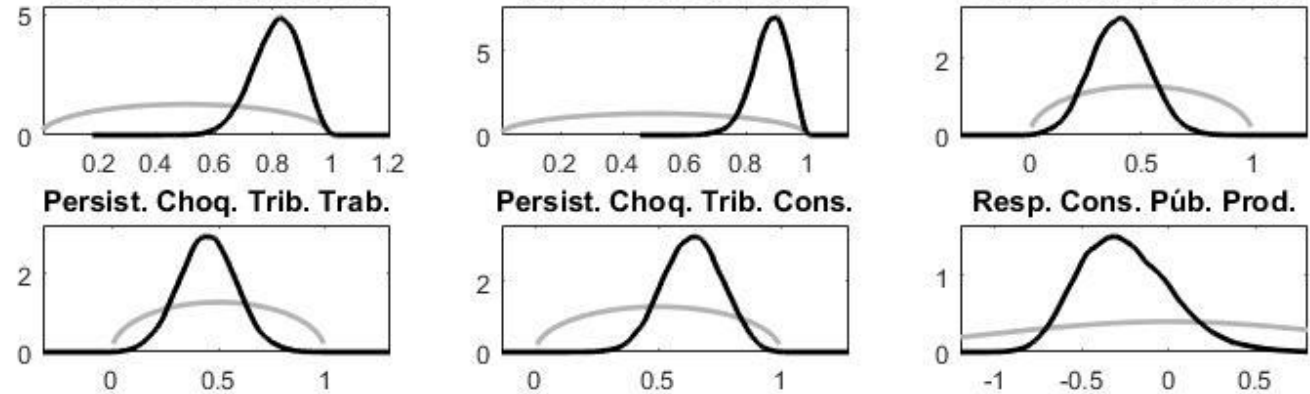

Resp. Cons. Púb. Prod.
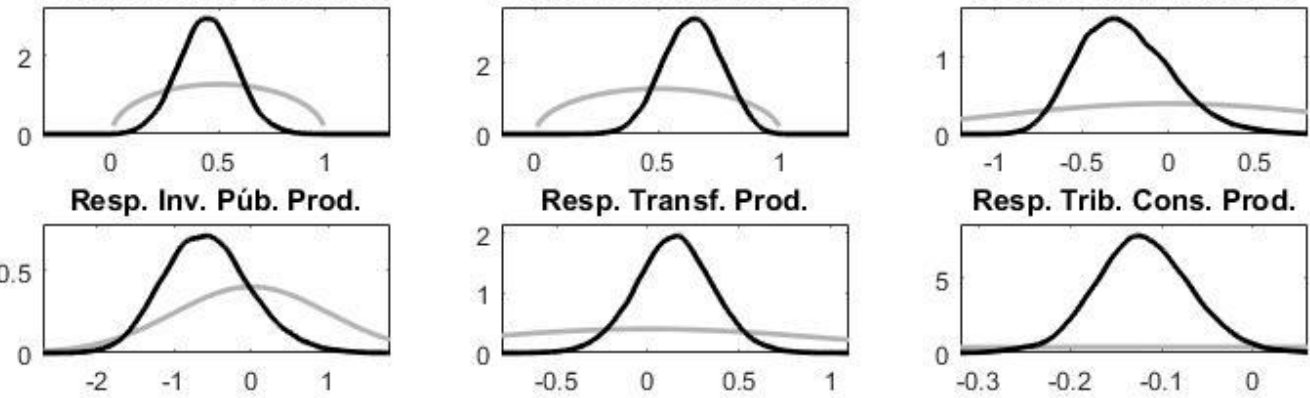

Resp. Trib. Cons. Prod.

Resp. Trib. Cap. Prod.

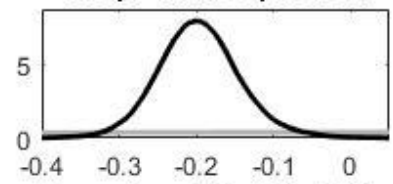

Resp. Trib. Trab. Prod.

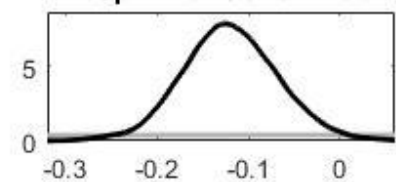

Resp. Inv. Púb. Dív. Púb.
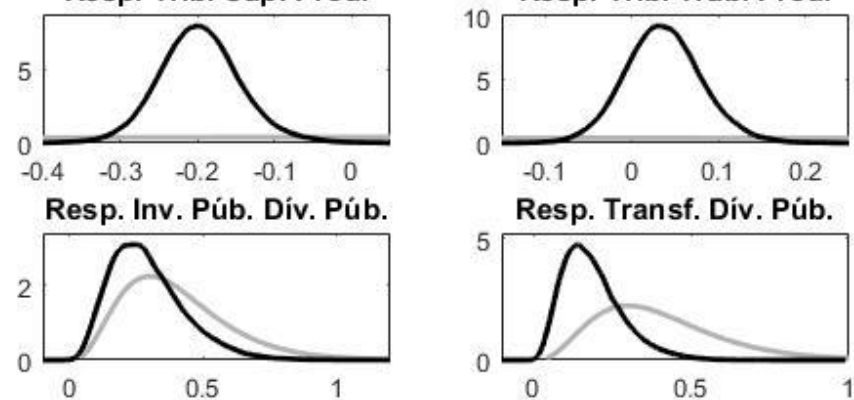

Resp. Cons. Púb. Dív. Púb.
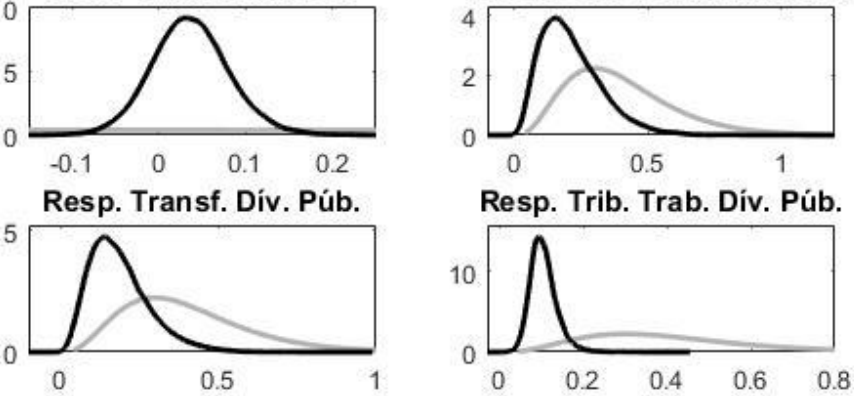

Resp. Trib. Trab. Div. Púb.

Resp. Trib. Cons. Dív. Púb.

Resp. Trib. Cap. Dív. Púb.
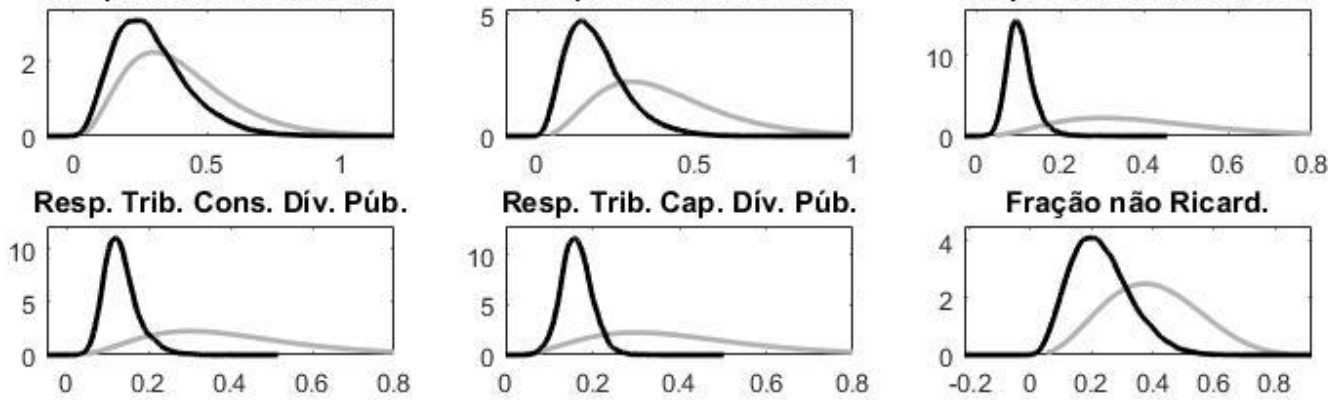

Fração não Ricard.

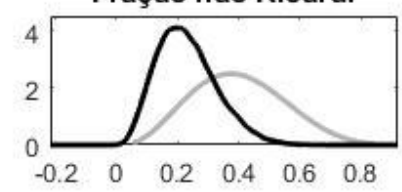

